Cahiers du MONDE RUSSE

\section{Cahiers du monde russe}

Russie - Empire russe - Union soviétique et États indépendants

$57 / 2-3 \mid 2016$

Famille et mobilité sociale en Russie, XVle-XVIIle siècles

\title{
k Istorii Boiarskoi Sem'i XVII v.
}

Sem'ia kniazia Nikity Ivanovicha Odoevskogo ${ }^{1}$

Une famille de bojare au XVII siècle : le prince Nikita Ivanovič Odoevskij et sa lignée

A seventeenth-century boyar family: Prince N.I. Odoevskii and his lineagePrince Nikita Ivanovich Odoevskii and his lineage: A seventeenth-century boyar family

\section{Pavel Sedov}

\section{(2) OpenEdition}

\section{Journals}

Édition électronique

URL : http://journals.openedition.org/monderusse/8358

DOI : 10.4000/monderusse.8358

ISSN : $1777-5388$

\section{Éditeur}

Éditions de l'EHESS

Édition imprimée

Date de publication : 1 avril 2016

Pagination : 311-341

ISBN : 978-2-7132-2541-3

ISSN : $1252-6576$

\section{Référence électronique}

Pavel Sedov, « k Istorii Boiarskoi Sem'i XVII v. », Cahiers du monde russe [Онлайн], 57/2-3 | 2016,

Выложить онлайн 01 avril 2019, Наводить справки в 27 avril 2019. URL : http://

journals.openedition.org/monderusse/8358; DOI : 10.4000/monderusse.8358

Ce document a été généré automatiquement le 27 avril 2019.

(ㄷ École des hautes études en sciences sociales 


\title{
k Istorii Boiarskoi Sem'i XVII v.
}

\author{
Sem'ia kniazia Nikity Ivanovicha Odoevskogo ${ }^{1}$ \\ Une famille de bojare au XVII siècle : le prince Nikita Ivanovič Odoevskij et sa \\ lignée
}

A seventeenth-century boyar family: Prince N.I. Odoevskii and his lineagePrince Nikita Ivanovich Odoevskii and his lineage: A seventeenth-century boyar family

\section{Pavel Sedov}

\section{NOTE DE L'AUTEUR}

1 [ПАВЕЛ В. СЕДОВ, «К ИСТОРИИ БОЯРСКОЙ СЕМЬИ XVII В.: СЕМЬЯ КНЯЗЯ Н.И. ОДОЕВСКОГО].

1 ПОЛОЖЕНИЕ ЗНАТИ В ОБЩЕСТВЕ ЯВЛЯЕТСЯ ОДНОЙ ИЗ ВАЖНЕЙШИХ ЕГО ХАРАКТЕРИСТИК. РАССМОТРЕНИЕ ЭТОГО ВОПРОСА ПРЕДПОЛАГАЕТ ИЗУЧЕНИЕ ИСТОРИИ КОНКРЕТНЫХ БОЯРСКИХ СЕМЕЙ. ВЫБОР ДЛЯ ЭТОЙ ЦЕЛИ СЕМЬИ КНЯЗЯ НИКИТЫ ИВАНОВИЧА ОДОЕВСКОГО ИМЕЕТ СЛЕДУЮЩИЕ ОСНОВАНИЯ. ЭТО ЕДВА ЛИ НЕ САМАЯ ВИДНАЯ БОЯРСКАЯ СЕМЬЯ ВТОРОЙ ПОЛОВИНЫ XVII ВЕКА, А ЕЕ ГЛАВУ КНЯЗЯ Н.И. ОДОЕВСКОГО МОЖНО СЧИТАТЬ ОДНИМ ИЗ САМЫХ ВЫДАЮЩИХСЯ БОЯР ЭТОГО СТОЛЕТИЯ. ОН РОДИЛСЯ В НАЧАЛЕ СМУТЫ И УМЕР ПРИ ПЕТРЕ І. КНЯЗЬ Н.И. ОДОЕВСКИЙ БЫЛ ОДНИМ ИЗ КРУПНЕЙШИХ ЗЕМЛЕВЛАДЕЛЬЦЕВ СТРАНЫ, ИМЕЛ КАМЕННЫЙ ДВОР В КРЕМЛЕ, ВОЗГЛАВЛЯЛ КОМИССИЮ ПО СОСТАВЛЕНИЮ СОБОРНОГО УЛОЖЕНИЯ 1649 Г., РАСПРАВНУЮ ПАЛАТУ, РЯД ВАЖНЕЙШИХ ПРИКАЗОВ, БЫВАЛ «ВЕЛИКИМ ПОСЛОМ». НА ПРОТЯЖЕНИИ НЕСКОЛЬКИХ ДЕСЯТИЛЕТИЙ СЕРЕДИНЫ И ВТОРОЙ ПОЛОВИНЫ СТОЛЕТИЯ ОН ВЫСТУПАЛ КАК ГЛАВА ВСЕЙ ДУМЫ И ОТ ЕЕ ИМЕНИ ПОЗДРАВЛЯЛ ЦАРЯ С НОВОЛЕТИЕМ 1 СЕНТЯБРЯ. ЕГО ДЕТИ, ВНУКИ, ПРАВНУКИ И ПРАПРАВНУКИ ЗАНИМАЛИ ВИДНОЕ ПОЛОЖЕНИЕ ПРИ МОСКОВСКОМ ДВОРЕ.

2 В СТАТЬЕ О.Е. КОШЕЛЕВОЙ ПРОАНАЛИЗИРОВАНО ЗЕМЛЕВЛАДЕНИЕ СЕМЬИ КНЯЗЕЙ ОДОЕВСКИХ. В НАСТОЯЩЕЙ РАБОТЕ БУДЕТ РАССМОТРЕН ДРУГОЙ АСПЕКТ ИСТОРИИ ЭТОЙ 
СЕМЬИ: ПРИДВОРНАЯ СЛУЖБА. ПОСТАВЛЕННУЮ ЗАДАЧУ ОБЛЕГЧАЮТ ГЕНЕАЛОГИЧЕСКИЕ ИССЛЕДОВАНИЯ Г.А. ВЛАСЬЕВА, А.П. БАРСУКОВА, МОНОГРАФИЯ Ю. АРСЕНЬЕВА 2 ДАННАЯ РАБОТА НЕ СТАВИТ ЦЕЛЬЮ В ДЕТАЛЯХ ПРОСЛЕДИТЬ ИСТОРИЮ СЕМЬИ КНЯЗЯ Н.И. ОДОЕВСКОГО И ЕГО РОДСТВЕННИКОВ ${ }^{3}$, ЧТО ВОЗМОЖНО ЛИШЬ В РАМКАХ ОТДЕЛЬНОГО ИССЛЕДОВАНИЯ. ЗАДАЧА ДАННОЙ СТАТЬИ БОЛЕЕ СКРОМНАЯ: РАССМОТРЕТЬ ПРИЧИНЫ УНИКАЛЬНОГО ВОЗВЫШЕНИЯ РОДА КНЯЗЕЙ ОДОЕВСКИХ В XVII В. ТРУДНО НАЗВАТЬ ДРУГУЮ БОЯРСКУЮ СЕМЬЮ, КОТОРАЯ ДОБИЛАСЬ БЫ СТОЛЬ ЖЕ ВПЕЧАТЛЯЮЩИХ УСПЕХОВ НА ПРОТЯЖЕНИИ ВСЕГО ХVII В. ЭТО БЫЛО РЕЗУЛЬТАТОМ НЕ КРАТКОГО ФАВОРА КАКОГО-НИБУДЬ ГОСУДАРЯ, А ДОЛГОСРОЧНОЙ ЦАРСКОЙ МИЛОСТИ, УДЕРЖИВАЕМОЙ НА ПРОТЯЖЕНИИ НЕСКОЛЬКИХ ПОКОЛЕНИЙ (СМ. СХЕМУ). ОДИН ЛИШЬ КНЯЗЬ Н.И. ОДОЕВСКИЙ БЫЛ БЛИЖНИМ БОЯРИНОМ ПЯТИ ЦАРЕЙ: МИХАИЛА ФЕДОРОВИЧА, АЛЕКСЕЯ МИХАЙЛОВИЧА, ФЕДОРА, ИВАНА И ПЕТРА АЛЕКСЕЕВИЧЕЙ. ПЕРВОСТЕПЕННЫЙ СТАТУС КНЯЗЕЙ ОДОЕВСКИХ XVII В. НЕ БЫЛ ПОДТВЕРЖДЕН В ПЕТРОВСКУЮ ЭПОХУ, И В XVIII В. ЭТА СЕМЬЯ ОКАЗАЛАСЬ НА ВТОРЫХ РОЛЯХ В ГОСУДАРСТВЕ.

\section{Семья князей Одоевских в царствование Михаила Федоровича (1613-1645)}

ПО СТЕЧЕНИЮ ОБСТОЯТЕЛЬСТВ РОД КНЯЗЕЙ ОДОЕВСКИХ СИЛЬНО ПОРЕДЕЛ В СМУТУ И В ПЕРВЫЕ ГОДЫ ПОСЛЕ НЕЕ. СТОЛЬНИК КНЯЗЬ ИВАН МИХАЙЛОВИЧ БЫЛ УБИТ ПОД МОСКВОЙ. КНЯЗЬ ИВАН НИКИТИЧ БОЛЬШОЙ МНИХА ПОЛУЧИЛ БОЯРСТВО ПРИ ЛЖЕДМИТРИИ І, ЗАТЕМ СЛУЖИЛ ЦАРЮ ВАСИЛИЮ ШУЙСКОМУ. БУДУЧИ ВОЕВОДОЙ НОВГОРОДА, ОН БЫЛ ВЫНУЖДЕН СДАТЬ ЕГО ШВЕДАМ В 1611 Г. И СЛУЖИЛ ИМ В НОВГОРОДЕ ДО СВОЕЙ СМЕРТИ 7 МАРТА 1616 Г. В НОВГОРОДЕ УМЕРЛИ И ТАМ ЖЕ БЫЛИ ПОХОРОНЕНЫ ОБА СТАРШИХ СЫНА БОЯРИНА: ВАСИЛИЙ УМЕР 23 АПРЕЛЯ 1612 Г., А ИВАН БОЛЬШОЙ «УБИЛ СЕБЯ САМ ИЗ ПИЩАЛИ» 21 АПРЕЛЯ 1616 Г., ТО ЕСТЬ СРАЗУ ПОСЛЕ СОРОЧИН ПО ОТЦУ СОПРОВОЖДАЯ ТЕЛО ОТЦА ДЛЯ ПОГРЕБЕНИЯ В ТРОИЦЕ-СЕРГИЕВ МОНАСТЫРЬ. ОТТУДА КНЯЗЬ НИКИТА, КОТОРОМУ ТОГДА БЫЛО ОКОЛО ДЕСЯТИ ЛЕТ, ОТПРАВИЛСЯ В МОСКВУ.

НАЧАЛО СЛУЖБЫ КНЯЗЯ НИКИТЫ ИВАНОВИЧА ПРИ ДВОРЕ ЦАРЯ МИХАИЛА БЫЛО ОБЫЧНЫМ ДЛЯ ПРЕДСТАВИТЕЛЯ АРИСТОКРАТИЧЕСКОЙ СЕМЬИ. В 1621-1624 ГГ. ОН УПОМИНАЕТСЯ НА ДВОРЦОВОЙ СЛУЖБЕ: «ВИНА НАРЯЖАЛ» И «СМОТРЕЛ В БОЛЬШОЙ СТОЛ» ВО ВРЕМЯ ЦАРСКИХ ЗАСТОЛИЙ, СИДЕЛ В ЗОЛОТОМ КАФТАНЕ НА ПРИЕМАХ ИНОЗЕМНЫХ ПОСЛОВ. НА ЦАРСКОЙ СВАДЬБЕ 1624 Г. С КНЯЖНОЙ МАРИЕЙ ВЛАДИМИРОВНОЙ ДОЛГОРУКОВОЙ ОН БЫЛ СРЕДИ ПОЕЗЖАН

КАРЬЕРА КНЯЗЯ НИКИТЫ ИВАНОВИЧА ОПРЕДЕЛИЛАСЬ С САМОГО НАЧАЛА ДВУМЯ ОБСТОЯТЕЛЬСТВАМИ ПРИДВОРНОГО ХАРАКТЕРА. 10 ФЕВРАЛЯ 1622 Г. ОН ЖЕНИЛСЯ НА ЕВДОКИИ ФЕДОРОВНЕ, ДОЧЕРИ БОЯРИНА Ф.И. ШЕРЕМЕТЕВА И ИРИНЫ БОРИСОВНЫ, УРОЖДЕННОЙ КНЯЖНЫ ЧЕРКАССКОЙ. «НАЗАВТРЕЯ СВОЕЙ СВАДЬБЫ» КНЯЗЬ НИКИТА ИВАНОВИЧ ПО ТРАДИЦИИ ЯВИЛСЯ К ЦАРЮ УДАРИТЬ ЧЕЛОМ И ПОЛУЧИЛ ЩЕДРЫЕ ЦАРСКИЕ ПОДАРКИ, КОТОРЫЕ ДЬЯК БУЛГАК МИЛОВАНОВ ОТВЕЗ ЕМУ НА ДВОР БЛАГОДАРЯ ЭТОМУ БРАКУ КНЯЗЬ НИКИТА ИВАНОВИЧ ВОШЕЛ В УЗКИЙ КРУГ КОМНАТНЫХ ЛЮДЕЙ ЦАРЯ. ПРИ НОВОЙ ДИНАСТИИ РОМАНОВЫХ ПОЛОЖЕНИЕ ПЕРВОСТАТЕЙНЫХ КНЯЖЕСКИХ РОДОВ ОПРЕДЕЛЯЛОСЬ УЖЕ РОДСТВОМ НЕ СТОЛЬКО С ДИНАСТИЕЙ ИВАНА КАЛИТЫ, СКОЛЬКО С НОВОЙ ЦАРСКОЙ ДИНАСТИЕЙ. БОЯРЕ Ф.И. ШЕРЕМЕТЕВ И КНЯЗЬ 
И.Б. ЧЕРКАССКИЙ БЫЛИ СВОЙСТВЕННИКАМИ ЦАРЯ И ИГРАЛИ КЛЮЧЕВУЮ РОЛЬ В ЦАРСКОЙ KOMHATE.

ВСЛЕД ЗА ТЕМ КНЯЗЬ НИКИТА ИВАНОВИЧ ВОШЕЛ В ЧИСЛО КОМНАТНЫХ СТОЛЬНИКОВ (СПАЛЬНИКОВ) ЦАРЯ МИХАИЛА ФЕДОРОВИЧА. ТОЧНОЕ ВРЕМЯ ЕГО ПОЖАЛОВАНИЯ В КОМНАТУ НЕИЗВЕСТНО, НО, ВИДИМО, ЭТО ПРОИЗОШЛО В СЕРЕДИНЕ 1620-Х ГОДОВ, КОГДА ОН СТАЛ ИСПОЛНЯТЬ ОБЫЧНЫЕ ДЛЯ СПАЛЬНИКОВ ПОРУЧЕНИЯ. НА ЦАРСКОЙ СВАДЬБЕ 5 ФЕВРАЛЯ 1626 Г. С ЕВДОКИЕЙ ЛУКЬЯНОВНОЙ СТРЕШНЕВОЙ КНЯЗЬ ИВАН «ВИНА НАРЯЖАЛ» И БЫЛ ЗА ЦАРЕМ «В МЫЛЬНЕ», КУДА ПО ОБЫЧАЮ ХОДИЛИ СПАЛЬНИКИ ЗНАЧЕНИЕ КОМНАТНЫХ СТОЛЬНИКОВ В ПРИДВОРНОЙ ЖИЗНИ ПРИВЛЕКЛО СПЕЦИАЛЬНОЕ ВНИМАНИЕ ИССЛЕДОВАТЕЛЕЙ ЛИШЬ В САМОЕ ПОСЛЕДНЕЕ ВРЕМЯ. В КОНТЕКСТЕ СТАВШИХ ТЕПЕРЬ ИЗВЕСТНЫМИ СИСТЕМАТИЧЕСКИХ СВЕДЕНИЙ О ЗНАЧЕНИИ ЭТОГО ЧИНА КАК В ПЕРВОЙ, ТАК И ВО ВТОРОЙ ПОЛОВИНЕ XVII В. КОМНАТНАЯ СЛУЖБА КНЯЗЕЙ ОДОЕВСКИХ ЯВЛЯЕТСЯ, ВИДИМО, САМЫМ ВПЕЧАТЛЯЮЩИМ ПРИМЕРОМ ПРИДВОРНОГО УСПЕХА. ВРЯД ЛИ СТОИТ УГЛУБЛЯТЬСЯ В СХОЛАСТИЧЕСКИЙ СПОР О ТОМ, ЧТО В ПЕРВУЮ ОЧЕРЕДЬ ОПРЕДЕЛЯЛО ПОЛОЖЕНИЕ ПРИ ЦАРСКОМ ДВОРЕ XVII В.: ПРОИСХОЖДЕНИЕ, ЗЕМЛЕВЛАДЕНИЕ, МЕСТО В ЦАРСКОЙ КОМНАТЕ, ЛИЧНЫЕ ДАРОВАНИЯ ИЛИ ИНЫЕ СЛАГАЕМЫЕ УСПЕХА. У РАЗНЫХ СЕМЕЙ ЭТИ УСЛОВИЯ БЫЛИ НЕОДИНАКОВЫ, ВСЕ ОНИ БЫЛИ ВАЖНЫ И ЖЕЛАННЫ. НО ДЛЯ КНЯЗЕЙ ОДОЕВСКИХ КОМНАТНАЯ СЛУЖБА СЫГРАЛА, ПОЖАЛУЙ, ПЕРВОСТЕПЕННУЮ РОЛЬ В ИХ ВОЗВЫШЕНИИ ПРИ ПЕРВЫХ РОМАНОВЫХ ЗЕМЛЕВЛАДЕНИЕ КНЯЗЯ НИКИТЫ ИВАНОВИЧА ПОНАЧАЛУ БЫЛО НЕ СЛИШКОМ ВЕЛИКО. УДЕЛЬНОЕ КНЯЖЕНИЕ ОДОЕВСКИХ, ГОРОД ЛИХВИН С УЕЗДОМ, ПОПАЛО В ОПРИЧНИНУ, И ОНИ УТРАТИЛИ НА НЕГО ПРАВА९. ВЛАДЕЛЕЦ ЛИХВИНСКОГО УДЕЛА КНЯЗЬ НИКИТА РОМАНОВИЧ ОДОЕВСКИЙ, РОДНОЙ ДЕД КНЯЗЯ НИКИТЫ ИВАНОВИЧА, БЫЛ ЗАМУЧЕН ПО ПРИКАЗУ ИВАНА ГРОЗНОГО В 1573 Г. С КОНЦА XVI В. НОВЫЕ ВЛАДЕНИЯ КНЯЗЕЙ ОДОЕВСКИХ СКЛАДЫВАЛИСЬ КАК ЦАРСКОЕ ПОЖАЛОВАНИЕ. КНЯЗЮ НИКИТЕ ИВАНОВИЧУ ПЕРЕШЛИ ВОТЧИНЫ ЕГО ОТЦА, БОЛЬШАЯ ЧАСТЬ КОТОРЫХ НАХОДИЛАСЬ В БЕЖЕЦКОМ ВЕРХУ НОВГОРОДСКОГО УЕЗДА (1 163 ЧЕТВ.), А ТАКЖЕ НЕБОЛЬШИЕ ВЛАДЕНИЯ В ДМИТРОВСКОМ (ПРИДАННАЯ ВОТЧИНА ЕГО МАТЕРИ АГАФЬИ ИГНАТЬЕВНЫ, УРОЖДЕННОЙ ТАТИЩЕВОЙ - 55 ЧЕТВ.), МЕЩЕРСКОМ И ЗУБЦОВСКОМ УЕЗДАХ ${ }^{10}$. ВЛАДЕНИЯ, ОСОБЕННО БЕЖЕЦКИЕ, БЫЛИ РАЗОРЕНЫ И ПОЭТОМУ НА ВСТРЕЧЕ ИНОЗЕМНЫХ ПОСЛОВ ОН ВЫСТАВЛЯЛ МАЛО ДАТОЧНЫХ ЛЮДЕЙ: 5 ЧЕЛОВЕК В 1627 Г., 6 - В 1630 Г., 6 И 10 - В 1631 11 .

9 АВГУСТА 1628 Г. НА ВОЕВОДСТВЕ В НОВГОРОДЕ УМЕР ДВОЮРОДНЫЙ БРАТ КНЯЗЯ НИКИТЫ ИВАНОВИЧА - БОЯРИН КНЯЗЬ ИВАН ИВАНОВИЧ МЕНЬШОЙ, А В СЛЕДУЮЩЕМ ГОДУ, 2 МАРТА, И ОТЕЦ ПОСЛЕДНЕГО - БОЯРИН КНЯЗЬ ИВАН НИКИТИЧ МЕНЬШОЙ ${ }^{12}$. КНЯЗЬ НИКИТА ИВАНОВИЧ ОТВЕЗ ТЕЛО СВОЕГО ДЯДИ В ТРОИЦУ И СДЕЛАЛ ПО НЕМ ВКЛАД 500 РУБ. ВИДИМО, ОН БЫЛ ЕГО ДУШЕПРИКАЗЧИКОМ ${ }^{13}$.

КНЯЗЬ НИКИТА ИВАНОВИЧ ОСТАЛСЯ ЕДИНСТВЕННЫМ ВЗРОСЛЫМ МУЖЧИНОЙ РОДА, И ПОЭТОМУ ПОЯВЛЕНИЕ У НЕГО СЫНОВЕЙ БЫЛО ОСОБЕННО БОЛЬШОЙ РАДОСТЬЮ. СТАРШИЙ СЫН МИХАИЛ РОДИЛСЯ, ВИДИМО, ОКОЛО 1623-1624 Г., А ВСКОРЕ ЗАТЕМ И ВТОРОЙ СЫН ФЕДОР. ИМЕНА СТАРШИХ СЫНОВЕЙ БЫЛИ СВЯЗАНЫ С РОДОВЫМ ПРЕДАНИЕМ КНЯЗЕЙ ОДОЕВСКИХ. ИХ ПРЕДОК КНЯЗЬ МИХАИЛ ЧЕРНИГОВСКИЙ ГЕРОИЧЕСКИ ПОГИБ В СТАВКЕ ХАНА В 1246 Г. И ВМЕСТЕ СО СВОИМ БОЯРИНОМ ФЕДОРОМ БЫЛ ПРИЧИСЛЕН К ЛИКУ СВЯТЫХ ${ }^{14}$. ИМЕНОВАНИЕ СТАРШЕГО СЫНА В ЧЕСТЬ ПРЕДКА, ПРОСЛАВИВШЕГО РОД ЕЩЕ В XIII В., ДОЛЖНО БЫЛО СЛУЖИТЬ НАПОМИНАНИЕМ О ЕГО ДРЕВНОСТИ И ЗНАТНОСТИ. 
ЦАРЬ С УВАЖЕНИЕМ ОТНОСИЛСЯ К ЗНАТНЫМ СПАЛЬНИКАМ, СЛУЖИВШИМ В ЕГО КОМНАТЕ. В 1633 Г. КНЯЗЬ Н.И. ОДОЕВСКИЙ БЫЛ НАЗНАЧЕН СХОДНЫМ ВОЕВОДОЙ БОЯРИНА КНЯЗЯ Д.М. ЧЕРКАССКОГО ДЛЯ ПОХОДА К СМОЛЕНСКУ. КНЯЗЬ НИКИТА ИВАНОВИЧ ОСМЕЛИЛСЯ МЕСТНИЧАТЬ С ГЛАВНЫМ ВОЕВОДОЙ, НО ПРОИГРАЛ МЕСТНИЧЕСКИЙ СПОР И БЫЛ НАПРАВЛЕН В ТЮРЬМУ. ОДНАКО УЖЕ ОТ ФРОЛОВСКИХ ВОРОТ КРЕМЛЯ ЦАРЬ ВЕЛЕЛ ВЕРНУТЬ КНЯЗЯ Н.И. ОДОЕВСКОГО И В ТЮРЬМУ ЕГО НЕ САЖАТЬ ${ }^{15}$. 12 ЯНВАРЯ 1640 Г., НА ИМЕНИНЫ ЦАРЕВНЫ ТАТЬЯНЫ МИХАЙЛОВНЫ, КНЯЗЬ НИКИТА ИВАНОВИЧ БЫЛ ПОЖАЛОВАН В БОЯРЕ ${ }^{16}$. ВЕРОЯТНО, ЭТО НАЗНАЧЕНИЕ БЫЛО СВЯЗАНО С ОБЪЯВЛЕНИЕМ ЕМУ НОВОЙ СЛУЖБЫ - НА ВОЕВОДСТВО В АСТРАХАНЬ (1640-1642) $)^{17}$. В АСТРАХАНИ БОЯРИН КНЯЗЬ Н.И. ОДОЕВСКИЙ ПРОЯВИЛ РАДЕНИЕ, ПОСТРОИВ КАЗАНСКУЮ ЦЕРКОВЬ С ПРИДЕЛОМ МИХАИЛА МАЛЕНИНА - В ЧЕСТЬ «ГОСУДАРЕВА АНГЕЛА» ${ }^{18}$. ПО ВОЗВРАЩЕНИИ В МОСКВУ ЦАРЬ НАГРАДИЛ ВОЕВОДУ ЗА ЕГО СЛУЖБУ ШУБОЙ, ПРИДАЧЕЙ К ОКЛАДУ В 50 РУБ. И ПОЖАЛОВАНИЕМ 500 ЧЕТВЕРТЕЙ ИЗ ПОМЕСТЬЯ В ВОТЧИНУ ${ }^{19}$.

СЛУЖЕБНОЕ ВОЗВЫШЕНИЕ КНЯЗЕЙ ОДОЕВСКИХ БЫЛО ПОДКРЕПЛЕНО ПОКРОВИТЕЛЬСТВОМ БОЯРИНА Ф.И. ШЕРЕМЕТЕВА, КОТОРЫЙ, ПОССОРИВШИСЬ СО СВОЕЙ РОДНЕЙ, ОТПИСАЛ ЗНАЧИТЕЛЬНУЮ ЧАСТЬ НАСЛЕДСТВА РОДСТВЕННИКАМ СВОЕЙ ДОЧЕРИ - КНЯЗЮ НИКИТЕ ИВАНОВИЧУ И ЕГО СЫНОВЬЯМ. ВСЕ ПОПЫТКИ ШЕРЕМЕТЕВЫХ ОСПОРИТЬ УТРАТУ ВОТЧИН И МОСКОВСКИХ ДВОРОВ ПОТЕРПЕЛИ НЕУДАЧУ. В 1645 Г. Ф.И. ШЕРЕМЕТЕВ УТВЕРДИЛ СВОЕ ЗАВЕЩАНИЕ У ЦАРЯ, А В 1649 Г. ПЕРЕПИСАЛ ЕГО В НОВОЙ РЕДАКЦИИ ${ }^{20}$. СОПЕРНИЧЕСТВО КНЯЗЯ Н.И. ОДОЕВСКОГО С РОДНЕЙ СВОЕГО ТЕСТЯ ЗА ОБЛАДАНИЕ НАСЛЕДСТВОМ ПОДТОЛКНУЛО ШЕРЕМЕТЕВЫХ НАЧАТЬ МЕСТНИЧЕСКИЙ СПОР. В ЯНВАРЕ 1645 Г. БОЯРИН И.П. ШЕРЕМЕТЕВ БИЛ ЧЕЛОМ В ОТЕЧЕСТВЕ НА КНЯЗЯ Н.И. ОДОЕВСКОГО, НО ПОЛУЧИЛ ОТПОВЕДЬ: «РОДИТЕЛИ ВАШИ ПРИ ПРЕЖНИХ ГОСУДАРЯХ БЕСПРЕСТАННО С ОДОЕВСКИМИ БЫВАЛИ, А НА НИХ ГОСУДАРЯМ НЕ БИВАЛИ ЧЕЛОМ ${ }^{21}$.

\section{Семья князей Одоевских в царствование Алексея Михайловича (1645-1676)}

С ВОЦАРЕНИЕМ АЛЕКСЕЯ МИХАЙЛОВИЧА КНЯЗЬЯ ОДОЕВСКИЕ ПОНАЧАЛУ СОХРАНЯЛИ ЗНАЧЕНИЕ БЛИЖНИХ ЛЮДЕЙ. В НОЧЬ С 13 НА 14 ИЮЛЯ 1645 Г. КНЯЗЬ НИКИТА ИВАНОВИЧ ВОЗГЛАВЛЯЛ ЦЕРЕМОНИЮ ПРИСЯГИ НОВОМУ ЦАРЮ И В ЭТОТ ЖЕ ДЕНЬ БЫЛ ПОЖАЛОВАН В БЛИЖНИЕ БОЯРЕ ЮНОГО ГОСУДАРЯ, КАК ЭТО БЫЛО И В ПРЕЖНЕЕ ЦАРСТВОВАНИЕ ${ }^{22}$. 7 АВГУСТА 1645 Г. ОН УВЕДОМИЛ ДАТСКОГО КОРОЛЕВИЧА ВОЛЬДЕМАРА О ТОМ, ЧТО ТОТ МОЖЕТ ЕХАТЬ ДОМОЙ, ЧТО ПОЛОЖИЛО КОНЕЦ НЕУДАЧНОМУ ПРОЕКТУ ЖЕНИТЬ ЕГО НА ЦАРЕВНЕ ИРИНЕ МИХАЙЛОВНЕЕ ${ }^{23}$. ЭТО ЦАРСКОЕ ПОРУЧЕНИЕ СВИДЕТЕЛЬСТВУЕТ О СОХРАНЕНИИ В ТОТ МОМЕНТ КНЯЗЕМ НИКИТОЙ ИВАНОВИЧЕМ ЗНАЧЕНИЯ БЛИЖНЕГО, КОМНАТНОГО ЧЕЛОВЕКА.

ЦАРСКИЙ ДЯДЬКА И ФАКТИЧЕСКИЙ ПРАВИТЕЛЬ СТРАНЫ БОЯРИН БОРИС ИВАНОВИЧ МОРОЗОВ ВИДЕЛ В КНЯЗЕ Н.И. ОДОЕВСКОМ СТАВЛЕННИКА БОЯРИНА Ф.И. ШЕРЕМЕТЕВА И УДАЛИЛ ЕГО ИЗ МОСКВЫ. 1 ФЕВРАЛЯ 1646 Г. ЕМУ БЫЛА СКАЗАНА СЛУЖБА ПЕРВЫМ ВОЕВОДОЙ БОЛЬШОГО ПОЛКА В БЕЛГОРОД ${ }^{24}$. НАКАНУНЕ ОТЪЕЗДА НА СЛУЖБУ КНЯЗЬ НИКИТА ИВАНОВИЧ ОСТАВАЛСЯ ДОВЕРЕННЫМ ЧЕЛОВЕКОМ Ф.И. ШЕРЕМЕТЕВА И 6 МАРТА 1646 Г. САМ ОТВЕЗ В ТРОИЦУ ВКЛАД СВОЕГО ТЕСТЯ ${ }^{25}$. 
В КОНЦЕ 1646 - НАЧАЛЕ 1647 Г. ПОД РУКОВОДСТВОМ КНЯЗЯ Н.И. ОДОЕВСКОГО СЛУЖИЛЫЕ ЛЮДИ ПОСТРОИЛИ ГОРОД БОЛХОВ И СООРУДИЛИ ЗЕМЛЯНОЙ ВАЛ НА МУРОМСКОЙ САКМЕ ${ }^{26}$ . СТРОИТЕЛЬСТВО ВАЛА ШЛО ТЯЖЕЛО, И ДВОРЯНЕ СТАЛИ ЖАЛОВАТЬСЯ НА ОДОЕВСКОГО В МОСКВУ. В ЭТИХ ЖАЛОБАХ БЫЛИ СОБРАНЫ ВСЕВОЗМОЖНЫЕ НАВЕТЫ НА ВОЕВОДУ: ОН БЕЗ ДЕЛА, ТЕРЯЯ ВРЕМЯ, СТОЯЛ 10 ДНЕЙ В СТЕПИ И ТОЛЬКО ЗАТЕМ ВЫСТАВИЛ У ВОЕВОДСКОГО ШАТРА ДЕРЕВЯННЫЙ РУБЛЕННЫЙ ОБРАЗЕЦ ВАЛА, КОТОРЫЙ ПОРУЧИЛ ДЕЛАТЬ «ГОРОДОДЕЛЬЦАМ НЕМЦАМ». ДВОРЯНЕ «ТОГО ОБРАЗЦА УЖАСНУЛИСЬ, ЧТО ДЕЛАТЬ БЫЛО ТЯЖЕЛО». СЛУЖИЛЫЕ ЛЮДИ ВОЗМУТИЛИСЬ НЕСПРАВЕДЛИВОСТЬЮ, С КОТОРОЙ ВОЕВОДА ОТМЕРИЛ КАЖДОМУ ОБЪЕМ РАБОТ. ДВОРЯНИН А. СОЛНЦЕВ «С ТОВАРИЩАМИ» ЯВИЛСЯ В ШАТЕР К ВОЕВОДЕ, «КРИЧАЛ И БИЛ ЧЕЛОМ БОЯРИНУ ШУМНО, И БОЯРИН ВЕЛЕЛ ВЫСЛАТЬ ЕГО ИЗ ШАТРА ВОН, А ГОВОРИЛ ЕМУ, ЧТО СДЕЛАТЬ ДВЕ САЖЕНИ ЕМУ МОЧНО». ОСОБЕННО «В КРУЧИНУ» БЫЛА КНЯЗЮ ЧЕЛОБИТНАЯ НА НЕГО ЗНАТНЫХ СТОЛЬНИКОВ КНЯЗЕЙ Д.А. И П.А. ДОЛГОРУКОВЫХ, КОТОРЫЕ ОБВИНЯЛИ ВОЕВОДУ В БЕСПЕЧНОСТИ. ОНИ УВЕДОМЛЯЛИ ЦАРЯ, ЧТО СЫНОВЬЯ КНЯЗЯ НИКИТЫ ИВАНОВИЧА ОХОТИЛИСЬ ВО ВРЕМЯ ПОХОДА С СОБАКАМИ И СОКОЛАМИ, ПОТОПТАЛИ ХЛЕБ МЕСТНЫХ ЖИТЕЛЕЙ И ДАЖЕ РАСПУГАЛИ ИХ КОЗ; ПО НОЧАМ СОБАКИ КНЯЗЯ ОДОЕВСКОГО ВЫЛИ, ПУГАЯ ВОЕННЫЙ ЛАГЕРЬ НЕДОБРЫМ ПРЕДЗНАМЕНОВАНИЕМ. В МОСКВЕ ЭТИ ЖАЛОБЫ РАЗБИРАЛА КОМИССИЯ ВО ГЛАВЕ С БОЯРИНОМ КНЯЗЕМ А.Н. ТРУБЕЦКИМ, НО ЧЕМ КОНЧИЛОСЬ ДЕЛО НЕИЗВЕСТНО ${ }^{27}$. СКОЛЬ БЫ НИ БЫЛИ ПРЕУВЕЛИЧЕННЫМИ ЭТИ НАВЕТЫ НА КНЯЗЯ Н.И. ОДОЕВСКОГО, ОНИ ВСЕ ЖЕ ОТРАЖАЮТ ОГРОМНУЮ ДИСТАНЦИЮ, КОТОРАЯ ОТДЕЛЯЛА ДВОРЯН, ВКЛЮЧАЯ ДАЖЕ И СТОЛЬНИКОВ ИЗ ВИДНЫХ РОДОВ, ОТ ЗНАТНОГО БОЯРИНА, ЗАБРОШЕННОГО ВОЛЕЮ ПРИДВОРНОЙ БОРЬБЫ ВДАЛЬ ОТ ЦАРСКИХ ПАЛАТ, ГДЕ ОН ПРИВЫК СЛУЖИТЬ ДО ТОГО. ЭТО БЫЛА НЕ ЕДИНСТВЕННАЯ ЖАЛОБА НА КНЯЗЯ Н.И. ОДОЕВСКОГО. УКРАИНСКИЕ МЕЩАНЕ ОБВИНЯЛИ ЕГО В ТОМ, ЧТО ОН НЕ ПУСТИЛ В МОСКОВСКИЙ ЛАГЕРЬ ПОД БЕЛГОРОДОМ ГОРИЛКУ И ТАБАК, УНИЧТОЖИВ ЭТИХ ТОВАРОВ НА ДЕСЯТЬ ТЫСЯЧ РУБЛЕЙ ${ }^{28}$.

ОДНАКО ПО ВОЗВРАЩЕНИИ В МОСКВУ КНЯЗЬ НИКИТА ИВАНОВИЧ ВНОВЬ ОБРЕЛ ЗНАЧЕНИЕ БЛИЖАЙШЕГО КОМНАТНОГО ЧЕЛОВЕКА, И НАВЕТЫ НА НЕГО НЕ ИМЕЛИ ПОСЛЕДСТВИЙ. 16 ЯНВАРЯ 1648 Г. НА СВАДЬБЕ АЛЕКСЕЯ МИХАЙЛОВИЧА С МАРИЕЙ ИЛЬИНИЧНОЙ КНЯЗЬ Н.И. ОДОЕВСКИЙ ПОЛУЧИЛ ПОЧЕТНУЮ ДОЛЖНОСТЬ ДРУЖКИ С ЦАРСКОЙ СТОРОНЫ, А ЕГО ЖЕНА АВДОТЬЯ ФЕДОРОВНА БЫЛА СВАХОЙ ${ }^{29}$.

СТОЛЬ ВЫСОКАЯ МИЛОСТЬ СТАЛА ЗАЛОГОМ ПОСЛЕДОВАВШЕГО ЗАТЕМ ВЫДАЮЩЕГОСЯ ПОРУЧЕНИЯ В СУДЬБЕ КНЯЗЯ НИКИТА ИВАНОВИЧА: 17 ИЮЛЯ 1648 Г. ОН ВОЗГЛАВИЛ КОМИССИЮ ДЛЯ СОСТАВЛЕНИЯ НОВОГО СВОДА ЗАКОНОВ ${ }^{30}$. ЭТО ПОРУЧЕНИЕ БЫЛО НЕСЛУЧАЙНЫМ. ИССЛЕДОВАТЕЛИ ОБРАТИЛИ ВНИМАНИЕ НА ТО, ЧТО КНЯЗЬ Н.И. ОДОЕВСКИЙ БЫЛ ЗНАКОМ С ВЫСОКОЙ КНИЖНОСТЬЮ, ВПОЛНЕ ВЛАДЕЛ ЭПИСТОЛЯРНЫМ ЖАНРОМ ${ }^{31}$. ПО СЛОВАМ СОВРЕМЕННИКА ПОЛЬСКОГО ПАНА ПАВЛА ПОТОЦКОГО (1670 Г.), ОН ИМЕЛ «БЛАГОРАЗУМИЕ (НЕ ВСЕГДА, ОДНАКО, ПРОНИЦАТЕЛЬНОЕ) <...> ОСНОВАТЕЛЬНЫЕ ПОЗНАНИЯ В СЛАВЯНСКОМ ЯЗЫКЕ И НЕКОТОРЫЕ СВЕДЕНИЯ В ИСТОРИИ ПОЛЬСКОЙ» ${ }^{32}$. ОН ПОКУПАЛ ИЗДАНИЯ МОСКОВСКОЙ ТИПОГРАФИИ: В 1650 Г. ПРОЛОГ И «УЧЕНИЕ И ХИТРОСТЬ РАТНОГО СТРОЕНИЯ ПЕХОТНЫХ ЛЮДЕЙ»З3. В 1665 Г. У НЕГО БРАЛИ «ДЛЯ ПЕРЕПИСКИ» «ИСТОРИЮ КАЗАНСКУЮ» ${ }^{34}$, ОН ЖЕ ВЛАДЕЛ И КНИГОЙ «ПРЕНИЯ С ГРЕКАМИ О ВЕРЕ» АРСЕНИЯ СУХАНОВА ${ }^{35}$. В 1675 Г. СЛУГА КНЯЗЯ НИКИТЫ ИВАНОВИЧА ТИХОМИР НИКОНОВ НАПИСАЛ СБОРНИК, ПРИНАДЛЕЖАВШИЙ ПОЗДНЕЕ СТОЛЬНИКУ Б.Л. ДУБЕНСКОМУ ${ }^{36}$. ЭТА КНИГА, НАДО ДУМАТЬ, БЫЛА НЕ ЕДИНСТВЕННОЙ, СОЗДАННОЙ НА ДВОРЕ КНЯЗЯ Н.И. ОДОЕВСКОГО. ЗОЛОТОПИСЕЦ ДМИТРИЙ КВАЧЕВСКИЙ 
ЖИЛ НА ДВОРЕ КНЯЗЯ И ЗА СВОЕ МАСТЕРСТВО БЫЛ ПРИВЛЕЧЕН К СОЗДАНИЮ «ТИТУЛЯРНИКА» В ПОСОЛЬСКОМ ПРИКАЗЕ ${ }^{37}$.

КНЯЗЬ Н.И. ОДОЕВСКИЙ ВХОДИЛ В КОМНАТНЫЙ КРУГ МИХАИЛА ФЕДОРОВИЧА И АЛЕКСЕЯ МИХАЙЛОВИЧА, КОГДА В ЦАРСКОМ ДВОРЦЕ ПОЛУЧИЛИ РАСПРОСТРАНЕНИЕ ИДЕИ «РЕВНИТЕЛЕЙ ДРЕВЛЕГО БЛАГОЧЕСТИЯ ${ }^{38}$. ВИДИМО, БОЯРИН СОЧУВСТВОВАЛ ОДНОЙ ИЗ ОСНОВНЫХ ИДЕЙ «РЕВНИТЕЛЕЙ БЛАГОЧЕСТИЯ» О ДУХОВНОМ СПАСЕНИИ ЧЕРЕЗ РЕЛИГИОЗНОЕ ПРОСВЕЩЕНИЕ. ОН СЧИТАЛ НЕОБХОДИМЫМ ДАТЬ ПРИЛИЧНОЕ ДЛЯ СВОЕГО ВРЕМЕНИ ОБРАЗОВАНИЕ ДЕТЯМ И ВНУКАМ. ДЛЯ ОБУЧЕНИЯ СТАРШЕГО СЫНА КНЯЗЯ МИХАИЛА БЫЛ ПРИГЛАШЕН КНИЖНИК САВВАТИЙ, БЛИЗКИЙ К СПРАВЩИКАМ ПЕЧАТНОГО ДВОРА. КНЯЖИЧУ МИХАИЛУ САВВАТИЙ ПОСВЯТИЛ СТИХОТВОРНЫЕ НАСТАВЛЕНИЯ: «ПРЕЩЕНИЕ ВКРАТЦЕ О ЛЕНОСТИ И НЕРАДЕНИИ ВСЯКОМУ, БЫВАЕМОМУ ВО УЧЕНИИ» И «АЗБУКА ОТПУСКНАЯ ТЕБЕ, МОЕМУ УЧЕНИКУ ${ }^{39}$.

21 МЛАДШИЙ СЫН ЯКОВ ЩОБРАЗОВАЛ СВОЙ УМ, ЗАНИМАЯСЬ ИЗУЧЕНИЕМ СЛАВЯНСКОГО ЯЗЫКА И ОТЛИЧАЕТСЯ БОЛЕЕ ПРИРОДНОЙ МУДРОСТИЮ, НЕЖЕЛИ ПРИОБРЕТЕННОЮ УЧЕНЫМИ ТРУДАМИ ${ }^{40}$. ЕМУ ПРИНАДЛЕЖАЛ ПЕВЧЕСКИЙ ОБИХОДНИК «ДЕМЕВСТВЕННИК» 41. ВНУКИ КНЯЗЯ НИКИТЫ ИВАНОВИЧА ТАКЖЕ БЫЛИ ЛЮДЬМИ КНИЖНЫМИ. В 1679 Г. БОЯРИН КНЯЗЬ ЮРИЙ МИХАЙЛОВИЧ, ПРОЕЗЖАЯ ЧЕРЕЗ ИВЕРСКИЙ МОНАСТЫРЬ, ПОЛУЧИЛ ОТ БРАТИИ В ПОДАРОК ДВЕ КНИГИ МОНАСТЫРСКОЙ ТИПОГРАФИИ: РАЙ И БРАШНО ${ }^{42}$ В ПЕРВОЙ ПОЛОВИНЕ 1680-Х ГОДОВ КНЯЗЬ ЮРИЙ МИХАЙЛОВИЧ СДЕЛАЛ ВКЛАД В ЦЕРКОВЬ ЗНАМЕНИЯ, «ЧТО НА ЕГО ДВОРЕ» - СБОРНИК НОВГОРОДСКИХ АГИОГРАФИЧЕСКИХ ПРОИЗВЕДЕНИЙ ${ }^{43}$.

КНЯЗЬ НИКИТА ИВАНОВИЧ ОДОЕВСКИЙ ОКАЗЫВАЛ ЗАМЕТНОЕ ВЛИЯНИЕ НА ВОСПИТАНИЕ НЕ ТОЛЬКО СВОИХ СЫНОВЕЙ И ВНУКОВ, НО ДАЖЕ И ПРАВНУКОВ. В СВОЕЙ ДУХОВНОЙ 1689 Г. ОН С ГОРДОСТЬЮ ПИСАЛ, ЧТО ВЗЯЛ К СЕБЕ В ДОМ СВОЕГО ПРАВНУКА КНЯЗЯ ЮРИЯ, СЫНА БОЯРИНА ЮРИЯ МИХАЙЛОВИЧА И ДАЛ ЕМУ ОБРАЗОВАНИЕ: «ПРАВНУКА СВОЕГО КНЯЗЯ ЮРЬЯ ЮРЬЕВИЧА ВЗЯЛ ЯЗ У ОТЦА ЕВО <... ЗА СЫНА МЕСТО ШТИ ЛЕТ, ВСКОРМИЛ ЕВО И ВЫУЧИЛ ${ }^{44}$. ВСЛЕД ЗА ТЕМ ПРАВНУКИ КНЯЗЯ Н.И. ОДОЕВСКОГО ПРОДОЛЖИЛИ ОБРАЗОВАНИЕ В СЛАВЯНО-ГРЕКО-ЛАТИНСКОЙ АКАДЕМИИ ${ }^{45}$. ВПЛОТЬ ДО КОНЦА ХVII СТОЛЕТИЯ В МОСКОВСКОМ ГОСУДАРСТВЕ НЕ БЫЛО СИСТЕМЫ ГОСУДАРСТВЕННОГО ШКОЛЬНОГО ОБРАЗОВАНИЯ, И ДЕТИ ИЗ ДВОРЯНСКИХ СЕМЕЙ ПОЛУЧАЛИ ОБРАЗОВАНИЕ ДОМА ${ }^{46}$. ЕЩЕ БОЛЕЕ НЕОБХОДИМЫМ КНИЖНОЕ УЧЕНИЕ БЫЛО В БОЯРСКОЙ СРЕДЕ, ПОСКОЛЬКУ В НЕМ ВИДЕЛИ ОБЯЗАТЕЛЬНОЕ УСЛОВИЕ ПРОДВИЖЕНИЯ ПО СЛУЖБЕ. СВЕРХ КНИЖНОГО УЧЕНИЯ ОТЕЦ ЛИЧНО ПЕРЕДАВАЛ СВОИМ СЫНОВЬЯМ ЗНАНИЯ И НАВЫКИ, НЕОБХОДИМЫЕ ДЛЯ БУДУЩЕЙ СЛУЖБЫ. ДУМНЫЙ ЧЕЛОВЕК БРАЛ СЫНОВЕЙ С СОБОЙ В ПОСОЛЬСТВО, НА ВОЕВОДСТВО, ДОБИВАЛСЯ НАЗНАЧЕНИЯ ИХ В СВОЙ ПРИКАЗ. БОЯРСКИЕ СЕМЬИ ОБЛАДАЛИ МОНОПОЛЬНЫМ ПРАВОМ ЗАНИМАТЬ ВЫСШИЕ ДОЛЖНОСТИ В ГОСУДАРСТВЕ И РАССМАТРИВАЛИ СВОЙ ОПЫТ КАК ПРИВИЛЕГИЮ, ПЕРЕДАВАЕМУЮ ПО НАСЛЕДСТВУ. ДОМАШНЕЕ ОБРАЗОВАНИЕ БЫЛО ТРАДИЦИЕЙ БОЯРСКИХ СЕМЕЙ, ХОТЯ В СВЯЗИ С УТРАТОЙ СЕМЕЙНЫХ АРХИВОВ XVII В. ОНА УСКОЛЬЗАЕТ ОТ ИССЛЕДОВАТЕЛЕЙ. БОЯРСКАЯ СЕМЬЯ КНЯЗЕЙ ОДОЕВСКИХ, ОЛИЦЕТВОРЯВШАЯ СОБОЙ ЦВЕТ МОСКОВСКОЙ ЗНАТИ, МАЛО СООТВЕТСТВОВАЛА ИРОНИЧЕСКИ-ПРИСТРАСТНОЙ ХАРАКТЕРИСТИКЕ БОЯРСТВА, ДАННОЙ ГРИГОРИЕМ КОТОШИХИНЫМ: СИДЯТ БОЯРЕ «БРАДЫ СВОИ УСТАВЯ, <... $>$ МНОГИЕ ИЗ НИХ ГРАМОТЕ НЕУЧЕНЫЕ И НЕ СТУДЕРОВАНЫЕ» ${ }^{47}$. ВЫСОКИЙ СТАТУС КНЯЗЯ НИКИТЫ ИВАНОВИЧА КАК СОСТАВИТЕЛЯ СОБОРНОГО УЛОЖЕНИЯ 1649 Г. БЫЛ ЗАКРЕПЛЕН В ТОМ ЖЕ ГОДУ НОВОСЕЛЬЕМ В НОВЫХ КАМЕННЫХ ПАЛАТАХ, 
ПОСТРОЕННЫХ В САМОМ КРЕМЛЕ НА ДВОРЕ, ЗАВЕЩАННОМ БОЯРИНОМ Ф.И. ШЕРЕМЕТЕВЫМ. 4 СЕНТЯБРЯ ПАТРИАРХ ОТОСЛАЛ КНЯЗЮ Н.И. ОДОЕВСКОМУ «НА НОВОСЕЛЬЕ» ТРАДИЦИОННЫЙ ПОДАРОК, СОЛОНКУ С ХЛЕБОМ ${ }^{48}$. КНЯЗЬ НИКИТА ИВАНОВИЧ ЕЗДИЛ В ОДНОЙ КАРЕТЕ С ЦАРЕМ - МИЛОСТЬ ЗНАЧИТЕЛЬНАЯ ДАЖЕ ДЛЯ БЛИЖНЕГО БОЯРИНА. ${ }^{49}$

УСПЕХ ПРИДВОРНОЙ КАРЬЕРЫ КНЯЗЯ Н.И.ОДОЕВСКОГО ПРОЛАГАЛ ПУТЬ И ДЛЯ ЕГО СЫНОВЕЙ. ИМ БЫЛО УГОТОВАНО ИДТИ ПО СТОПАМ ОТЦА, КОТОРЫЙ ПРИСТРОИЛ ИХ В СТОЛЬНИКИ ЦАРЕВИЧА АЛЕКСЕЯ МИХАЙЛОВИЧА ${ }^{50}$. С ВОЦАРЕНИЕМ ПОСЛЕДНЕГО ОНИ СТАЛИ ЕГО СПАЛЬНИКАМИ. СТОЛЬНИКИ ЦАРЕВИЧЕЙ, И В ОСОБЕННОСТИ ЦАРСКИЕ СПАЛЬНИКИ, БЫЛИ УЧАСТНИКАМИ ПОВСЕДНЕВНОЙ ЖИЗНИ ЦАРСКОЙ СЕМЬИ, СВИДЕТЕЛЯМИ ИНТИМНЫХ ПОДРОБНОСТЕЙ ДВОРЦОВОГО БЫТА. У НИХ ВОЗНИКАЛИ ОСОБЫЕ ДОВЕРИТЕЛЬНЫЕ ОТНОШЕНИЯ С ГОСУДАРЕМ, КОТОРЫЕ ОНИ СОХРАНЯЛИ И В ДАЛЬНЕЙШЕМ. ПО ТРАДИЦИИ СПАЛЬНИКИ ПРИ ПОЛУЧЕНИИ ДУМНОГО ЧИНА СТАНОВИЛИСЬ ЧЛЕНАМИ КОМНАТНОЙ ДУМЫ, ХРАНИТЕЛЯМИ ВЫСШИХ ГОСУДАРСТВЕННЫХ СЕКРЕТОВ, УЧАСТНИКАМИ ПРИДВОРНОГО ВЛИЯНИЯ.

СВИДЕТЕЛЬСТВОМ ЭТИХ БЛИЗКИХ ОТНОШЕНИЙ ЯВЛЯЮТСЯ ПИСЬМА ЦАРЯ АЛЕКСЕЯ МИХАЙЛОВИЧА. В ПОСЛАНИИ НОВГОРОДСКОМУ МИТРОПОЛИТУ НИКОНУ О СМЕРТИ ПАТРИАРХА ИОСИФА АЛЕКСЕЙ МИХАЙЛОВИЧ СООБЩИЛ, КТО В НАИБОЛЬШЕЙ СТЕПЕНИ РАЗДЕЛИЛ С НИМ СКОРБЬ ПО УМЕРШЕМ ВЛАДЫКЕ: «КОТОРЫЕ ОТ БЛИЖНИХ БЫЛИ, СО МНОЮ ВСЕ ПЕРЕРВАЛИСЬ, ПЛАЧУЧИ, А ВСЕХ ПУЩИ ТРУБЕЦКОЙ, ДА КНЯЗЬ МИХАЙЛО ОДОЕВСКОЙ, ДА МИХАЙЛО РТИЩЕВ, ДА ВАСИЛЕЙ БУТУРЛИН ${ }^{51}$. СОХРАНИЛОСЬ ДВА ЦАРСКИХ ПОСЛАНИЯ КНЯЗЮ Н.И. ОДОЕВСКОМУ В СВЯЗИ С ТЕМ, ЧТО КНЯЗЬ НИКИТА ИВАНОВИЧ ОДОЕВСКИЙ БЫЛ ПОСЛАН НА ВОЕВОДСТВО В КАЗАНЬ (1651-1653) ${ }^{52}$, КУДА ОН ВЗЯЛ С СОБОЙ МЛАДШИХ СЫНОВЕЙ АЛЕКСЕЯ И ЯКОВА (СТАРШИХ СЫНОВЕЙ СПАЛЬНИКОВ МИХАИЛА И ФЕДОРА БОЯРИН ОСТАВИЛ В МОСКВЕ). ЭТИ ПИСЬМА ОТРАЖАЮТ АТМОСФЕРУ ДОВЕРИТЕЛЬНОСТИ, СУЩЕСТВОВАВШУЮ МЕЖДУ ЦАРЕМ И ЕГО КОМНАТНЫМИ ЛЮДЬМИ. В ПИСЬМЕ 3 СЕНТЯБРЯ 1653 Г. ЦАРЬ ПОДЕЛИЛСЯ С КНЯЗЕМ НИКИТОЙ ИВАНОВИЧЕМ СВОИМИ ЧУВСТВАМИ В СВЯЗИ С ПЕРЕНЕСЕНИЕМ МОЩЕЙ МИТРОПОЛИТА ФИЛИППА КОЛЫЧЕВА В МОСКВУ 53.21 НОЯБРЯ ТОГО ЖЕ ГОДА АЛЕКСЕЙ МИХАЙЛОВИЧ ЛИЧНЫМ ПОСЛАНИЕМ ИЗВЕСТИЛ КНЯЗЯ Н.И. ОДОЕВСКОГО О СМЕРТИ ЕГО СЫНА КНЯЗЯ МИХАИЛА. ЦАРЬ ТРОГАТЕЛЬНО ОПИСЫВАЕТ, КАК НАКАНУНЕ КОНЧИНЫ ОН ПОБЫВАЛ В ПОДМОСКОВНОМ ИМЕНИИ КНЯЗЕЙ ОДОЕВСКИХ:

БЫЛ Я У ТЕБЯ В ВЕШНЯКОВЕ, А ОН ЗДРАВ БЫЛ: ПОТЧИВАЛ МЕНЯ ДА РАД ТАКОВ, А ЕВО ТАКОВА РАДОСТНА НИКОЛИ НЕ ВИДАЛ; ДА ЛОШАДЬЮ ОН ДА КНЯЗЬ ФЕДОР ЧЕЛОМ УДАРИЛИ, И Я МОЛВИЛ ИМ: “ПО ТОЛЬ Я ПРИЕЗЖАЛ К ВАМ, ЧТО ГРАБИТЬ ВАС?” - И ОН ПЛАЧУЧИ ДА ГОВОРИТ МНЕ: “МНЕ ДЕ, ГОСУДАРЬ, ТЕБЯ НЕ ВИДАТЬ ЗДЕСЬ: ВОЗМИТЕ, ГОСУДАРЬ, ДЛЯ РАДИ ХРИСТА, ОБРАДУЙ БАТЮШКА И НАС, НАМ ЖЕ И ДО ВЕКА ТАКОВА ГОСТЯ НЕ ВИДАТЬ". И Я, ВИДЯ ИХ НЕЛЕСТНОЕ ПРОШЕНИЕ И РАДОСТЬ НЕСУМЕНУЮ, ВЗЯЛ ЖЕРЕБЦА ТЕМНОСЕРА. НЕ ЛОШАДЬ ДОРОГА МНЕ, ВСЕГО ЛУТЧИ ИХ НЕЛИЦЕМЕРНАЯ СЛУЖБА, И ПОСЛУШАНИЕ, И РАДОСТЬ ИХ КО МНЕ, ЧТО ОНИ РАДОВАЛИСЯ МНЕ ВСЕМ СЕРДЦЕМ. ДА ЖАЛУЮЧИ ТЕБЯ И ИХ ВЕЗДЕ БЫЛ, И В КОНЮШНЯХ, ВСЕГО СМОТРЕЛ, ВО ВСЕХ ЖИЛИЩАХ БЫЛ, И КУШАЛ У НИХ В ХОРОМЕХ, И ПОСЛЕ КУШАНИЯ ПОСЛАЛ Я К ПОКРОВСКОМУ ТЕШИТСЯ В РОЩИ В КАРАЧЕЛЬСКИЕ; ОН СО МНОЮ ЗДОРОВ БЫЛ И ПРИЕХАЛ ТОГО ДНИ К НОЧИ В ПОКРОВСКОЕ. ДА ЖАЛОВАЛ ИХ ОБЕИХ ВИНОМ И РОМАНЕЕЮ, И ПОДАЧАМИ И КАМКАМИ, И ЕЛИ У МЕНЯ, И КАК ОТОШЛО ВЕЧЕРНЕЕ КУШАНЬЕ, А ОН СТАЛ ИЗ-ЗА СТОЛА И ПОЧАЛ СТОНАТЬ ГОЛОВОЮ, ГОЛОВА-ДЕ БЕЗМЕРНО БОЛИТ <... А ПЕРЕД ПЯТНИЦЕЮ, В КОТОРУЮ НЕ СТАЛО <...> ПОЧАЛА КРОВЬ ИДТИ ИЗ НОСА БЕЗПРЕСТАНИ, А СКАЗЫВАЛ 
МНЕ КНЯЗЬ ФЕДОР, ВЕДРА-ДЕ, ГОСУДАРЬ, С ТРИ ВЫШЛО, ДА КАК-ДЕ УНЯЛАСЬ, ТАК И ОТХОДИТЬ НАЧАЛ.

ДАЛЕЕ ЦАРЬ ПРОСТРАННО ИЗЛОЖИЛ «БОЯРИНУ НАШЕМУ И СЛУГЕ» СЛОВА СОЧУВСТВИЯ, ДОБАВИВ

И МЫ ТЕБЯ НЕ ПОКИНЕМ И З ДЕТМИ, ИХ ЖАЛОВАЛИ И ВПРЕД РАД ЖАЛОВАТЬ СЫНА ЕГО ЮРИЯ, А ОТЦА РАД ПОМИНАТЬ. А КНЯЗЬ ФЕДОРА Я ПОЖАЛОВАЛ ОТ ПЕЧАЛИ УТЕШИЛ, А НА ВЗНОС И НА ВСЕ ПОГРЕБАЛЬНЫЯ Я ПОСЛАЛ СКОЛЬКО БОГ ИЗВОЛИЛ, ПОТОМУ ЧТО ВПРЯМ УЗНАЛ И ПРОВЕДАЛ ПРО ВАС, ЧТО ОПРИЧ БОГА НА НЕБЕСИ, А НА ЗЕМЛИ ОПРИЧ МЕНЯ, НИ У КОВО У ВАС НЕТ; И Я РАД ИХ И ВАС ЖАЛОВАТЬ, ТОЛКО ТЫ, КНЯЗЬ НИКИТА, ПОМНИ БОЖИЮ МИЛОСТЬ, А НАШЕ ЖАЛОВАНИЕ. КАК ЖИВОВА ЕГО ПОЖАЛОВАЛ, ТАК И ПОМИНАТЬ РАД.

ДАЛЕЕ АЛЕКСЕЙ МИХАЙЛОВИЧ УПОМИНАЕТ ПРЕДЫДУЩИЕ СВОИ ПИСЬМА КНЯЗЮ Н.И. ОДОЕВСКОМУ С ИЗЛОЖЕНИЕМ СВОИХ МЫСЛЕЙ О ВЗАИМООТНОШЕНИЯХ С БОЯРАМИ, ЗАКЛЮЧАЯ: «МЫ ТЕБЕ И С ДЕТМИ И СО ВНУЧАТЫ ПО БОЗЕ РОДИТЕЛИЕ ${ }^{54}$. В ОТНОШЕНИИ СВОИХ КОМНАТНЫХ ЛЮДЕЙ АЛЕКСЕЙ МИХАЙЛОВИЧ ВЫСТУПАЕТ КАК ГЛАВА БОЛЬШОГО СЕМЕЙСТВА. ОН ВНИКАЛ В СЕМЕЙНЫЕ ДЕЛА БЛИЖНИХ ЛЮДЕЙ, ХОРОШО ЗНАЛ ИХ ЛИЧНЫЕ ОСОБЕННОСТИ И ПРОДВИГАЛ ИХ ПО СЛУЖБЕ КАК НАИБОЛЕЕ ДОВЕРЕННЫХ СЛУГ.

НА ПАСХУ 15 АПРЕЛЯ 1655 Г. ЦАРЬ ПОЖАЛОВАЛ КНЯЗЯ ФЕДОРА НИКИТИЧА ОДОЕВСКОГО ИЗ СПАЛЬНИКОВ В БОЯРЕ В СВЯЗИ С НАЗНАЧЕНИЕМ ЕГО ВОЕВОДОЙ ДЛЯ ПОХОДА К АСТРАХАНИ ПРОТИВ ТАТАР 55 . КНЯЗЮ ФЕДОРУ НИКИТИЧУ ЕДВА МИНУЛО ТРИДЦАТЬ ЛЕТ ВОЗРАСТ ЧРЕЗВЫЧАЙНО МОЛОДОЙ ДЛЯ БОЯРСКОГО ЧИНА. В ПИСЬМЕ БОЯРИНУ В.В. БУТУРЛИНУ ЦАРЬ ПОДРОБНО ОПИСАЛ МОТИВЫ СВОЕЙ ИСКЛЮЧИТЕЛЬНОЙ МИЛОСТИ:

ДЛЯ ЕВО ВЕЛИКОВА ПОКАЯНИЯ БОГУ И К НАМ ЗЕЛНОВА ПОСЛУШАНИЯ, ЧТО ПОКАЯЛСЯ БОГУ И НАМ ВСЕМ СЕРДЦЕМ, НЕ КАК НЕ СТАРОЙ КНЯЗЬ ФЕДОР СТАЛ, НЕ КАК ЛЕТОСЬ ХОДИЛ ДУРОСТЬЮ, А НЫНЕ ВО ВСЕМ ЖЕЛАЕТ ОТ НАС УКАЗУ И ОТ ОТЦА НАШЕГО (ПАТРИАРХА НИКОНА. - П.С.) БЛАГОСЛОВЕНИЯ, А ЕСТЬЛИ БЫ НРАВУ СВОЕВО НЕ ПЕРЕМЕНИЛ, И Я Б ЕВО И НЕ ПОМЫСЛИЛ ПОСЛАТЬ, И О ТОМ НАМ, ВЕЛИКОМУ ГОСУДАРЮ, ЗЕЛО БИЛ ЧЕЛОМ ОТ ВСЕЯ ДУШИ, ЧТОБ ТЫ ЕГО ПРОСТИЛ <...>. А ОН ОБЕЩАЕТ ДЛЯ НАС, ВЕЛИКОГО ГОСУДАРЯ ДРУГОМ БЫТЬ, И ВЕДАЕШЬ ТЫ НАШ ОБЫЧАЙ: ХТО К НАМ НЕ ВСЕМ СЕРДЦЕМ СТАНЕТ РАБОТАТЬ, И МЫ К НЕМУ С МИЛОСТИЮ НЕ ВСКОРЕ ПРИРАЗИМСЯ. ${ }^{56}$

ЦАРЬ ПООЩРЯЛ ТЕХ ПРИДВОРНЫХ, КОТОРЫЕ ЖЕЛАЛИ ВО ВСЕМ УГОЖДАТЬ ЕМУ, А НЕ ОТСТАИВАТЬ «ДУРОСТИЮ» СВОЕ МНЕНИЕ. АЛЕКСЕЙ МИХАЙЛОВИЧ ОТКРЫТО ЗАЯВЛЯЛ, ЧТО ЗНАТНЫЕ СПАЛЬНИКИ ДОЛЖНЫ «ПЕРЕМЕНИТЬ СВОЙ НРАВ», ИНАЧЕ ОНИ НЕ ДОЖДУТСЯ БОЯРСКОГО ЧИНА. В СЛЕДУЮЩЕМ ГОДУ КНЯЗЬ ФЕДОР НИКИТИЧ БЫЛ НАЗНАЧЕН ЕХАТЬ С ОТЦОМ В ВИЛЬНО ДЛЯ ПЕРЕГОВОРОВ СО ШВЕДАМИ, НО ВНЕЗАПНО СКОНЧАЛСЯ. 19 ИЮЛЯ 1656 Г. КНЯЗЬ НИКИТА ИВАНОВИЧ СООБЩИЛ ЦАРЮ, ЧТО «СЫНА ЕГО БОЯРИНА КНЯЗЯ ФЕДОРА НИКИТИЧА ОДОЕВСКОГО НЕ СТАЛО» ${ }^{57}$. 1650-Е ГОДЫ БЫЛИ ТЯЖЕЛЫМИ ДЛЯ СЕМЬИ КНЯЗЯ НИКИТЫ ИВАНОВИЧА. ВСЛЕД ЗА СТАРШИМ СЫНОМ, 15 ДЕКАБРЯ 1655 Г. УМЕР КНЯЗЬ АЛЕКСЕЙ НИКИТИЧ. 15 ИЮНЯ 1656 Г. УМЕРЛА МЛАДШАЯ ДОЧЬ - КНЯГИНЯ ПРАСКОВЬЯ НИКИТИЧНА, ЖЕНА КНЯЗЯ Г.С. ЧЕРКАССКОГО. 18 ИЮЛЯ 1656 ГОДА УМЕР ТРЕТИЙ СЫН - КНЯЗЬ ФЕДОР НИКИТИЧ ${ }^{58}$. СМЕРТЬ ТРЕХ СЫНОВЕЙ СОСРЕДОТОЧИЛА ЗЕМЕЛЬНЫЕ БОГАТСТВА СЕМЬИ В РУКАХ КНЯЗЯ НИКИТЫ ИВАНОВИЧА И БОЛЕЕ ВСЕГО - В СОБСТВЕННОСТИ МЛАДШЕГО СЫНА ЯКОВА. КНЯЗЬ ЯКОВ НИКИТИЧ НАЧАЛ СЛУЖБУ 1 ОКТЯБРЯ 1653 Г. В КОМНАТНЫХ СТОЛЬНИКАХ, ИСПОЛНЯЯ ОБЫЧНЫЕ ДЛЯ СПАЛЬНИКОВ СЛУЖБЫ. В ВОЕННЫХ ПОХОДАХ 1654 И 1656 ГГ. ОН С ДРУГИМИ СПАЛЬНИКАМИ БЫЛ ЯСАУЛОМ, «И ЗА ГОСУДАРЕМ ИМ ЖЕ ЕЗДИТЬ», «ВИНА 
НАРЯЖАЛ» И ЧАШНИЧАЛ ПЕРЕД ГОСУДАРЕМ, В 1657 Г. БЫЛ РЫНДОЙ «ПЕРЕД ГОСУДАРЕМ У СААДАКА $\aleph^{59}$. В 1658 Г. КНЯЗЬ ЯКОВ НИКИТИЧ ЕЗДИЛ В СВИТЕ ПОСОЛЬСТВА НА СЪЕЗД С ПОЛЬСКИМИ КОМИССАРАМИ В ВИЛЬНО; ПОСОЛЬСТВО ВОЗГЛАВЛЯЛИ ЕГО ОТЕЦ И СТАРШИЙ БРАТ ФЕДОР. В СВЯЗИ С НАЗНАЧЕНИЕМ НА ВОЕВОДСТВО В АСТРАХАНЬ КНЯЗЮ ЯКОВУ НИКИТИЧУ БЫЛО СКАЗАНО БОЯРСТВО ${ }^{60}$. ВО ВРЕМЯ АСТРАХАНСКОГО ВОЕВОДСТВА (16631666) ${ }^{61}$, ПО СЛОВАМ СОВРЕМЕННИКА-ПОЛЯКА, КНЯЗЬ ЯКОВ НИКИТИЧ «ОПРАВДАЛ СИЕ ПОСПЕШНОЕ ВОЗВЫШЕНИЕ (ПОЖАЛОВАНИЕ БОЯРСТВА. - П.С.) ПОХВАЛЬНЫМ УПРАВЛЕНИЕМ» ${ }^{62}$. В ЦЕНТРАЛЬНОМ ПОЛИТИЧЕСКОМ КОНФЛИКТЕ СЕРЕДИНЫ XVII В. - ЦАРЯ АЛЕКСЕЯ МИХАЙЛОВИЧА С ПАТРИАРХОМ НИКОНОМ - КНЯЗЬ НИКИТА ИВАНОВИЧ СЛЕДОВАЛ МНЕНИЮ ГОСУДАРЯ. С.В. ЛОБАЧЕВ СПРАВЕДЛИВО ОТМЕТИЛ, ЧТО ВРАЖДЕБНОСТЬ БОЯРИНА КНЯЗЯ Н.И.ОДОЕВСКОГО К НИКОНУ НАЧАЛАСЬ НЕ РАНЬШЕ КОНФЛИКТА ВЛАСТОЛЮБИВОГО ПАТРИАРХА С ЦАРЕМ. КОГДА ЖЕ РАЗРЫВ ОТНОШЕНИЙ СТАЛ СВЕРШИВШИМСЯ ФАКТОМ, ЦАРЬ РАЗ ЗА РАЗОМ ДОВЕРЯЛ ВЕСТИ ЭТО ВАЖНЕЙШЕЕ ГОСУДАРСТВЕННОЕ ДЕЛО КНЯЗЮ НИКИТЕ ИВАНОВИЧУ. В ДЕКАБРЕ 1662 Г. ТОТ ВОЗГЛАВИЛ КОМИССИЮ, ПРИЗВАННУЮ ОСУДИТЬ НИКОНА. В ИЮНЕ 1663 Г. - ДРУГУЮ КОМИССИЮ, НАПРАВЛЕННУЮ К ОПАЛЬНОМУ ПАТРИАРХУ В ВОСКРЕСЕНСКИЙ МОНАСТЫРЬ ПО ПОВОДУ ПРОКЛЯТИЯ НИКОНОМ ЦАРСКОЙ СЕМЬИ. 18 ФЕВРАЛЯ 1664 Г. НИКОН ВНЕЗАПНО ПРИЕХАЛ В МОСКВУ. ЦАРЬ ТУТ ЖЕ ПОСЛАЛ В УСПЕНСКИЙ СОБОР ДУМСКУЮ ДЕЛЕГАЦИЮ ВО ГЛАВЕ С БОЯРИНОМ КНЯЗЕМ Н.И. ОДОЕВСКИМ СПРОСИТЬ НИКОНА О ЦЕЛЯХ ЕГО САМОВОЛЬНОГО ПРИЕЗДА. НА СОБОРЕ 1666 Г. КНЯЗЬ НИКИТА ИВАНОВИЧ БЫЛ ОБВИНИТЕЛЕМ НИКОНА И ВСЛЕД ЗА ТЕМ ПРИСУТСТВОВАЛ НА ЦЕРЕМОНИИ ЕГО НИЗЛОЖЕНИЯ ${ }^{63}$. НЕУДИВИТЕЛЬНО, ЧТО НИКОН ОТПЛАТИЛ БОЯРИНУ РЕЗКИМ ОТЗЫВОМ: «КНЯЗЬ НИКИТА ЧЕЛОВЕК ПРЕГОРДОЙ, СТРАХУ БОЖИЯ В СЕРДЦЫ НЕ ИМЕЕТ, И БОЖЕСТВЕННАГО ПИСАНИЯ И ПРАВИЛ СВЯТЫХ АПОСТОЛ И СВЯТЫХ ОТЕЦ НИЖЕ ЧТЕТ, НИЖЕ РАЗУМЕЕТ И ЖИТИ В НИХ НЕ ХОЩЕТ, И ЖИВУЩИХ В НИХ НЕНАВИДИТ, ЯКО ВРАГОВ СУЩИХ, САМ БЫВ ВРАГ ВСЯКОЙ ИСТИНЕ ${ }^{64}$. НО БЛИЖНИЙ БОЯРИН НЕ БОЯЛСЯ ПАТРИАРШЕГО ГНЕВА И ЕГО ПРОКЛЯТИЙ. В ПРИСТРАСТНОМ ОТЗЫВЕ НИКОНА ЕСТЬ ОДНА ДЕТАЛЬ, В КОТОРОЙ УГАДЫВАЕТСЯ РЕАЛЬНАЯ ЧЕРТА КНЯЗЯ. «ПРЕГОРДЫЙ» БОЯРИН НЕ БЫЛ ПОХОЖ НА ЦАРСКОГО ЛИЗОБЛЮДА: СТАРАТЕЛЬНО ИСПОЛНЯЯ ЦАРСКУЮ ВОЛЮ, ОН ДЕРЖАЛСЯ С ВАЖНОСТЬЮ, ПРИЛИЧНОЙ ЕГО ПЕРВОСТАТЕЙНОМУ СТАТУСУ.

ЭТУ ЖЕ ВАЖНОСТЬ КНЯЗЯ Н.И. ОДОЕВСКОГО ОТМЕТИЛ И СТОРОННИЙ НАБЛЮДАТЕЛЬ, АВСТРИЙСКИЙ ПОСОЛ АВГУСТИН МЕЙЕРБЕРГ, ПРИСУТСТВОВАВШИЙ ПРИ ТОМ, КАК БОЯРИН ПОЗДРАВЛЯЛ ЖЕНУ СМОЛЕНСКОГО ВОЕВОДЫ В 1662 Г.: «ИЗ ТОЛПЫ ПОЗДРАВИТЕЛЕЙ ВЫДЕЛЯЛСЯ КНЯЗЬ НИКИТА ИВАНОВИЧ ОДОЕВСКИЙ <... ПОТОМОК СТОЛЬКИХ ВЕНЦЕНОСНЫХ ЛИЦ» ${ }^{65}$. ПОЛЬСКИЙ ПАН ПАВЕЛ ПОТОЦКИЙ, НЕСКОЛЬКО ЛЕТ ЖИВШИЙ В МОСКВЕ, ИМЕЛ ВОЗМОЖНОСТЬ БЛИЖЕ ПОЗНАКОМИТЬСЯ С КНЯЗЕМ НИКИТОЙ ИВАНОВИЧЕМ И, ВИДИМО, БЕСЕДОВАЛ С НИМ. ПО ЕГО СЛОВАМ, «ОТЯГЧЕННАЯ БОЛЕЗНЯМИ СТАРОСТЬ ЧАСТО ПРЕПЯТСТВУЕТ» КН. Н.И. ОДОЕВСКОМУ «ПРИСУТСТВОВАТЬ В ТАЙНОМ СОВЕТЕ СВОЕГО ГОСУДАРЯ» ${ }^{66}$.

[ОН] ПРОИСХОДИТ ОТ ЗНАМЕНИТОГО И ПОЧТИ ЦАРСКОГО РОДА КНЯЗЕЙ ЧЕРНИГОВСКИХ <...> ПРЕДКИ ЕГО ПРОМЕНЯЛИ СВОЙ УДЕЛ НА БЕЗУСЛОВНОЕ ПОДДАНСТВО, И ОН ЖИВЕТ ТЕПЕРЬ СМЕШАННЫЙ В ТОЛПЕ ПОДДАННЫХ И ПО СВОЕМУ БЛАГОРАЗУМИЮ (НЕ ВСЕГДА ОДНАКО ПРОНИЦАТЕЛЬНОМУ) И ПО БЛАГОРОДНЫМ ЧУВСТВОВАНИЯМ, НЕ ИСТРЕБИВШИМИСЯ В ЕГО СЕРДЦЕ, ОН ДОСТОИН ЛУЧШЕЙ УЧАСТИ И ОТЕЧЕСТВА, УСТРОЕННОГО САМЫМ ЛУЧШИМ ОБРАЗОМ. ${ }^{67}$ 
В ЭТОЙ ХАРАКТЕРИСТИКЕ ЗАМЕТНО ПРЕДСТАВЛЕНИЕ ПОЛЬСКОГО ПАНА ОБ УНИЖЕННОМ ПОЛОЖЕНИИ ЗНАТИ В МОСКОВСКОМ ГОСУДАРСТВЕ. НО, ПОХОЖЕ, САМ КНЯЗЬ НИКИТА ИВАНОВИЧ СТРЕМИЛСЯ ИМЕННО К ТОМУ, ЧТО ПОЛЬСКИЙ ПАН ОСУЖДАЛ. ЗНАТНОСТИ, БОГАТСТВУ, ПРИДВОРНОМУ ВЛИЯНИЮ КНЯЗЯ Н.И. ОДОЕВСКОГО МОГ ПОЗАВИДОВАТЬ И ПОЛЬСКИЙ МАГНАТ.

КНЯЗЬЯ ОДОЕВСКИЕ СТАЛИ ОДНОЙ ИЗ БОГАТЕЙШИХ БОЯРСКИХ СЕМЕЙ. В 1647 Г. КНЯЗЬ НИКИТА ИВАНОВИЧ С ДЕТЬМИ МИХАИЛОМ И ФЕДОРОМ ВЛАДЕЛ 2714 ДВОРАМИ ${ }^{68}$. В 1678 Г. БОЯРЕ КНЯЗЬЯ Н.И., Я.Н. И Ю.М. ОДОЕВСКИЕ ВЛАДЕЛИ ВМЕСТЕ 4248 ДВОРАМИ, СВЕРХ ТОГО КРАВЧИЙ КНЯЗЬ В.Ф. ОДОЕВСКИЙ ИМЕЛ ОДНИХ ЛИШЬ ВОТЧИН 725 ДВОРОВ ${ }^{69}$. ЭТИ ДАННЫЕ НЕ УЧИТЫВАЮТ ПОЖАЛОВАНИЯ В «ДИКИХ ПОЛЯХ» НА ЮГЕ СТРАНЫ. КНЯЗЬ Я.Н. ОДОЕВСКИЙ ПОЛУЧИЛ В 1673-1674 ГГ. 3000 ЧЕТВЕРТЕЙ В ЕПИФАНСКОМ УЕЗДЕ, А КНЯЗЬ В.Ф. ОДОЕВСКИЙ В 1676-1677 ГГ. - 1500 ЧЕТВЕРТЕЙ ЗЕМЛИ В ДОНКОВСКОМ ${ }^{70}$. О БОГАТСТВЕ КНЯЗЕЙ ОДОЕВСКИХ СВИДЕТЕЛЬСТВУЮТ И КАМЕННЫЕ ХРАМЫ В ИХ ПОДМОСКОВНЫХ УСАДЬБАХ, СОХРАНИВШИЕСЯ ДОНЫНЕ - ВЫДАЮЩИЕСЯ ПАМЯТНИКИ ЗОДЧЕСТВА XVII В. В 1660-1670-Е ГОДЫ ИХ СТРОИЛ СОБСТВЕННЫЙ ЗОДЧИЙ БОЯРСКОЙ СЕМЬИ ПАВЕЛ ПОТЕХИН: НИКОЛЬСКУЮ ЦЕРКОВЬ В СЕЛЕ УРЮПИНО В ВОТЧИНЕ КНЯЗЯ Н.И. ОДОЕВСКОГО И ТРИ В ВОТЧИНАХ КНЯЗЯ Я.Н. ОДОЕВСКОГО - АРХАНГЕЛЬСКУЮ В ОДНОИМЕННОМ СЕЛЕ, КАЗАНСКУЮ В СЕЛЕ МАРКОВЕ И ТРОИЦКУЮ В СЕЛЕ ОСТАНКИНО ${ }^{71}$.

В 1660-Е ГОДЫ НА ПРИДВОРНУЮ СЛУЖБУ ВСТУПАЛО СЛЕДУЮЩЕЕ ПОКОЛЕНИЕ СЕМЬИ КНЯЗЕЙ ОДОЕВСКИХ - ВНУКОВ КНЯЗЯ НИКИТЫ ИВАНОВИЧА. КНЯЗЬЯ СТЕПАН И ВАСИЛИЙ, ДЕТИ УМЕРШЕГО КНЯЗЯ ФЕДОРА НИКИТИЧА, БЫЛИ ОПРЕДЕЛЕНЫ В СТОЛЬНИКИ НАСЛЕДНИКА ПРЕСТОЛА АЛЕКСЕЯ АЛЕКСЕЕВИЧА ${ }^{72}$, ТОЧНО ТАКЖЕ КАК ИХ ОТЕЦ СЛУЖИЛ В СТОЛЬНИКАХ ЦАРЕВИЧА АЛЕКСЕЯ МИХАЙЛОВИЧА. В АПРЕЛЕ 1666 Г. КНЯЗЬ СТЕПАН ФЕДОРОВИЧ УМЕР ${ }^{73}$, А КНЯЗЬ ВАСИЛИЙ ФЕДОРОВИЧ СТАЛ ЗАМЕТНОЙ ФИГУРОЙ В КОМНАТАХ НАСЛЕДНИКА ПРЕСТОЛА. ЭТО БЫЛО СВЯЗАНО НЕ ТОЛЬКО С НЕЗАУРЯДНЫМИ ЛИЧНЫМИ КАЧЕСТВАМИ КНЯЗЯ ВАСИЛИЯ, НО И С ПОКРОВИТЕЛЬСТВОМ ОКОЛЬНИЧЕГО Ф.М. РТИЩЕВА БОЛЬШОГО, ВОСПИТАТЕЛЯ («ДЯДЬКИ») ЦАРЕВИЧА АЛЕКСЕЯ АЛЕКСЕЕВИЧА. НА ДОЧЕРИ Ф.М. РТИЩЕВА - АКУЛИНЕ КНЯЗЬ ВАСИЛИЙ ФЕДОРОВИЧ ЖЕНИЛСЯ В АВГУСТЕ ИЛИ СЕНТЯБРЕ $1668 \Gamma^{74}$

37 В СВЯЗИ СО СМЕРТЬЮ ЦАРЕВИЧА АЛЕКСЕЯ АЛЕКСЕЕВИЧА КНЯЗЬ В.Ф. ОДОЕВСКИЙ БЫЛ ПЕРЕВЕДЕН В СТОЛЬНИКИ СЛЕДУЮЩЕГО ПО СТАРШИНСТВУ ЦАРСКОГО СЫНА - ФЕДОРА АЛЕКСЕЕВИЧА ${ }^{75}$. ЭТА СЛУЖБА ПРИ НАСЛЕДНИКЕ ПРЕСТОЛА СТАЛА ЗАЛОГОМ ВОЗВЫШЕНИЯ КНЯЗЯ ВАСИЛИЯ ФЕДОРОВИЧА И ВСЕЙ СЕМЬИ КНЯЗЕЙ ОДОЕВСКИХ В ГОДЫ ЦАРСТВОВАНИЯ ФЕДОРА АЛЕКСЕЕВИЧА.

КНЯЗЬЯ ОДОЕВСКИЕ НЕ СТОЯЛИ В СТОРОНЕ ОТ ПРИДВОРНОЙ БОРЬБЫ ВОКРУГ ВТОРОГО БРАКА ЦАРЯ АЛЕКСЕЯ МИХАЙЛОВИЧА С НАТАЛЬЕЙ КИРИЛЛОВНОЙ НАРЫШКИНОЙ. ГЛАВНОЙ СОПЕРНИЦЕЙ НАТАЛЬИ КИРИЛЛОВНЫ БЫЛА АВДОТЬЯ БЕЛЯЕВА, КОТОРУЮ ПРИВЕЗ ВО ДВОРЕЦ ЕЕ ПОКРОВИТЕЛЬ ДВОРЯНИН ИВАН ШИХАРЕВ. В РЕШАЮЩИЙ МОМЕНТ СМОТРИН ВО ДВОРЦЕ БЫЛО ПОДБРОШЕНО ПОДМЕТНОЕ ПИСЬМО С ОБВИНЕНИЯМИ В АДРЕС ДУМНОГО ДВОРЯНИНА А.С. МАТВЕЕВА, ПРЕДСТАВИВШЕГО ЦАРЮ НАТАЛЬЮ КИРИЛЛОВНУ. ПОДОЗРЕНИЕ ПАЛО НА И. ШИХАРЕВА, НО ЕГО ВИНА НЕ БЫЛА ДОКАЗАНА. ПОСЛЕ ОКОНЧАНИЯ СЛЕДСТВИЯ И. ШИХАРЕВ ПЕРЕШЕЛ СЛУЖИТЬ ВО ДВОР БОЯРИНА КНЯЗЯ Я.Н. ОДОЕВСКОГО И ВЕЛ ЕГО ДЕЛА В ПРИКАЗАХ. ПОКРОВИТЕЛЬСТВО И. ШИХАРЕВУ СО СТОРОНЫ КНЯЗЯ Я.Н. ОДОЕВСКОГО ПОЗВОЛЯЕТ ПРЕДПОЛАГАТЬ НАСТОРОЖЕННОСТЬ И 
ДАЖЕ ВРАЖДЕБНОСТЬ ЗНАТНЕЙШЕЙ СЕМЬИ В ДУМЕ ПО ОТНОШЕНИЮ К ХУДОРОДНОМУ ЛЮБИМЦУ ЦАРЯ А.С. МАТВЕЕВУ, «СЫНУ УБОГОГО ПОПА», КАК ЕГО НАЗЫВАЛИ ПРИ ДВОРЕ ${ }^{76}$. С БОЯРЫНЕЙ Ф.П. МОРОЗОВОЙ. ПРИДВОРНАЯ БОЯРЫНЯ БЫЛА СВЯЗАНА С РОДСТВЕННИКАМИ ПЕРВОЙ ЖЕНЫ АЛЕКСЕЯ МИХАЙЛОВИЧА И, СОСЛАВШИСЬ НА БОЛЕЗНЬ, НЕ ЯВИЛАСЬ НА СВАДЬБУ. В ОТВЕТ НА СКРЫТОЕ НЕПОВИНОВЕНИЕ БОЯРЫНИ ЦАРЬ ЗАЯВИЛ: «ЕДИН ИЗ НАС ОДОЛЕЕТ ВСЯКО». ПРОТИВ НЕЕ БЫЛО НАЧАТО СЛЕДСТВИЕ ПО ОБВИНЕНИЮ В ПРИВЕРЖЕННОСТИ ДОНИКОНОВСКОМУ ОБРЯДУ, О ЧЕМ БЫЛО ХОРОШО ИЗВЕСТНО И РАНЕЕ. ДЕЛО ДОШЛО ДО ПЫТОК СТРОПТИВОЙ БОЯРЫНИ, КОТОРАЯ ТОЛЬКО ЧТО ТАЙНО ПРИНЯЛА ПОСТРИГ И НЕ ЖЕЛАЛА ОТКАЗЫВАТЬСЯ ОТ СВОИХ УБЕЖДЕНИЙ. «НАД МУКАМИ» БОЯРЫНИ ЦАРЬ УКАЗАЛ СТОЯТЬ СВОИМ БЛИЖНИМ БОЯРАМ КНЯЗЬЯМ И.А. ВОРОТЫНСКОМУ И Я.Н. ОДОЕВСКОМУ. ЦАРЬ И ПАТРИАРХ ПРЕДЛОЖИЛИ СЖЕЧЬ МОРОЗОВУ НА КОСТРЕ, НО «БОЯРЕ НЕ ПОТЯНУЛИ», ТО ЕСТЬ НЕ САНКЦИОНИРОВАЛИ СТОЛЬ ЖЕСТОКУЮ РАСПРАВУ НАД ПРЕДСТАВИТЕЛЬНИЦЕЙ ДРЕВНЕГО БОЯРСКОГО РОДА. ТОГДА АЛЕКСЕЙ МИХАЙЛОВИЧ ПРИКАЗАЛ ТАЙНО УМОРИТЬ БОЯРЫНЮ И ЕЕ ЕДИНОМЫШЛЕННИЦ ГОЛОДОМ ${ }^{77}$.

ЭТА ДРАМАТИЧЕСКАЯ ИСТОРИЯ РАСКРЫВАЕТ ХАРАКТЕРНЫЕ ЧЕРТЫ МОСКОВСКОГО БОЯРСТВА XVII В. ОНО БЫЛО РАЗДЕЛЕНО НА СОПЕРНИЧАВШИЕ МЕЖДУ СОБОЙ КЛАНЫ И НЕ ВЫСТУПАЛО ЕДИНЫМ ЛАГЕРЕМ, НО В РЕШАЮЩИЙ МОМЕНТ ОКАЗАЛОСЬ В СОСТОЯНИИ НЕ ПОДДЕРЖАТЬ ДАЖЕ ЦАРСКОЕ ПРЕДЛОЖЕНИЕ. В ТАКОЙ СИТУАЦИИ РОЛЬ БЛИЖНИХ БОЯР ПРИОБРЕТАЛА ОСОБОЕ ЗНАЧЕНИЕ. ЦАРЬ НУЖДАЛСЯ В ПРЕДАННЫХ СЛУГАХ, СПОСОБНЫХ ИсПОЛНИТЬ ЛюБУЮ ЕГО ВОЛЮ.

ЕДВА ЗАКОНЧИЛИСЬ ПЫТКИ МОРОЗОВОЙ, КАК ЦАРЬ ДАЛ КНЯЗЮ Я.Н. ОДОЕВСКОМУ НОВОЕ ПОРУЧЕНИЕ. ПОСЛЕ РАЗГРОМА РАЗИНСКОГО ДВИЖЕНИЯ И СДАЧИ МЯТЕЖНОЙ АСТРАХАНИ АЛЕКСЕЙ МИХАЙЛОВИЧ БЫЛ НЕДОВОЛЕН ТЕМ, КАК БОЯРИН И.Б. МИЛОСЛАВСКИЙ ВЕЛ СЛЕДСТВИЕ ПРОТИВ ВОССТАВШИХ. ЦАРЬ ПОСЛАЛ ЕМУ НА СМЕНУ КНЯЗЯ ЯКОВА НИКИТИЧА, КОТОРЫЙ ПРИБЫЛ В АСТРАХАНЬ В КОНЦЕ ИЮНЯ 1672 Г. ПО СЛОВАМ ОЧЕВИДЦА, ГОЛЛАНДСКОГО ОФИЦЕРА НА РУССКОЙ СЛУЖБЕ ЛЮДВИГА ФАБРИЦИУСА, КНЯЗЬ ЯКОВ НИКИТИЧ

БЫЛ БЕЗЖАЛОСТНЫЙ ЧЕЛОВЕК. <...> СВИРЕПСТВОВАЛ ОН ДО УЖАСА: МНОГИХ ПОВЕЛЕЛ КОГО ЗАЖИВО ЧЕТВЕРТОВАТЬ, КОГО ЗАЖИВО СЖЕЧЬ, КОМУ ВЫРЕЗАТЬ ИЗ ГЛОТКИ ЯЗЫК, КОГО ЗАЖИВО ЗАРЫТЬ В ЗЕМЛЮ. <... О ОН НАГНАЛ НА БЕДНЫХ ЛЮДЕЙ ТАКОЙ УЖАС, ЧТО НИКТО НЕ ОСМАЛИВАЛСЯ БОЛЬШЕ ПРОСИТЬ ЕГО ЗА КОГО-ЛИБО. <...> ОН НАСТОЛЬКО ПРИВЫК К ЛЮДСКИМ МУКАМ, ЧТО ПО УТРАМ НИЧЕГО НЕ МОГ СЪЕСТЬ, НЕ ПОБЫВАВ В ЗАСТЕНКЕ. ТАМ ОН ПРИКАЗЫВАЛ, НЕ ЖАЛЕЯ СИЛ, БИТЬ КНУТОМ, ПОДЖАРИВАТЬ, ВЗДЫМАЯ НА ДЫБУ. ЗАТО ПОТОМ ОН МОГ ЕСТЬ И ПИТЬ ЗА тРоих. $^{78}$

ПО ВОЗВРАЩЕНИИ В МОСКВУ КНЯЗЬ ЯКОВ НИКИТИЧ ПОЛУЧИЛ ОТ ЦАРЯ ЩЕДРУЮ МИЛОСТЬ - 3000 ЧЕТВЕРТЕЙ «ДИКОГО ПОЛЯ» В ЕПИФАНСКОМ УЕЗДЕ, ЧТО В ТРИ РАЗА ПРЕВЫШАЛО НОРМУ ДЛЯ БОЯРИНА ${ }^{79}$. ТАК АЛЕКСЕЙ МИХАЙЛОВИЧ ЖАЛОВАЛ ТЕХ, КТО «ХОДИЛ НЕ ДУРОСТИЮ» СВОЕЙ, А «ВО ВСЕМ ЖЕЛАЕТ ОТ НАС УКАЗУ».

\section{Семья князей Одоевских в царствование Федора Алексеевича (1676-1682)}

С ВОЦАРЕНИЕМ ЮНОГО И БОЛЕЗНЕННОГО ФЕДОРА АЛЕКСЕЕВИЧА РОЛЬ БОЯРСКОЙ ДУМЫ ВОЗРОСЛА. В НОЧЬ ВОЦАРЕНИЯ БОЯРЕ КН. Н.И. И Я.Н. ОДОЕВСКИЕ ВЫСТУПИЛИ КАК 
ПЕРВОСТАТЕЙНЫЕ БОЯРЕ, ПРИНИМАЯ ПРИСЯГУ МОСКОВСКИХ ЧИНОВ В «ПЕРЕДНЕЙ». МОСКОВСКИЕ ЧИНЫ, КОТОРЫЕ НЕ ПОСПЕЛИ К ЭТОЙ ПРИСЯГЕ, ПРИСЯГАЛИ ПОЗДНЕЕ В СТОЛОВОЙ УЖЕ ОДНОМУ КН. Я.Н. ОДОЕВСКОМУ «С ТОВАРИЩИ» ${ }^{80}$.

С ПЕРВЫХ ЖЕ ДНЕЙ НОВОГО ЦАРСТВОВАНИЯ (МЕЖДУ 1 И 8 ФЕВРАЛЯ 1676 Г.) КНЯЗЬ Н.И. ОДОЕВСКИЙ СМЕНИЛ БОЯРИНА А.С. МАТВЕЕВА У РУКОВОДСТВА АПТЕКАРСКИМ ПРИКАЗОМ ${ }^{81}$. ДОЛЖНОСТЬ АПТЕЧНОГО БОЯРИНА ОЗНАЧАЛА ВЫСШУЮ СТЕПЕНЬ ЦАРСКОГО ДОВЕРИЯ. КНЯЗЬ НИКИТА ИВАНОВИЧ ПОВЕЛ ДЕЛО ИНАЧЕ, ЧЕМ БЫЛО ПРИ А.С. МАТВЕЕВЕ, ОТСТРАНИВ ОТ ЛЕЧЕНИЯ ЦАРЯ ПРЕЖНИХ ДОКТОРОВ. 14 ФЕВРАЛЯ НОВЫЙ АПТЕЧНЫЙ БОЯРИН СОБРАЛ КОНСИЛИУМ ВРАЧЕЙ И ОБЪЯВИЛ ИМ, ЧТО ЦАРЬ ЩСКОРБИТ НОЖКАМИ». НА СЛЕДУЮЩИЙ ДЕНЬ КНЯЗЬ НИКИТА ИВАНОВИЧ САМОЛИЧНО ОТНЕС НОВЫЕ ЛЕКАРСТВА В ЦАРСКИЕ ХОРОМЫ, А 25 ФЕВРАЛЯ ЛЕКАРСТВО ОТНОСИЛ ЕГО ВНУК КНЯЗЬ ВАСИЛИЙ ФЕДОРОВИЧ ${ }^{82}$. ТАКИМ ОБРАЗОМ, КНЯЗЬЯ ОДОЕВСКИЕ ЦЕЛИКОМ ДЕРЖАЛИ В СВОИХ РУКАХ НАДЗОР ЗА ЗДОРОВЬЕМ ЦАРЯ ФЕДОРА. 8 ФЕВРАЛЯ ЦАРЬ УКАЗАЛ КНЯЗЬЯМ Н.И. ОДОЕВСКОМУ И Ю.А. ДОЛГОРУКОВУ «ТАЙНОЙ ПРИКАЗ ОПИСАТЬ И ДЕЛА РАЗОБРАТЬ ${ }^{83}$. ТАЙНЫЙ ПРИКАЗ БЫЛ СОЗДАН ПРИ АЛЕКСЕЕ МИХАЙЛОВИЧЕ КАК ОРГАН ЛИЧНОГО НАДЗОРА ЦАРЯ ЗА ВСЕЙ СИСТЕМОЙ УПРАВЛЕНИЯ, И БОЯРЕ НЕ ДОЛЖНЫ БЫЛИ ДАЖЕ ВХОДИТЬ В ЕГО ПОМЕЩЕНИЯ. ТЕПЕРЬ БОЯРЕ ВО ГЛАВЕ С КН. Н.И. ОДОЕВСКИМ РУКОВОДИЛИ ЛИКВИДАЦИЕЙ ПРИКАЗА. РАЗБОР ДЕЛ ПРИКАЗА ПРОДОЛЖАЛСЯ ВСЕ ЦАРСТВОВАНИЕ ФЕДОРА АЛЕКСЕЕВИЧА, А ЕГО УПРАЗДНЕНИЕ СТАЛО ЗНАКОВЫМ СОБЫТИЕМ ПОЛИТИЧЕСКОЙ ЖИЗНИ СТРАНЫ. ПРИ ЮНЫХ И БОЛЬНЫХ ГОСУДАРЯХ ПОСЛЕДНЕЙ ЧЕТВЕРТИ ХVII В. РЕАЛЬНОЕ ВЕДЕНИЕ ГОСУДАРСТВЕННЫХ ДЕЛ ПЕРЕШЛО К ПЕРВОСТАТЕЙНЫМ БОЯРАМ.

В.Н. ТАТИЩЕВ В СОЧИНЕНИИ «ЦАРСТВОВАНИЕ ФЕДОРА АЛЕКСЕЕВИЧА», ИСПОЛЬЗУЯ НЕ ДОШЕДШИЕ ДО НАС ИСТОЧНИКИ, ПИСАЛ, ЧТО ПОСЛЕ СМЕРТИ АЛЕКСЕЯ МИХАЙЛОВИЧА «БОЛЬШУЮ СИЛУ В УПРАВЛЕНИИ ИМЕЛИ» БОЯРЕ КН. Ю.А. ДОЛГОРУКОВ, Б.М. ХИТРОВО. НА ПОЛЯХ РУКОПИСИ В.Н. ТАТИЩЕВ ПРИПИСАЛ К УКАЗАННЫМ ИМЕНАМ: «ДА СТАРЫХ ЖЕ БОЛЯР» КНЯЗЬ Н.И. ОДОЕВСКИЙ ${ }^{4}$. НА АУДИЕНЦИИ ГОЛЛАНДСКИМ ПОСЛАМ 14 АПРЕЛЯ КНЯЗЬ НИКИТА ИВАНОВИЧ СТОЯЛ У ТРОНА И ПОДДЕРЖИВАЛ РУКУ ЦАРЯ ФЕДОРА, КОГДА ОН ПО НЕДОСТАТКУ СИЛ С ТРУДОМ ПРИПОДНИМАЛ СВОЙ ГОЛОВНОЙ УБОР ${ }^{85}$.

ПРИДВОРНЫЙ УСПЕХ КНЯЗЕЙ ОДОЕВСКИХ ВОПЛОТИЛСЯ В ПОЖАЛОВАНИЕ НОВЫХ ЧИНОВ. 7 МАЯ КНЯЗЬ В.Ф. ОДОЕВСКИЙ БЫЛ ПОЖАЛОВАН В КРАВЧИЕ «С ПУТЕМ». «В ПУТЬ» ОН ПОЛУЧИЛ КОНСКИЕ ПОШЛИНЫ ГОРОДА ГОРОХОВЦА «ВПРЕДЬ ПОКАМЕСТО ГОРОД ГОРОХОВЕЦ БУДЕТ ${ }^{86}$. НА ЦАРСКИЕ ИМЕНИНЫ 8 ИЮНЯ КНЯЗЬ Ю.М. ОДОЕВСКИЙ БЫЛ ПОЖАЛОВАН В БОЯРЕ ${ }^{87}$. ТАКИМ ОБРАЗОМ, СРАЗУ ТРИ ПОКОЛЕНИЯ ОДНОЙ СЕМЬИ ЗАСЕДАЛИ В ДУМЕ: КНЯЗЬ НИКИТА ИВАНОВИЧ, ЕГО СЫН ЯКОВ НИКИТИЧ И ВНУК ЮРИЙ МИХАЙЛОВИЧ. К ТОМУ ЖЕ ДРУГОЙ ВНУК - КНЯЗЬ ВАСИЛИЙ ФЕДОРОВИЧ - СТАЛ КРАВЧИМ, ЧТО СООТВЕТСТВОВАЛО ЧИНУ ОКОЛЬНИЧЕГО. НИКОГДА НИ ОДНОЙ СЕМЬЕ ЗА ВСЮ ИСТОРИЮ ДУМЫ НЕ УДАВАЛОСЬ ДОСТИЧЬ ТАКОГО РЕЗУЛЬТАТА.

ВО ВРЕМЯ ЦАРСКОГО ВЕНЧАНИЯ 18 ИЮНЯ 1676 Г. НА ОСОБОМ «ЧЕРТОЖНОМ» МЕСТЕ СТОЯЛИ БОЯРЕ КН. Н.И. ОДОЕВСКИЙ, КН. Ю.А. ДОЛГОРУКОВ, Б.М. ХИТРОВО ${ }^{88}$. НА ЭТОЙ ВАЖНЕЙШЕЙ ЦЕРЕМОНИИ КНЯЗЬ НИКИТА ИВАНОВИЧ ЗАНИМАЛ МЕСТО ПЕРВОГО БОЯРИНА СТРАНЫ. НА СЛЕДУЮЩИЙ ДЕНЬ ЦАРЬ ПРИНИМАЛ ПОЗДРАВЛЕНИЯ ОТ БОЯР И ВЛАСТЕЙ. ЭТУ ЦЕРЕМОНИЮ ВОЗГЛАВЛЯЛИ БОЯРЕ КНЯЗЬЯ Ю.А.ДОЛГОРУКОВ И Н.И. И Я.Н. ОДОЕВСКИЕ ${ }^{89}$. 
25 ИЮЛЯ ЦАРЬ УКАЗАЛ КНЯЗЯ В.Ф. ОДОЕВСКОГО ПИСАТЬ В БОЯРСКИХ СПИСКАХ ВЫШЕ ОКОЛЬНИЧИХ «ДЛЯ ТОГО, ЧТО ОН ТОЕ ЧЕСТЬЮ ПОЖАЛОВАН С ПУТЕМ» И ЕМУ БЫЛ НАЗНАЧЕН ВЫСОКИЙ ОКЛАД 350 РУБЛЕЙ ${ }^{0}$. КРАВЧИЙ КНЯЗЬ ВАСИЛИЙ ФЕДОРОВИЧ ПРИНАДЛЕЖАЛ К УЗКОМУ КРУГУ КОМНАТНЫХ ЛЮДЕЙ, ЗАСТУПНИЧЕСТВОМ КОТОРЫХ ЦАРЬ ЖАЛОВАЛ В МОСКОВСКИЕ ЧИНЫ. 18 СЕНТЯБРЯ 1676 Г. КНЯЗЬ В.Ф. ОДОЕВСКИЙ «СКАЗАЛ» УКАЗ О ПОЖАЛОВАНИИ И.И. ЛИХАРЕВА В СТОЛЬНИКИ ${ }^{91} .30$ ЯНВАРЯ 1677 Г., В ДНИ ЦАРСКОЙ БОЛЕЗНИ, ОН «ПРИНЯЛ В ПЕРЕДНЕЙ» СКРОЕННЫЕ ДЛЯ ГОСУДАРЯ ПОДУШКИ 92. В ИЮНЕ - ИЮЛЕ 1677 Г. ИЗВЕЩАЛ ПИСЬМАМИ ИЗ ГОСУДАРЕВЫХ ПОХОДОВ В МОСКВУ О ЦАРСКИХ УКАЗАХ ОТНОСИТЕЛЬНО НАЗНАЧЕНИЙ ДУМНЫХ ЛЮДЕЙ, О ПРИСЫЛКЕ ЛЕКАРСТВ ДЛЯ ФЕДОРА АЛЕКСЕЕВИЧА ${ }^{93}$.

КНЯЗЬ Я.Н. ОДОЕВСКИЙ ВЕДАЛ МОСКВУ НА ВРЕМЯ ЦАРСКИХ ОТЪЕЗДОВ ИЗ СТОЛИЦЫ. ВО ВРЕМЯ ОДНОГО ИЗ ТАКИХ ЦАРСКИХ ПОХОДОВ ОН ВЕЛ СЛЕДСТВИЕ ПО ОБВИНЕНИЮ БОЯРИНА А.С. МАТВЕЕВА В КОЛДОВСТВЕ. В СТОРОЖНЕ ПРИ АРХАНГЕЛЬСКОМ СОБОРЕ КНЯЗЬ ЯКОВ НИКИТИЧ «С ТОВАРИЩИ» ДОПРАШИВАЛИ ХОЛОПА А.С. МАТВЕЕВА, ОБВИНИВШЕГО СВОЕГО ГОСПОДИНА В ЧЕРНОКНИЖИИ. ЭТО ДЕЛО И В ДАЛЬНЕЙШЕМ ОСТАЛОСЬ В ВЕДЕНИИ ЯКОВА НИКИТИЧА, ИМЕВШЕГО БОЛЬШОЙ ОПЫТ ДОЗНАНИЯ В ЗАСТЕНКЕ. БОЯРИН И.М. МИЛОСЛАВСКИЙ ИНИЦИИРОВАЛ ВСЕ НОВЫЕ И НОВЫЕ ДЕЛА ПРОТИВ А.С. МАТВЕЕВА И НАРЫШКИНЫХ, ПЕРЕДАВАЯ ИХ В КОМИССИЮ КНЯЗЯ Я.Н. ОДОЕВСКОГО. ОДНОВРЕМЕННО РАБОТАЛА И ВТОРАЯ СЛЕДСТВЕННАЯ КОМИССИЯ ВО ГЛАВЕ С БОЯРИНОМ КНЯЗЕМ Ю.А. ДОЛГОРУКОВЫМ. ВОЗМОЖНО, СУЩЕСТВОВАНИЕ ДВУХ КОМИССИЙ ОТРАЖАЛО БОРЬБУ В ДУМЕ ВОКРУГ СУДЬБЫ ОПАЛЬНОГО КАНЦЛЕРА. ИМЕННО КНЯЗЬ Ю.А. ДОЛГОРУКОВ ПРЕДЛАГАЛ ПРЕКРАТИТЬ ПЫТКИ И ОСТАНОВИТЬ КОЛДОВСКОЙ ПРОЦЕСС, ОХВАТИВШИЙ ДЕСЯТКИ ПРИДВОРНЫХ ${ }^{94}$.

ОДЕРЖКА КНЯЗЬЯМИ ОДОЕВСКИМИ ДЕЙСТВИЙ И.М. МИЛОСЛАВСКОГО ПРОЯВИЛАСЬ И ОСЕНЬЮ 1677 Г. ПО ОКОНЧАНИИ ПОХОДА РУССКОЙ АРМИИ К ЧИГИРИНУ В ДУМЕ ОБСУЖДАЛСЯ ВОПРОС О ТОМ, КОМУ ИЗ ВОЕВОД ДОЛЖНЫ ДОСТАТЬСЯ ГЛАВНЫЕ ЛАВРЫ ПОБЕДИТЕЛЯ. БОЯРЕ «РАЗДЕЛИШАСЯ ПОПОЛАМ»: ОДНИ СТОЯЛИ ЗА БОЯРИНА КНЯЗЯ В.В. ГОЛИЦЫНА, А ДРУГИЕ ЗА БОЯРИНА КНЯЗЯ Г.Г. РОМОДАНОВСКОГО. В РЕШАЮЩИЙ МОМЕНТ ОБСУЖДЕНИЯ БОЯРИН И.М. МИЛОСЛАВСКИЙ ВЫСКАЗАЛСЯ В ПОЛЬЗУ КН. В.В. ГОЛИЦЫНА. ЭТОГО ЖЕ МНЕНИЯ ПРИДЕРЖИВАЛСЯ И КРАВЧИЙ КНЯЗЬ В.Ф. ОДОЕВСКИЙ. ЕГО ДЕД КНЯЗЬ НИКИТА ИВАНОВИЧ ПРИСУТСТВОВАЛ НА ЗАСЕДАНИИ, НО ПРЯМЫХ ДАННЫХ О ЕГО МНЕНИИ ПО ДАННОМУ ВОПРОСУ НЕ СОХРАНИЛОСЬ ${ }^{95}$. ОДНАКО, ВРЯД ЛИ ВНУК ВЫСКАЗЫВАЛСЯ НА ДУМСКОМ ЗАСЕДАНИИ ПРОТИВ СВОЕГО ДЕДА. ПО ВОЗРАСТУ НИКТО ИЗ КНЯЗЕЙ ОДОЕВСКИХ НЕ ГОДИЛСЯ В СПАЛЬНИКИ ЦАРЯ ФЕДОРА, И ВЛИЯНИЕ СЕМЬИ В ЦАРСКОЙ КОМНАТЕ ПОДДЕРЖИВАЛ В ПЕРВУЮ ОЧЕРЕДЬ КРАВЧИЙ КНЯЗЬ В.Ф. ОДОЕВСКИЙ. 12 НОЯБРЯ 1677 Г. ОН «ВЗЯЛ И ОТНЕС» В ЦАРСКИЕ ХОРОМЫ ЛЕКАРСТВА ${ }^{96}$. В СЛЕДУЮЩЕМ МЕСЯЦЕ КРАВЧИЙ ВОСПОЛЬЗОВАЛСЯ ЦАРСКОЙ МИЛОСТЬЮ И ПОЛУЧИЛ ИЗ КАЗНЫ ЦЕРКОВНУЮ УТВАРЬ ДЛЯ СВОЕЙ ДВОРОВОЙ «ЦЕРКВИ НА ВОРОТАХ». 19 ЯНВАРЯ 1678 Г. ОН «СШОД СВЕРХУ» ПРИКАЗАЛ ЛЕЧИТЬ ДОКТОРА Л. БЛЮМЕНТРОСТА ${ }^{97}$.

ЕГО СТАРШИЕ РОДСТВЕННИКИ ВЫПОЛНЯЛИ ПРЕДСТАВИТЕЛЬСКИЕ ФУНКЦИИ. ОТ ИМЕНИ ВСЕЙ ДУМЫ КНЯЗЬ НИКИТА ИВАНОВИЧ ГОВОРИЛ ПОЗДРАВИТЕЛЬНОЕ СЛОВО ЦАРЮ НА ПРАЗДНИКЕ НОВОЛЕТИЯ 1 СЕНТЯБРЯ 1677 Г. ${ }^{98}$ КАК БЛИЖНИЙ БОЯРИН ОН БЫЛ ВХОЖ В ЦАРСКИЕ ПОКОИ: 8 НОЯБРЯ 1677 Г. ОН ПРИНЕС В ЦАРСКИЕ ПОКОИ ЯЩИК С ПИСЬМАМИ ИЗ АРХИВА ТАЙНОГО ПРИКАЗА, КОТОРЫЙ РАЗБИРАЛИ ПОД ЕГО НАЧАЛОМ ${ }^{99}$ В ЯНВАРЕ 1678 Г. УЗКИЙ СОВЕТ ПЯТИ БЛИЖНИХ БОЯР (КНЯЗЬЯ Н.И. ОДОЕВСКИЙ, Ю.А.ДОЛГОРУКОВ, А 
ТАКЖЕ Б.М. И И.Б. ХИТРОВО, Р.М. СТРЕШНЕВ) ОБСУДИЛ ПОСОЛЬСКИЙ НАКАЗ ${ }^{100}$. В ТОМ ЖЕ МЕСЯЦЕ НА ПРИЕМЕ НИДЕРЛАНДСКОГО РЕЗИДЕНТА БЛИЖЕ ВСЕХ К ТРОНУ СТОЯЛИ КНЯЗЬЯ Н.И. ОДОЕВСКИЙ И Ю.А. ДОЛГОРУКОВ ${ }^{101}$. ПРОЧИХ КНЯЗЕЙ ОДОЕВСКИХ НА ВРЕМЯ УДАЛИЛИ ИЗ МОСКВЫ. В ОКТЯБРЕ 1677 Г. КНЯЗЬ ЯКОВ НИКИТИЧ ПОЛУЧИЛ НАЗНАЧЕНИЕ ВОЗГЛАВИТЬ ПОСОЛЬСТВО В РЕЧЬ ПОСПОЛИТУЮ. В ДЕКАБРЕ, С УСТАНОВЛЕНИЕМ ЗИМНЕГО ПУТИ, ПОСОЛЬСТВО ВЫЕХАЛО ИЗ МОСКВЫ ${ }^{102}$. ОКОЛО 5 ФЕВРАЛЯ 1678 Г. БОЯРИН КНЯЗЬ Ю.М. ОДОЕВСКИЙ ВМЕСТЕ С ДВУМЯ СЫНОВЬЯМИ ВЫЕХАЛ ИЗ МОСКВЫ НА ВОЕВОДСТВО В НОВГОРОД ${ }^{103}$. ЧЕЛОБИТЧИКИ БЫСТРО ОЦЕНИЛИ ХАРАКТЕР НОВОГО ВОЕВОДЫ:

ЗЕЛО ЧЕЛОВЕК СТРОПОТЕН, <...> И ПРИМЕНИТЦЕ К ЕВО НРАВУ НЕВЕДОМО КАК. СПЕРВУ ПОКАЗАЛСЯ, БУТТО НЕ ЕМЛЕТ, А НЫНЕ, ХТО ПРИНЕСЕТ, ЗНАТНО, ЧТО НЕ ОТКИНЕТ, А ДЬЯКИ В НЕМ ВОЛНЫ, НЕ ТАК КАК ПРИ УРУСОВЕ (ПРЕЖНЕМ ВОЕВОДЕ. П.с.).

ПО ОТЗЫВАМ ЧЕЛОБИТЧИКОВ, ВОЕВОДА БЫЛ «ЧЕЛОВЕК СВОЕНРАВНОЙ, В МАЛОМ <...> ЧЕМ ПРОГНЕВИШЬ, А И БОЛШИМ ГНЕВУ НЕ УТОЛИШЬ»; «БОЯРИН РЬЯНОЙ, НИКОИМИ МЕРАМИ СРОКУ УПРОСИТЬ НЕМОЧНО» ${ }^{104}$. ОТЗЫВЫ О КНЯЗЕ Ю.М. ОДОЕВСКОМ ПОМОГАЮТ ПОНЯТЬ, ПОЧЕМУ ОН НЕ ИГРАЛ ПЕРВОСТЕПЕННОЙ РОЛИ ПРИ МОСКОВСКОМ ДВОРЕ. КНЯЗЬ ЮРИЙ МИХАЙЛОВИЧ ТЯЖЕЛО БОЛЕЛ И МАЛО ВСТУПАЛСЯ В ДЕЛА: «БОЯРИН <...> В ПРИКАЗЕ НЕ БЫВАЕТ И КО ВЛАДЫКЕ НА БЛАГОСЛОВЕНИЕ НЕ ХОДИТ, А НА ДВОРЕ НИКОИМИ МЕРАМИ ПОБИТЬ ЧЕЛОМ НЕМОЧНО, ПОТОМУ ЧТО БОЯРИН НЕМОЩЕН, А ДЕЛА ВСЯКИЕ ДЕЛАЮТ ДЬЯКИ» ${ }^{105}$. ДЛЯ ЛЕЧЕНИЯ БОЯРИНА ИЗ МОСКВЫ БЫЛ «НАСКОРО» ПОСЛАН ЦАРСКИЙ ДОКТОР Л. БЛЮМЕНТРОСТ ${ }^{106}$.

ЛЕТОМ 1678 Г. В МОСКВУ ПРИЕХАЛО ПОЛЬСКОЕ ПОСОЛЬСТВО. ПЕРЕГОВОРЫ С ПОСЛАМИ ВОЗГЛАВИЛИ БОЯРЕ КНЯЗЬЯ Н.И. И Я.Н. ОДОЕВСКИЕ. 7 АВГУСТА НА ЦЕРЕМОНИИ ПОДТВЕРЖДЕНИЯ АНДРУСОВСКОГО ПЕРЕМИРИЯ КНЯЗЬ НИКИТА ИВАНОВИЧ КАК ГЛАВА ПОСОЛЬСКОЙ КОМИССИИ СТОЯЛ РЯДОМ С ЦАРЕМ ${ }^{107}$. ОДНАКО, ВОЕННОГО СОЮЗА С РЕЧЬЮ ПОСПОЛИТОЙ ДОСТИЧЬ НЕ УДАЛОСЬ. В АВГУСТЕ 1678 Г. ОТТОМАНСКАЯ АРМИЯ ЗАХВАТИЛА ЧИГИРИН, ПРЕДРЕШИВ ТЕМ САМЫМ ИСХОД ВСЕЙ ВОЙНЫ. В ЭТИ ТРЕВОЖНЫЕ ДНИ ЦАРЬ ОТПРАВИЛСЯ МОЛИТЬСЯ ВО ФЛОРИЩЕВУ ПУСТЫНЬ, И КРАВЧИЙ КНЯЗЬ В.Ф. ОДОЕВСКИЙ СОПРОВОЖДАЛ ЕГО. С ДОРОГИ КРАВЧИЙ НАПИСАЛ ПИСЬМО В МОСКВУ СВОЕМУ ДЯДЕ БОЯРИНУ КНЯЗЮ И.А. ВОРОТЫНСКОМУ С ИЗЛОЖЕНИЕМ ЦАРСКОГО УКАЗА О МЕРОПРИЯТИЯХ ПО ОБОРОНЕ КИЕВА ОТ ВОЗМОЖНОГО ТУРЕЦКОГО НАПАДЕНИЯ ${ }^{108}$. ПРИМЕЧАТЕЛЬНО, ЧТО ИМЕННО КРАВЧЕМУ КНЯЗЮ ВАСИЛИЮ ФЕДОРОВИЧУ ЦАРЬ ДОВЕРИЛ ИЗВЕСТИТЬ ОСТАВЛЕННЫХ В СТОЛИЦЕ БОЯР И ПАТРИАРХА О СВОИХ ПРЕДЛОЖЕНИЯХ ПО ЭТОМУ ВАЖНЕЙШЕМУ ВОПРОСУ ТЕХ ДНЕЙ.

ПО ВОЗВРАЩЕНИИ В МОСКВУ КН. В.Ф. ОДОЕВСКИЙ СТАЛ АКТИВНО ВМЕШИВАТЬСЯ В ДЕЛА ВОЕННОГО УПРАВЛЕНИЯ. 7 НОЯБРЯ 1678 Г. «ЦЕСАРСКИЕ ЗЕМЛИ ИНОЗЕМЕЦ» ПРЕДЛОЖИЛ ЕМУ ПЕРЕВООРУЖИТЬ РУССКУЮ ПЕХОТУ НОВЫМИ РУЖЬЯМИ. ЭТО ПРЕДЛОЖЕНИЕ КРАВЧИЙ ДОНЕС ЦАРЮ И ПОЛУЧИЛ РАЗРЕШЕНИЕ ВЫДЕЛИТЬ 100 СТВОЛОВ ДЛЯ ПРОВЕДЕНИЯ ЭКСПЕРИМЕНТА. ИЗ ЗАТЕИ НИЧЕГО НЕ ВЫШЛО, НО ЭТОТ ЭПИЗОД УКАЗЫВАЕТ НА АКТИВНОЕ СТРЕМЛЕНИЕ КРАВЧЕГО КНЯЗЯ ВАСИЛИЯ ФЕДОРОВИЧА ЗАНИМАТЬСЯ ДЕЛАМИ ВЫСШЕГО ГОСУДАРСТВЕННОГО УПРАВЛЕНИЯ ${ }^{109}$. 27 АПРЕЛЯ 1680 Г. БОЯРИН КНЯЗЬ Н.И. ОДОЕВСКИЙ, ЕГО СЫН ЯКОВ И ВНУКИ КНЯЗЬ Ю.М. ОДОЕВСКИЙ И В.Ф. ОДОЕВСКИЙ ПОДАЛИ ЧЕЛОБИТНУЮ О ПОЖАЛОВАНИИ ИМ «РОДИТЕЛЬСКОГО НАСЛЕДИЯ» ВОТЧИН КНЯЗЕЙ ВОРОТЫНСКИХ. В СВЯЗИ СО СМЕРТЬЮ 
ПОСЛЕДНЕГО В РОДЕ КНЯЗЕЙ ВОРОТЫНСКИХ КНЯЗЬЯ ОДОЕВСКИЕ ПРЕТЕНДОВАЛИ НА ИХ ВОТЧИНЫ, ОБОСНОВЫВАЯ СВОИ ПРАВА ТЕМ, ЧТО ВАСИЛИЙ ІІІ ПОЖАЛОВАЛ ЧАСТЬ ГОРОДА ОДОЕВА ПРАДЕДУ КНЯЗЯ Н.И. ОДОЕВСКОГО - КНЯЗЮ И.М. ВОРОТЫНСКОМУ. В ЧЕЛОБИТНОЙ УПОМЯНУТО ВЛАДЕНИЕ КНЯЗЕМ И.М.ВОРОТЫНСКИМ ГОРОДАМИ НОВОСИЛЕМ И ЧЕРНЬЮ С УЕЗДАМИ, СТАРОДУБОМ РЯПОЛОВСКИМ И ПЕРЕМЫШЛЕМ. ЭТИ УДЕЛЬНЫЕ ВОСПОМИНАНИЯ ПОЗВОЛЯЮТ ОЦЕНИТЬ ПРЕДСТАВЛЕНИЯ КНЯЗЕЙ ОДОЕВСКИХ ОБ ИХ СТАТУСЕ ПРИ МОСКОВСКОМ ДВОРЕ. СЛУЖБА В ЦАРСКИХ СПАЛЬНИКАХ НЕ ИСТРЕБИЛА ПАМЯТЬ О ВЕЛИКОМ ПРОШЛОМ СВОЕГО РОДА, КОТОРОМУ ПОСЛЕ ПРЕСЕЧЕНИЯ РОДА КНЯЗЕЙ ВОРОТЫНСКИХ НЕ ОСТАЛОСЬ РОВНИ СРЕДИ МОСКОВСКИХ БОЯР. ПРОСЬБА КНЯЗЕЙ ОДОЕВСКИХ НЕ БЫЛА УДОВЛЕТВОРЕНА: ВИДИМО, ЕЕ СОЧЛИ ЧРЕЗМЕРНОЙ ДЛЯ РОДА И ТАК ОБЛАДАВШЕГО КРУПНЕЙШИМИ ЗЕМЕЛЬНЫМИ БОГАТСТВАМИ. ОБЪЕДИНЕНИЕ РОДОВЫХ ВОТЧИН ДВУХ ПЕРВОСТАТЕЙНЫХ БОЯРСКИХ СЕМЕЙ, ДА ЕЩЕ ПО ПРАВУ УДЕЛЬНОЙ СТАРИНЫ, ГРОЗИЛО ПРЕВРАТИТЬ КНЯЗЕЙ ОДОЕВСКИХ В МАГНАТОВ НА МАНЕР РЕЧИ ПОСПОЛИТОЙ ${ }^{110}$.

ЭТА УПУЩЕННАЯ ВОЗМОЖНОСТЬ НАПРАВЛЯЛА ДЕЯТЕЛЬНОСТЬ КНЯЗЕЙ ОДОЕВСКИХ В ПРИВЫЧНОЕ ДЛЯ НИХ РУСЛО ПРИДВОРНОЙ СЛУЖБЫ. В ЦАРСКИХ КОМНАТАХ ОНИ ОБРЕТАЛИ ВЛИЯНИЕ, КОТОРОЕ В ХVII ВЕКЕ ЦЕНИЛОСЬ НЕ МЕНЬШЕ, ЧЕМ УДЕЛЬНЫЕ ВОСПОМИНАНИЯ. 9 МАЯ 1680 Г. КРАВЧИЙ С ПУТЕМ КНЯЗЬ В.Ф. ОДОЕВСКИЙ БЫЛ ПОЖАЛОВАН В БОЯРЕ ${ }^{111}$.

6013 АВГУСТА 1680 Г. БОЯРИН КНЯЗЬ В.Ф. ОДОЕВСКИЙ ОТНЕС ЦАРЮ ЛЕКАРСТВО, КОТОРОЕ ВРАЧ СОВЕТОВАЛ «ОБМОЧА ПЛАТОК, ТОЛКО НЕ КИСЕЙНОЙ, ВЧЕТВЕРО И ПРИЛОЖИТЬ К БОЛНОМУ ОКУ, ПРИВЕЗАВ К ТОМУ ПЛАТОМ, А КАК ВЫСОХНЕТ ТОТ ПЛАТОК, ОПЯТЬ НАМОЧА ПРИЛОЖИТЬ ДНЕМ 5 ИЛИ 6 ИЛИ БОЛШИ ПО ИЗВОЛУ» ${ }^{112}$. 8 МАЯ 1681 КНЯЗЬ В.Ф. ОДОЕВСКИЙ БЫЛ ПОЖАЛОВАН В ДВОРЕЦКИЕ НА МЕСТО УМЕРШЕГО ЦАРСКОГО «ШЕПТУНА» БОЯРИНА Б.М. ХИТРОВО ${ }^{113}$. ОТНЫНЕ ЕМУ ПОЛАГАЛОСЬ ВЕЗДЕ СОПРОВОЖДАТЬ ГОСУДАРЯ И УЖЕ 12 МАЯ ТОГО ЖЕ ГОДА НАЧАЛОСЬ СТРОИТЕЛЬСТВО В ЗАГОРОДНОЙ ЦАРСКОЙ РЕЗИДЕНЦИИ СЕЛЕ ВОРОБЬЕВЕ «ДВОРА, ГДЕ СТОЯТЬ» КНЯЗЮ ВАСИЛИЮ ФЕДОРОВИЧУ ${ }^{114} .21$ ФЕВРАЛЯ 1682 Г. ОН ОБЪЯВЛЯЛ ЦАРЮ ГОСТЕЙ И ПОСАДСКИХ ЛЮДЕЙ, ЯВИВШИХСЯ «С ПОДНОСОМ» ПО СЛУЧАЮ ЦАРСКОЙ СВАДЬБЫ ${ }^{115}$. ВОЗМОЖНОСТЬ УГОДИТЬ ГОСУДАРЮ БЫЛА ВЕРНЕЙШИМ СРЕДСТВОМ ЗАСЛУЖИТЬ ЦАРСКУЮ МИЛОСТЬ. 29 ФЕВРАЛЯ 1680 Г. «ПО ПРИКАЗУ» КНЯЗЯ В.Ф. ОДОЕВСКОГО «К ЕГО ГОСУДАРЕВУ ТЕРСКОМУ АРГАМАКУ ОТДАНЫ ПОДКОВЫ СЕРЕБРЯНЫЕ» ${ }^{116}$.

6118 ОКТЯБРЯ 1680 Г. БОЯРЕ КНЯЗЬЯ Н.И. И Я.Н. ОДОЕВСКИЕ ВОЗГЛАВИЛИ ВНОВЬ СОЗДАННУЮ РАСПРАВНУЮ ПАЛАТУ - ОРГАН ВЫСШЕГО ПРАВОСУДИЯ. ЭТО НАЗНАЧЕНИЕ ПЕРЕДАВАЛО ПОД БОЯРСКИЙ НАДЗОР СПРАВЕДЛИВОСТЬ СУДА И ПРАВИЛЬНОСТЬ ИСПОЛНЕНИЯ ЗАКОНОВ В СТРАНЕ. В СРЕДНЕВЕКОВОЙ РУСИ ЗНАЧЕНИЕ ДОЛЖНОСТИ ОПРЕДЕЛЯЛОСЬ «ПО ЧЕЛОВЕКУ СМОТРЯ». АВТОРИТЕТ КНЯЗЯ НИКИТЫ ИВАНОВИЧА, ПОД НАДЗОРОМ КОТОРОГО БЫЛО СОЗДАНО СОБОРНОЕ УЛОЖЕНИЕ 1649 Г., ДОЛЖЕН БЫЛ СООТВЕТСТВОВАТЬ СТАТУСУ РАСПРАВНОЙ ПАЛАТЫ КАК «ПРАВОСУДНОЙ», КАК ЕЕ В ПРОСТОРЕЧИИ ИМЕНОВАЛИ ЧЕЛОБИТЧИКИ. РАСПРАВНАЯ ПАЛАТА СТАЛА СВОЕГО РОДА «ВОТЧИНОЙ» КНЯЗЕЙ ОДОЕВСКИХ. ПРИГОВОРЫ ПАЛАТЫ ДЕЛАЛИСЬ ОТ ИМЕНИ БОЯР КНЯЗЕЙ Н.И. И Я.Н. ОДОЕВСКИХ «С ТОВАРЫЩИ», ХОТЯ В ПАЛАТЕ БЫЛО ОКОЛО ДЕСЯТИ ДУМНЫХ ЛЮДЕЙ. В 1681 Г. В ПАЛАТУ БЫЛ НАЗНАЧЕН ЕЩЕ И КНЯЗЬ Ю.М. ОДОЕВСКИЙ ${ }^{117}$, ЧТО ЗАКРЕПИЛО ВЛИЯНИЕ СЕМЬИ НА РАССМОТРЕНИЕ СПОРНЫХ СУДЕБНЫХ ДЕЛ СТРАНЫ. В СВОЕЙ ДЕЯТЕЛЬНОСТИ КНЯЗЬЯ ОДОЕВСКИЕ РУКОВОДСТВОВАЛИСЬ НЕ СТОЛЬКО ЗАКОНОМ, 
СКОЛЬКО МНЕНИЕМ ЦАРСКОЙ СЕМЬИ, ЕСЛИ ОНО БЫЛО ВЫСКАЗАНО ПО КАКОМУ-ТО ДЕЛУ. ТАК В МНОГОЛЕТНЕМ ЗЕМЕЛЬНОМ СПОРЕ ДВУХ ТИХВИНСКИХ МОНАСТЫРЕЙ КНЯЗЬЯ ОДОЕВСКИЕ ВЫНЕСЛИ, НАКОНЕЦ, ПОСТАНОВЛЕНИЕ, А ПОТОМ СРАЗУ ИЗМЕНИЛИ ЕГО НА ПРОТИВОПОЛОЖЕННОЕ. В МАРТЕ 1682 Г. БОЯРЕ КНЯЗЬЯ ОДОЕВСКИЕ ОБЪЯСНИЛИ СВОЕ НОВОЕ РЕШЕНИЕ ПРОИГРАВШЕЙ СТОРОНЕ ТАК: «ЗАСТУПАЮТ ДЕ ЗА НИХ, СТАРИЦ, ГОСУДАРЫНИ ЦАРЕВНЫ, А ОСЛЫШИТЦА ДЕ ИМ ИХ НЕЛЬЗЯ, А НАМ ОТ ТОГО ДЕЛА ВЕЛЕНО И ОТСТАТЬ» ${ }^{118}$.

В НАШЕМ РАСПОРЯЖЕНИИ НЕТ ПРЯМЫХ ДАННЫХ О ТОМ, КАК В ПРЕДСТАВЛЕНИИ ЭТОЙ БОЯРСКОЙ СЕМЬИ УЖИВАЛИСЬ ОСОЗНАНИЕ ВЕЛИЧИЯ СОБСТВЕННОГО РОДА И СЛУЖБА НЕСКОЛЬКИХ ПОКОЛЕНИЙ КНЯЗЕЙ ОДОЕВСКИХ В ЦАРСКИХ ПОКОЯХ. ОТВЕТ НА ЭТОТ ВОПРОС ЛОГИЧНО ИСКАТЬ В МОСКОВСКОЙ ТРАДИЦИИ ВЛАСТИ, ПО КОТОРОЙ ДРЕВНОСТЬ СЛУЖБЫ РОДА НЕ ПРОТИВОРЕЧИЛА ЦАРСКИМ МИЛОСТЯМ, А, НАПРОТИВ, БЫЛА ИХ СПРАВЕДЛИВЫМ ОПРАВДАНИЕМ. БОЯРСКАЯ ЧЕСТЬ И КРУПНЫЕ ЗЕМЕЛЬНЫЕ ПОЖАЛОВАНИЯ НЕ ПРОТИВОСТОЯЛИ ЦАРСКОЙ ВЛАСТИ, А БЫЛИ ЧАСТЬЮ СИСТЕМЫ САМОДЕРЖАВИЯ. ЗАСЕДАЯ В ГОСУДАРЕВОЙ ДУМЕ, ПРИСЛУЖИВАЯ В ЦАРСКОЙ КОМНАТЕ, БОЯРСКАЯ СЕМЬЯ РАЗДЕЛЯЛА УБЕЖДЕНИЕ, ВЫРАЖЕННОЙ В ПОГОВОРКЕ: «БЕЗ ПРАВДЫ БОЯРСКОЙ ЦАРЬ БОГА ПРОГНЕВИТ ${ }^{119}$.

ЭВОЛЮЦИЯ СИСТЕМЫ ВЛАСТИ ВО ВТОРОЙ ПОЛОВИНЕ XVII В. ВНОСИЛА ИЗМЕНЕНИЯ В ДРЕВНЮЮ ТРАДИЦИЮ БОЯРСКОГО СОВЕТА. РАЗРАСТАНИЕ СИСТЕМЫ УПРАВЛЕНИЯ, РАЗВИТИЕ ЗАКОНОДАТЕЛЬСТВА, ОПЫТ СОСЕДНИХ ГОСУДАРСТВ ПОДСКАЗЫВАЛИ РАЗЛИЧНЫЕ МОДЕЛИ ПОВЕДЕНИЯ ЗНАТИ В НОВЫХ УСЛОВИЯХ. В 1681-1682 ГГ. В НЕДРАХ ДУМЫ ВОЗНИК ПРОЕКТ, ПОЛУЧИВШИЙ В ИСТОРИЧЕСКОЙ ЛИТЕРАТУРЕ НАЗВАНИЕ «БОЯРСКОЙ ПОПЫТКИ». «ПАЛАТСКИЕ БОЯРЕ» СОВЕТОВАЛИ ЦАРЮ ПОЖИЗНЕННО («ВЕЧНО») ПРИСВОИТЬ ДУМНЫМ ЛЮДЯМ НАМЕСТНИЧЕСКИЕ ТИТУЛЫ, КОТОРЫЕ ОНИ ИСПОЛЬЗОВАЛИ ТОЛЬКО ПРИ ДИПЛОМАТИЧЕСКИХ ПЕРЕГОВОРАХ. ПРИКРЫВАЯСЬ ТРАДИЦИЕЙ, ЭТО ПРЕДЛОЖЕНИЕ, ПО СУТИ, МЕНЯЛО СТАТУС ДУМНЫХ ЛЮДЕЙ В ОТНОШЕНИИ ГОСУДАРЯ, ПОСКОЛЬКУ ЗАКРЕПЛЯЛО ЗА САМЫМИ АРИСТОКРАТИЧЕСКИМИ РОДАМИ НЕЗЫБЛЕМОЕ, «ВЕЧНОЕ» ПРАВО СОВЕТОВАТЬ ГОСУДАРЮ, КАК УПРАВЛЯТЬ СТРАНОЙ. НЕ СЛУЧАЙНО ПАТРИАРХ ИОАКИМ РЕШИТЕЛЬНО ВЫСТУПИЛ ПРОТИВ ПРОЕКТА, ПОЛАГАЯ, ЧТО БОЯРЕ, «ОБОГАТЯСЬ И ВОЗГОРДЕВ», «ОБСТУПЯТ» САМОДЕРЖАВИЕ. БОЯРИН КНЯЗЬ Н.И. ОДОЕВСКИЙ ИМЕЛ НА ТОТ МОМЕНТ ВЫСШИЙ НАМЕСТНИЧЕСКИЙ ТИТУЛ, И БЫЛО БЫ СТРАННО, ЕСЛИ БЫ ОН ВЫСТУПАЛ ПРОТИВ ЭТОГО ПРОЕКТА. ДА И САМО РЕШЕНИЕ ДУМЫ НА ЭТОТ СЧЕТ БЕЗ УЧЕТА МНЕНИЯ БОЯРСКОЙ СЕМЬИ ОДОЕВСКИХ ПРЕДСТАВЛЯЕТСЯ МАЛОВЕРОЯТНЫМ ${ }^{120}$. ПО СВИДЕТЕЛЬСТВУ ПОЛЬСКОГО ПОСЛАННИКА, КАК РАЗ В ЭТО ВРЕМЯ, В ДЕКАБРЕ 1681 Г., КНЯЗЬЯ ОДОЕВСКИЕ ВЫСТУПАЛИ В ДУМЕ ЗА СБЛИЖЕНИЕ С РЕЧЬЮ ПОСПОЛИТОЙ И ПРОЕКТ ПРИСВОЕНИЯ ДУМНЫМ ЧИНАМ НАМЕСТНИЧЕСКИХ ТИТУЛОВ НА ПОЛЬСКИЙ МАНЕР МОГ БЫТЬ ЧАСТЬЮ ЭТОЙ ИХ ПОЗИЦИИ. ПРОТИВОДЕЙСТВОВАЛИ КНЯЗЬЯМ ОДОЕВСКИМ В ЭТОМ ВОПРОСЕ НАИБОЛЕЕ КОНСЕРВАТИВНО НАСТРОЕННЫЕ БОЯРЕ КНЯЗЬЯ Ю.А. ДОЛГОРУКОВ И И.А. ХОВАНСКИЙ ${ }^{121}$.

\section{Семья князей Одоевских в годы регенства царевны Софьи (1682-1689)}

64 В БОРЬБЕ ПРИДВОРНЫХ ГРУППИРОВОК ПОСЛЕ СМЕРТИ ФЕДОРА АЛЕКСЕЕВИЧА КНЯЗЬЯ ОДОЕВСКИЕ ПРИДЕРЖИВАЛИСЬ УЖЕ ПРОВЕРЕННОЙ ЛИНИИ ПОВЕДЕНИЯ. В ПЕРВУЮ 
ОЧЕРЕДЬ ОНИ СТРЕМИЛИСЬ УДЕРЖАТЬСЯ В ЦАРСКОЙ КОМНАТЕ. НА ЧЕТВЕРТЫЙ ДЕНЬ НОВОГО ЦАРСТВОВАНИЯ В СПАЛЬНИКИ ЦАРЯ ПЕТРА БЫЛИ ПОЖАЛОВАНЫ ТРОЕ КНЯЗЕЙ ОДОЕВСКИХ, ДЕТЕЙ БОЯРИНА КНЯЗЯ ЮРИЯ МИХАЙЛОВИЧА: КНЯЗЬ ЮРИЙ, КНЯЗЬ МИХАИЛ И КНЯЗЬ ВАСИЛИЙ ${ }^{122}$. ОДНАКО В ЦЕЛОМ КЛАН КНЯЗЕЙ ОДОЕВСКИХ ДЕРЖАЛ СТОРОНУ МИЛОСЛАВСКИХ. ДАТСКИЙ ПОСОЛ ХИЛЬДЕБРАНТ ФОН ГОРН В ДОНЕСЕНИИ 23 ОКТЯБРЯ 1682 Г. СООБЩАЛ ИЗ МОСКВЫ, ЧТО В СВЯЗИ С ВОЦАРЕНИЕМ ПЕТРА В ОБХОД ЦАРЕВИЧА ИВАНА

ДРУГИЕ ЖЕ БОЯРЕ, В ОСОБЕННОСТИ СТАРИК ОДОЕВСКИЙ <... БЫЛИ СИЛЬНО ПРИНИЖЕНЫ ПО ТОЙ ПРИЧИНЕ, ЧТО В БЫЛЫЕ ВРЕМЕНА К НЕМУ [А. С. МАТВЕЕВУ] ОТНОСИЛИСЬ НАСТОЛЬКО ВРАЖДЕБНО, ЧТО ОКАЗАЛОСЬ ВОЗМОЖНЫМ НАНЕСТИ ЕМУ РЯД ОЧЕВИДНЫХ ОСКОРБЛЕНИЙ. ${ }^{123}$ ЗДЕСЬ РЕЧЬ ШЛА О РОЛИ КНЯЗЕЙ ОДОЕВСКИХ В ИНТРИГАХ ПРОТИВ НАРЫШКИНЫХ И ССЫЛКЕ А.С. МАТВЕЕВА В НАЧАЛЕ ЦАРСТВОВАНИЯ ФЕДОРА АЛЕКСЕЕВИЧА. СВЕРХ ТОГО, В МАЕ 1682 Г. КНЯЗЬ НИКИТА ИВАНОВИЧ БУДТО БЫ ОТВЕСИЛ ОПЛЕУХУ РОДНОМУ БРАТУ ЦАРИЦЫ ИВАНУ НАРЫШКИНУ, СКАНДАЛЬНО РАНО ПОЖАЛОВАННОМУ В БОЯРСТВО В ДВАДЦАТЬ ЛЕТ. ПРИ ЭТОМ КНЯЗЬ НИКИТА ИВАНОВИЧ ОБОЗВАЛ ЦАРСКОГО ДЯДЮ «СОБАКОЙ» ${ }^{124}$. В ЭТОМ КОНФЛИКТЕ КНЯЗЬ НИКИТА ИВАНОВИЧ ВЫСТУПАЕТ КАК ГЛАВА ВСЕЙ ДУМЫ, ПОДНЯВ РУКУ НА ДЯДЮ САМОГО ЦАРЯ. ПЕРВОСТАТЕЙНЫЙ БОЯРИН КНЯЗЬ НИКИТА ИВАНОВИЧ ВЫСТУПАЛ НЕ ПРОТИВ ЦАРСКОЙ ВОЛИ, А ПРОТИВ НАРУШЕНИЯ ТРАДИЦИИ, КОГДА МОЛОДОЙ БОЯРИН, ГОДИВШИЙСЯ ЕМУ ВО ВНУКИ, А ТО И В ПРАВНУКИ, ПОПЫТАЛСЯ ВЫЙТИ НА ПЕРВОЕ МЕСТО. НЕСОМНЕННО, РЕШИМОСТЬ ПЕРВОГО БОЯРИНА СТРАНЫ ОПИРАЛАСЬ НА ПОДДЕРЖКУ СО СТОРОНЫ ЧАСТИ ЦАРСКОЙ СЕМЬИ, СТОЯВШЕЙ ЗА ЦАРЕВИЧА ИВАНА. О РОЛИ КНЯЗЕЙ ОДОЕВСКИХ В ДВОРЦОВОЙ ЖИЗНИ В ЭТИ ДНИ СООБЩАЛ И СТРЯПЧИЙ ВАЛДАЙСКОГО ИВЕРСКОГО МОНАСТЫРЯ. В ПИСЬМЕ 8 ИЮНЯ 1682 Г. ИЗ МОСКВЫ ОН ПИСАЛ СВОИМ ВЛАСТЯМ, ЧТО КНЯЗЬ В.Ф. ОДОЕВСКИЙ «БЕЗПРЕСТАННО У ВЕЛИКИХ ГОСУДАРЕЙ ВВЕРХУ, И С ВЕРХУ МАЛО СЪЕЗЖАЕТ» ${ }^{125}$.

НО БЛИЖЕ ВСЕХ К ЦАРЕВНЕ СОФЬЕ ОКАЗАЛСЯ БОЯРИН КНЯЗЬ ЯКОВ НИКИТИЧ ОДОЕВСКИЙ. НАЧИНАЯ С 20 МАЯ, И В ИЮНЕ-ИЮЛЕ ОН ЧАСТО ОТНОСИЛ ВЕЩИ В ХОРОМЫ СОФЬИ АЛЕКСЕЕВНЫ, В ТОМ ЧИСЛЕ ЧУЛКИ ${ }^{126} .24$ ИЮНЯ ОН РАСПОРЯДИЛСЯ ПОЖАЛОВАТЬ СУКНА ПРИДВОРНЫМ, БЛИЗКИМ К СОФЬЕ И МИЛОСЛАВСКИМ ${ }^{127}$. ПО ПОЗДНЕЙШЕМУ СВИДЕТЕЛЬСТВУ УЧАСТНИКА СОБЫТИЙ, ВО ВРЕМЯ РАСПРАВ СТРЕЛЬЦОВ НАД НАРЫШКИНЫМИ В МАЕ 1682 Г., КНЯЗЬ Я. Н. ОДОЕВСКИЙ, «ПО ПРИРОДЕ СВОЕЙ ГОРАЗДО БОЯЗЛИВЫЙ И ВЕСЬМА ТОРОПКИЙ ЧЕЛОВЕК», ПРЯМО ЗАЯВИЛ ЦАРИЦЕ НАТАЛЬЕ КИРИЛЛОВНЕ, ЧТО ВЫДАТЬ ЕЕ БРАТА ВСЕ ЖЕ ПРИДЕТСЯ: «СКОЛЬКО ВАМ, ГОСУДАРЫНЯ, НИ ЖАЛЕТЬ, ОТДАВАТЬ ВАМ ЕГО НУЖНО БУДЕТ, А ТЕБЕ ИВАНУ, ОТСЮДА СКОРЕЕ ИДТИ НАДОБНО, ЕЖЕЛИ НАМ ВСЕМ ЗА ОДНОГО ТЕБЯ ЗДЕСЬ ПОГУБЛЕННЫМ БЫТЬ» ${ }^{128}$.

НЕСКОЛЬКО ИНАЧЕ ИЗЛАГАЕТ ПОЗИЦИЮ КНЯЗЕЙ ОДОЕВСКИХ В ПРИДВОРНОЙ БОРЬБЕ ЭТОГО ВРЕМЕНИ СОВРЕМЕННИК СОБЫТИЙ КНЯЗЬ Б.И. КУРАКИН. ОН ПИСАЛ СВОЮ ИСТОРИЮ О ПЕТРЕ СОРОК ЛЕТ СПУСТЯ НЕ ТОЛЬКО ПО СВОИМ ВОСПОМИНАНИЯМ, НО И ПО РАССКАЗАМ ВЫРАСТИВШЕЙ ЕГО БАБУШКИ КНЯГИНИ У.И. ОДОЕВСКОЙ. В 1682 Г. УМЕРЛИ ДЕД И РОДИТЕЛИ КНЯЗЯ И.Б. КУРАКИНА,

И С ТОГО ГОДА В НАШЕМ СИРОТСТВЕ НЕ ОСТАВИЛА НАС И ДОМ НАШ БАБКА НАША, КНЯГИНЯ УЛЬЯНА ИВАНОВНА ОДОЕВСКАЯ, СУПРУГА КНЯЗЯ АЛЕКСЕЯ НИКИТИЧА СЫНА КНЯЗЬ НИКИТЫ ИВАНОВИЧА ОДОЕВСКОГО, А МАТЬ НАШЕЙ МАТЕРИ ФЕДОСЬИ АЛЕКСЕЕВНЫ. МОГУ ОБ НЕЙ ОПИСАТЬ, ЧТО ОНАЯ ЖЕНА БЫЛА ВЕЛИКОГО УМА И НАБОЖНАЯ И В ОСТИНЕ ОТ ВСЕХ. 
В ЭТОЙ СВЯЗИ ОСВЕДОМЛЕННОСТЬ КНЯЗЯ Б.И. КУРАКИНА О СЕМЕЙНЫХ ДЕЛАХ КНЯЗЕЙ ОДОЕВСКИХ НЕСОМНЕННА. НАКАНУНЕ ВОССТАНИЯ ЦАРЕВНА СОФЬЯ

КАК БЫЛА ПРИНЦЕССА УМА ВЕЛИКАГО, ТОТЧАС ВЗЯЛА ПРАВЛЕНИЕ, А ИЗ БОЯР КНЯЗЬ ЯКОВ НИКИТИЧ ОДОЕВСКОЙ, КОТОРОЙ ВСЕ ПОХОРОНЫ ТОКМО ОТПРАВЛЯЛ. ХОТЯ МНОГИЕ БОЯРЕ, КАК ОТЕЦ ЕГО КНЯЗЬ НИКИТА ИВАНОВИЧ ОДОЕВСКИЙ И ДРУГИЕ, НО ОНЫЕ ВСЕ ПЕРВЫЕ БОЯРЕ УВИДЕЛИ ИНТРИГИ ЦАРЕВНЫ СОФЬИ АЛЕКСЕЕВНЫ, УЧИНИЛИ СЕБЯ НЕУТРАЛЬНЫМИ И СМОТРЕЛИ, ЧТО ПРОИЗОЙДЕТ, ЧАЯ ОТ ТОГО ЗАМЕШАНИЮ ВЕЛИКОМУ. ${ }^{129}$

КНЯЗЬ И.Б. КУРАКИН СМЯГЧИЛ АНТИНАРЫШКИНСКУЮ ПОЗИЦИЮ КНЯЗЕЙ ОДОЕВСКИХ В РЕШАЮЩИЙ МОМЕНТ ВОСШЕСТВИЯ ПЕТРА НА ПРЕСТОЛ. В ЕГО ИЗЛОЖЕНИИ КНЯЗЬ Н.И. ОДОЕВСКИЙ КАК ГЛАВА ДУМЫ ЗАНИМАЛ САМОСТОЯТЕЛЬНУЮ ВЫЖИДАТЕЛЬНУЮ позицию.

КАК БЫ ТО НИ БЫЛО, В ГОДЫ РЕГЕНТСТВА КНЯЗЬЯ ОДОЕВСКИЕ СОХРАНИЛИ СВОЕ ПРИДВОРНОЕ ЗНАЧЕНИЕ, ПРИМКНУВ К ПОБЕДИВШЕЙ ПРИДВОРНОЙ ГРУППИРОВКЕ. ПО СВИДЕТЕЛЬСТВУ ПОЛЬСКОГО ГОНЦА, ПОБЫВАВШЕГО В МОСКВЕ В ФЕВРАЛЕ 1683 Г., НАИБОЛЕЕ ВЛИЯТЕЛЬНЫМИ БОЯРАМИ В ЭТО ВРЕМЯ БЫЛИ И.М. МИЛОСЛАВСКИЙ, КНЯЗЬЯ Я.Н. ОДОЕВСКИЙ, В.В. ГОЛИЦЫН, М.А. ЧЕРКАСКИЙ ${ }^{130}$. НА БЛИЗОСТЬ БОЯРИНА КНЯЗЯ В.Ф. ОДОЕВСКОГО К МИЛОСЛАВСКИМ УКАЗЫВАЕТ ПОРУЧЕНИЕ ЕМУ В 1683 Г. «СМЕТИТЬ» ПОСТРОЙКИ И, «ДОЛОЖА ВЕЛИКИХ ГОСУДАРЕЙ», ДОСТРОИТЬ ИХ В РОДОВОЙ ОБИТЕЛИ МИЛОСЛАВСКИХ - МОСКОВСКОМ ЗНАМЕНСКОМ МОНАСТЫРЕЕ ${ }^{131} .25$ НОЯБРЯ 1684 Г. СРЕДИ ШЕСТИ КОМНАТНЫХ БОЯР, СЛУШАВШИХ ПОСОЛЬСКИЙ СТАТЕЙНЫЙ СПИСОК, ДВОЕ БЫЛИ ИЗ СЕМЬИ ОДОЕВСКИХ: КНЯЗЬ НИКИТА ИВАНОВИЧ И КНЯЗЬ ВАСИЛИЙ ФЕДОРОВИЧ ${ }^{132}$.

71 ДО СВОЕЙ СМЕРТИ 14 ДЕКАБРЯ 1686 Г. КНЯЗЬ ВАСИЛИЙ ФЕДОРОВИЧ БЫЛ НЕ ТОЛЬКО ДВОРЕЦКИМ, ТО ЕСТЬ ВОЗГЛАВЛЯЛ ПРИКАЗ БОЛЬШОГО ДВОРЦА И СВЯЗАННЫЙ С НИМ СУДНЫЙ ДВОРЦОВЫЙ ПРИКАЗ, НО ВМЕСТЕ С ДЕДОМ КНЯЗЕМ Н.И. ОДОЕВСКИМ РУКОВОДИЛ ЕЩЕ И АПТЕКАРСКИМ ПРИКАЗОМ ${ }^{133}$. ЭТИ КЛЮЧЕВЫЕ ДВОРЦОВЫЕ ДОЛЖНОСТИ ПОЗВОЛЯЛИ ЕМУ ЗАНИМАТЬ САМОСТОЯТЕЛЬНУЮ ПОЗИЦИЮ ДАЖЕ ПО ОТНОШЕНИЮ К БОЯРИНУ КНЯЗЮ В.В. ГОЛИЦЫНУ - «СТОЛПУ» РЕЖИМА РЕГЕНТСТВА. В ЯНВАРЕ 1683 Г. ОН СКАЗАЛ ДАТСКОМУ ПОСЛУ, ЧТО РОССИЯ ПОДДЕРЖИТ ДАНИЮ В ВОЙНЕ ПРОТИВ ШВЕЦИИ, ХОТЯ ПРИСУТСТВОВАВШИЙ ЗДЕСЬ ЖЕ ГЛАВА ПОСОЛЬСКОГО ПРИКАЗА КНЯЗЬ В.В.ГОЛИЦЫН ДИПЛОМАТИЧНО УКЛОНИЛСЯ ОТ ПРЯМЫХ ЗАЯВЛЕНИЙ ${ }^{134}$. В ГОДЫ РЕГЕНТСТВА БОЯРИН КНЯЗЬ Н.И.ОДОЕВСКИЙ ДОКЛАДЫВАЛ ЦАРЕВНЕ ДЕЛА ТЕКУЩЕГО УПРАВЛЕНИЯ ${ }^{135}$, ВОЗГЛАВЛЯЛ БОЯРСКИЕ КОМИССИИ, ОСТАВЛЯЕМЫЕ НА ГОСУДАРЕВОМ ДВОРЕ НА ВРЕМЯ ЦАРСКИХ ОТЪЕЗДОВ ${ }^{136}$. КНЯЗЮ НИКИТЕ ИВАНОВИЧУ ДОВЕЛОСЬ ПЕРЕЖИТЬ ДВУХ СВОИХ ВНУКОВ. 10 ДЕКАБРЯ 1685 Г. ОН ПОГРЕБАЛ В ТРОИЦЕ-СЕРГИЕВОМ МОНАСТЫРЕ ТЕЛО БОЯРИНА КНЯЗЯ Ю.М. ОДОЕВСКОГО ${ }^{137}$. ГОД СПУСТЯ УМЕР И БОЯРИН КНЯЗЬ ВАСИЛИЙ ФЕДОРОВИЧ. НАКАНУНЕ КОНЧИНЫ КНЯЗЬ В.Ф. ОДОЕВСКИЙ СОВЕРШАЛ БОГОМОЛЬНЫЕ ШЕСТВИЯ ПО МОНАСТЫРЯМ: В ИЮЛЕАВГУСТЕ 1685 Г. ОН «ПОЕХАЛ ПО МОНАСТЫРЕМ МОЛИТЦА» ${ }^{138}$. В ПИСЬМЕ ИЗ МОСКВЫ В НОВГОРОД 8 НОЯБРЯ 1686 Г. ИВЕРСКИЕ МОНАХИ СООБЩАЛИ, ЧТО КНЯЗЬ В.Ф. ОДОЕВСКИЙ «ГОРАЗДО СКОРБЕН, И ЛЕКАРИ ЛЕЧИТ ПОКИНУЛИ ПОТОМУ, ЧТО У НЕГО ПЕЧЕНЬ ГНИЕТ И ИДЕТ НЕ К ЖИВОМУ, НО К СМЕРТИ» ${ }^{139} .14$ ДЕКАБРЯ ТОГО ЖЕ ГОДА ОН СКОНЧАЛСЯ. В АВГУСТЕ 1687 Г. УМЕРЛА И ЕГО ВДОВА АКУЛИНА ФЕДОРОВНА ${ }^{140}$.

7312 ФЕВРАЛЯ 1689 Г. УМЕР И САМ КНЯЗЬ НИКИТА ИВАНОВИЧ ${ }^{141}$. В СВОЕЙ ДУХОВНОЙ ОН ОСТАВИЛ ЗА СТАРШЕГО В СЕМЬЕ СВОЕГО СЫНА КНЯЗЯ ЯКОВА НИКИТИЧА, НАКАЗАВ ВСЕЙ 
РОДНЕ СЛУШАТЬСЯ ЕГО. В ЭТИХ ПОСЛЕДНИХ НАСТАВЛЕНИЯХ ЗАМЕТНЫ ЧЕРТЫ БЫТА БОЯРСКОЙ СЕМЬИ, ДЕСЯТИЛЕТИЯ ЖИВШЕЙ ПОД НАДЗОРОМ ВЫДАЮЩЕГОСЯ ГЛАВЫ РОДА КНЯЗЯ НИКИТЫ ИВАНОВИЧА. ТЕПЕРЬ ОН ЗАВЕЩАЛ, ЧТОБЫ СЫН БРАЛ С НЕГО ПРИМЕР:

О ВСЯКИХ ДЕЛАХ ДЕДА СВОЕГО БОЯРИНА КНЯЗЯ ЯКОВА НИКИТИЧА СПРАШИВАТЦА, ТАК ЖЕ И МЕЖ СЕБЯ ИМ ПРАВНУЧЕТОМ МОИМ КНЯЗЬ МИХАИЛУ И КНЯЗЬ ЮРЬЮ, И КНЯЗЬ ВАСИЛЬЮ, И КНЯЗЬ АЛЕКСЕЮ ЖИТЬ ПОЛЮБОВНО: НЕ БРАНИТИСЯ И НЕ ДРАТСЯ. А БУДЕТ МАТЕРИ СВОЕЙ ПОЧИТАТЬ НЕ СТАНУТ И ПОСЛУШНЫ НЕ БУДУТ, И ИХ СМИРЯТЬ ДЕДУ ИХ, А МОЕМУ СЫНУ БОЯРИНУ КНЯЗЮ ЯКОВУ НИКИТИЧЮ.

С СВОЕЙ СТОРОНЫ, КНЯЗЮ ЯКОВУ НИКИТИЧЮ НАДЛЕЖАЛО К РОДНЕ БЫТЬ МИЛОСТИВУ В МОЕ И В ОТЦА ИХ МЕСТО, И ВНУЧАТ СВОИХ, А МОИХ ПРАВНУЧАТ, ОТ ВСЯКОГО ДУРНА УНИМАТЬ, ЧТОБ ЕВО И МАТЬ СВОИ ПОЧИТАЛИ И НИЧЕМ БЫ ИХ НЕ КРУЧИНИЛИ, И МЕЖ СЕБЯ НЕ БРАНИЛИСЬ И НЕ ДРАЛИСЬ, ЖИЛИ БЫ СМИРНО И З СВОЕЮ БРАТЬЕЮ ЛЮБОВНО, И О ВСЯКИХ ДЕЛАХ ЕВО СПРАШИВАЛИСЬ.

А ЕЖЕЛИ

ПОЧИТАТЬ И СЛУШАТЬ НЕ СТАНУТ И МЕЖ СЕБЯ СТАНУТ БРАНИТИСЯ И ДРАТСЯ, И ЕМУ ПОЖАЛОВАТЬ ВМЕСТО МЕНЯ И ОТЦА ИХ ВСЯКО НАКАЗАТЬ ВОЛНО, И УЧИТЬ ИХ И НАКАЗЫВАТЬ ВСЯКОМУ ДОБРУ КАК ДЕТЕЙ СВОИХ. ${ }^{142}$

ЭТО ПРОСТРАННОЕ НАСТАВЛЕНИЕ КНЯЗЯ НИКИТЫ ИВАНОВИЧА СТОИТ ОСОБНЯКОМ В РЯДУ ДРУГИХ ДУХОВНЫХ ТОГО ВРЕМЕНИ И ОТРАЖАЕТ ТУ РОЛЬ, КОТОРУЮ ОН ИГРАЛ В УПРАВЛЕНИИ ЧЕТЫРЕХ ПОКОЛЕНИЙ СВОЕЙ МНОГОЧИСЛЕННОЙ СЕМЬИ ${ }^{143}$. ТРИЖДЫ ПОВТОРЕННЫЙ НАКАЗ СВОИМ ДОМОЧАДЦАМ «НЕ БРАНИТЬСЯ И НЕ ДРАТЬСЯ» ПОДСКАЗЫВАЕТ, ЧТО ОБЯЗАННОСТИ ГЛАВЫ СЕМЬИ ВОСПРИНИМАЛАСЬ КНЯЗЕМ НИКИТОЙ ИВАНОВИЧЕМ КАК МНОГОТРУДНЫЙ И ПОСТОЯННЫЙ НАДЗОР В ДУХЕ «ДОМОСТРОЯ».

СЕМЬЯ КНЯЗЯ Н.И. ОДОЕВСКОГО СОГЛАСОВАННО ДЕЙСТВОВАЛА НА ПРОТЯЖЕНИИ ВСЕГО XVII В. В ЭТОМ, НЕСОМНЕННО, БЫЛА ЗАСЛУГА ГЛАВЫ РОДА - ЧЕЛОВЕКА НЕЗАУРЯДНЫХ ЗНАНИЙ, ЖИТЕЙСКОГО ОПЫТА, ЗАВИДНОГО ДОЛГОЛЕТИЯ И СИЛЬНОГО ХАРАКТЕРА. ОН УВЕРЕННО ПРАВИЛ НЕСКОЛЬКИМИ ПОКОЛЕНИЯМИ СВОИХ ДЕТЕЙ, ВНУКОВ И ПРАВНУКОВ, НЕ ВЫПУСКАЯ ИХ ИЗ «ДОМОВОГО ПОДДАНСТВА» ${ }^{144}$ И НЕ ПОЗВОЛИВ НИ ОДНОМУ ИЗ СВОИХ РОДСТВЕННИКОВ ОСПОРИТЬ МНЕНИЕ ГЛАВЫ СЕМЬИ «СВОЕЮ ДУРОСТИЮ». В ЭТОМ ЕДИНСТВЕ БЫЛА ЕЩЕ ОДНА ПРИЧИНА УСПЕХА КНЯЗЕЙ ОДОЕВСКИХ В XVII В., НАРЯДУ С ПРИДВОРНОЙ СЛУЖБОЙ. В ЦАРСКОЙ КОМНАТЕ КНЯЗЬЯ ОДОЕВСКИЕ ДЕРЖАЛИСЬ ВМЕСТЕ: СНАЧАЛА СТАРШИЕ ПОКОЛЕНИЯ ПРИСТРАИВАЛИ СВОИХ ДЕТЕЙ И ВНУКОВ В ЦАРСКИЕ СПАЛЬНИКИ, А ЗАТЕМ МЛАДШИЕ ПРЕДСТАВИТЕЛИ РОДА ИСПОЛЬЗОВАЛИ СВОЕ ВЛИЯНИЕ НА ЦАРЯ В ИНТЕРЕСАХ ВСЕЙ СЕМЬИ.

\section{Семья князей Одоевских в конце XVII века}

ПОСЛЕ ПАДЕНИЯ РЕЖИМА РЕГЕНТСТВА СОГЛАСОВАННОСТЬ ДЕЙСТВИЙ КНЯЗЕЙ ОДОЕВСКИХ ОБЕРНУЛАСЬ ПРОТИВ НИХ: ОНИ БЫЛИ СЛИШКОМ СВЯЗАНЫ С СОФЬЕЙ И ЦАРЕМ ИВАНОМ, ЧТОБЫ ЭТО МОЖНО БЫЛО ЗАБЫТЬ. В 1691 Г. КНЯЗЬ Я.Н. ОДОЕВСКИЙ УСТУПИЛ РУКОВОДСТВО РАСПРАВНОЙ ПАЛАТОЙ БОЯРИНУ КНЯЗЮ М.Я. ЧЕРКАССКОМУ ${ }^{145}-$ СВОЕМУ ЗЯТЮ. ОСТАВЛЯЯ ВЫНУЖДЕННО СТОЛЬ ВАЖНЫЙ ПОСТ, КНЯЗЬ ЯКОВ НИКИТИЧ СУМЕЛ ВСЕ ЖЕ ПЕРЕДАТЬ ЕГО ПРЕДСТАВИТЕЛЮ СВОЕЙ СЕМЬИ.

СОСТАВЛЕННАЯ ПЕРЕД СМЕРТЬЮ ДУХОВНАЯ КНЯЗЯ Я.Н. ОДОЕВСКОГО НЕ СОДЕРЖАЛА СТОЛЬ ЖЕ ПОДРОБНЫХ НАСТАВЛЕНИЙ РОДНЕ, КАК ДУХОВНАЯ ЕГО ОТЦА. ВИДИМО, КНЯЗЬ ЯКОВ НИКИТИЧ ПРИДАВАЛ ПОСЛУШАНИЮ ДОМОЧАДЦЕВ МЕНЬШЕЕ ЗНАЧЕНИЕ, ЧЕМ КНЯЗЬ 
НИКИТА ИВАНОВИЧ. ПЕРЕД СМЕРТЬЮ КНЯЗЬ Я.Н. ОДОЕВСКИЙ ОБРАЩАЛ ОСОБОЕ ВНИМАНИЕ НА ДРУГИЕ ДЕТАЛИ СЕМЕЙНОГО БОЯРСКОГО БЫТА. В ПЕРЕЧНЕ ИКОН, КОТОРЫМИ ОН БЛАГОСЛОВИЛ СВОИХ РОДСТВЕННИКОВ, КНЯЗЬ ЯКОВ НИКИТИЧ СООБЩАЛ ПОДРОБНОСТИ, ВИДИМО, ДОРОГИЕ ЕГО СЕРДЦУ. СВОЕГО ВНУКА КНЯЗЯ АЛЕКСЕЯ МИХАЙЛОВИЧА ЧЕРКАССКОГО ОН БЛАГОСЛОВИЛ ИКОНОЙ БОГОРОДИЦЫ ДОНСКОЙ «ОБЛОЖЕН СЕРЕБРОМ В ЧЕКАН МОЛЕНИЕ ПРАДЕДА МОЕГО КНЯЗЯ ДАНИЛА СЕМЕНОВИЧА ОДОЕВСКОГО, ЧТО ПРИВЕЗ Я ИЗ ДОБРАГО МОНАСТЫРЯ». ВНУКУ КНЯЗЮ ЮРИЮ ЮРЬЕВИЧУ ОДОЕВСКОМУ ЗАВЕЩАЛ БЛАГОСЛОВЕНИЕ: ЩОБРАЗ СПАСОВ СТОЯЩЕЙ, ОКЛАД РЕЗНОЙ В КИОТЕ, КОТОРЫМ БЛАГОСЛОВИЛ МЕНЯ ОТЕЦ МОЙ БОЯРИН АНИКИТА ИВАНОВИЧ СТАРОЕ МОЛЕНЬЕ ДЕДА ЕВО, А МОЕВО ПРАДЕДА КНЯЗЯ НИКИТЫ РОМАНОВИЧА ОДОЕВСКОГО». ВНУКУ КНЯЗЮ АЛЕКСЕЮ ЮРЬЕВИЧУ ОДОЕВСКОМУ БОЯРИН ПЕРЕДАЛ ОБРАЗ СПАСОВ, ОБЛОЖЕН СЕРЕБРОМ В ЧЕКАН В ДЕРЕВЯННОМ КИОТЕ, КОТОРЫМ БЛАГОСЛОВИЛ МЕНЯ, ОТХОДЯ СЕГО СВЕТА, ОТЕЦ МОЙ БОЯРИН КНЯЗЬ АНИКИТА ИВАНОВИЧ МОЛЕНИЕ ДЯДИ ЕВО, А МОЕВО ДЕДА, БОЯРИНА КНЯЗЯ ИВАНА МЕНШОВА НИКИТИЧА ОДОЕВСКАГО ${ }^{146}$. ПОХОЖЕ, ЧТО КНЯЗЬ ЯКОВ НИКИТИЧ ОЩУЩАЛ СЕБЯ ХРАНИТЕЛЕМ СЕМЕЙНОЙ ТРАДИЦИИ И НЕ ХОТЕЛ, ЧТОБЫ ОНА ПРЕРВАЛАСЬ С ЕГО КОНЧИНОЙ. ОСОБЕННО ТРОГАТЕЛЬНО ЕГО УЧАСТИЕ В СУДЬБЕ ИКОНЫ, ВЫВЕЗЕННОЙ ИМ ЛИЧНО ИЗ РОДОВОГО ДОБРЕНСКОГО МОНАСТЫРЯ В ЛИХВИНЕ, ГДЕ ДО СЕРЕДИНЫ XVI В. РАСПОЛАГАЛОСЬ УДЕЛЬНОЕ ВЛАДЕНИЕ КНЯЗЕЙ ОДОЕВСКИХ.

У КНЯЗЯ ЯКОВА НИКИТИЧА НЕ БЫЛО СЫНОВЕЙ, И ПОСЛЕ ЕГО СМЕРТИ В АВГУСТЕ 1697 Г. РОД ПРОДОЛЖИЛСЯ ОТ ДЕТЕЙ БОЯРИНА КНЯЗЯ ЮРИЯ МИХАЙЛОВИЧА, КОТОРЫЕ НЕ СМОГЛИ ЗАСЛУЖИТЬ ДОВЕРИЕ ПЕТРА, НЕСМОТРЯ НА ИХ СЛУЖБУ В СПАЛЬНИКАХ. В РЕЗУЛЬТАТЕ, В ПЕТРОВСКУЮ ЭПОХУ КНЯЗЬЯ ОДОЕВСКИЕ УЖЕ НЕ ЗАНИМАЛИ ПЕРВЫХ ПОСТОВ В ГОСУДАРСТВЕ. ИХ СУДЬБА В XVIII В. УДОСТОИЛАСЬ ИРОНИЧНЫХ ЗАМЕЧАНИЙ В ЗНАМЕНИТЫХ «ЗАПИСКАХ» КНЯЗЯ ПЕТРА ДОЛГОРУКОВА. ПО ЕГО СЛОВАМ, КНЯЗЬ ВАСИЛИЙ ЮРЬЕВИЧ ОДОЕВСКИЙ «БЫЛ ЖАЛКОЙ ЛИЧНОСТЬЮ, А ЕГО ЖЕНА, НЕСМОТРЯ НА ЗНАТНОСТЬ РОЖДЕНИЯ И СОЛИДНОЕ БОГАТСТВО, ОТЛИЧАЛАСЬ ПРИ ДВОРЕ СВОИМ ПОДОБОСТРАСТИЕМ». КОГДА ЕЕ ДОЧЬ БЫЛА СОСЛАНА ЗА УЧАСТИЕ В ДВОРЦОВОМ ЗАГОВОРЕ, ОНА ОСМЕЛИЛАСЬ БЫЛО ПРОСИТЬ У ЕЛИЗАВЕТЫ ПЕТРОВНЫ ПОМИЛОВАНИЯ. ПОЛУЧИВ ОТКАЗ, СЕМИДЕСЯТИЛЕТНЯЯ КНЯГИНЯ ОДОЕВСКАЯ «ГРОХНУЛАСЬ НА КОЛЕНИ С ВОПЛЕМ: “ВИНОВАТА, МАТУШКА, ЭТО Я ТАК СДУРУ”».

ЕДИНСТВЕННЫЙ СЫН ЭТИХ РОДИТЕЛЕЙ КНЯЗЬ ИВАН, ПО СЛОВАМ КНЯЗЯ ПЕТРА ДОЛГОРУКОВА, «БЫЛ ОДНИМ ИЗ САМЫХ ЖАЛКИХ ЛЮДЕЙ СВОЕГО ВРЕМЕНИ: ПРОМОТАВ СОСТОЯНИЕ ОТЦА, <..> ОН ЖИЛ ТЕМ, ЧТО ПЛУТОВАЛ В КАРТАХ, А ИНОГДА <..> ПРИКАРМАНИВАЛ СТАВКИ, ЛЕЖАВШИЕ НА СТОЛЕ». ОТ НАСЛЕДНИКА ПРЕСТОЛА, БУДУЩЕГО ИМПЕРАТОРА ПЕТРА III,

ПОЛУЧИВ ЗА ЭТО ПОЩЕЧИНУ, БЫЛ ВЫКИНУТ ВОН ПИНКОМ НОГИ, ЧТО, ВПРОЧЕМ, НЕ ПОМЕШАЛО ЕМУ ПОЗДНЕЕ СТАТЬ СЕНАТОРОМ, ДЕЙСТВИТЕЛЬНЫМ ТАЙНЫМ СОВЕТНИКОМ И ПОЛУЧИТЬ ОРДЕН СВ.АЛЕКСАНДРА НЕВСКОГО НА ЛЕНТЕ. ОН СОДЕРЖАЛ ОРКЕСТР КРЕПОСТНЫХ МУЗЫКАНТОВ И ПОСЫЛАЛ ИХ ИГРАТЬ ПО ДОМАМ, А ВЫРУЧКУ ЗАБИРАЛ СЕБЕ, И ЭТО УЖЕ БУДУЧИ СЕНАТОРОМ.

КНЯЗЬ ПЕТР ДОЛГОРУКОВ СЧИТАЛ УМЕСТНЫМ ВСПОМНИТЬ В СВЯЗИ С ИСТОРИЕЙ АРИСТОКРАТИЧЕСКОЙ СЕМЬИ КНЯЗЕЙ ОДОЕВСКОГО ПУШКИНСКИЕ СТРОКИ:

ЕЗЕРСКИЙ САМ ЖЕ ТВЕРДО ВЕДАЛ, ЧТО ДЕД ЕГО, ВЕЛИКИЙ МУЖ, ИМЕЛ ДВЕНАДЦАТЬ ТЫСЯЧ ДУШ. <..> 
А САМ ОН ЖАЛОВАНЬЕМ ЖИЛ,

И РЕГИСТРАТОРОМ СЛУЖИЛ. CEMbE: НЕ ВАКСИЛ ЦАРСКИХ САПОГОВ,

ДАЛЬНЕЙШЕЕ ПОВЕСТВОВАНИЕ КНЯЗЯ ПЕТРА ДОЛГОРУКОВА О СЕМЬЕ КНЯЗЕЙ ОДОЕВСКИХ XVIII В. ЛИШЬ УСИЛИВАЕТ ПРОЦИТИРОВАННЫЕ ОЦЕНКИ ${ }^{147}$.

ПРИ ХАРАКТЕРИСТИКЕ РУССКОЙ РОДОВИТОЙ ЗНАТИ ХVIII В. ЧАСТО ИСПОЛЬЗУЮТ ДРУГИЕ ПУШКИНСКИЕ СТРОКИ. В СТИХОТВОРЕНИИ «МОЯ РОДОСЛОВНАЯ» ПОЭТ РАЗМЫШЛЯЛ О ПРИЧИНАХ УПАДКА СВОЕГО РОДА И ВСЕЙ СТАРОМОСКОВСКОЙ АРИСТОКРАТИИ: «РОДОВ ДРЯХЛЕЮЩИХ ОБЛОМОК (И, ПО НЕСЧАСТЬЮ, НЕ ОДИН)». ПРИЧИНУ УГАСАНИЯ СТАРОЙ АРИСТОКРАТИИ ПУШКИН ВИДЕЛ В ТОМ, ЧТО ОНА НЕ СТАЛА ПРИСЛУЖИВАТЬ ЦАРСКОЙ

НЕ ТОРГОВАЛ МОЙ ДЕД БЛИНАМИ, НЕ ПЕЛ С ПРИДВОРНЫМИ ДЬЯЧКАМИ, В КНЯЗЬЯ НЕ ПРЫГАЛ ИЗ ХОХЛОВ. ${ }^{148}$

ИСТОРИЯ КНЯЗЕЙ ОДОЕВСКИХ В XVII В. ПОКАЗЫВАЕТ, ЧТО ОНИ КАК РАЗ СТРЕМИЛИСЬ ВЫДВИНУТЬСЯ НА ДВОРЦОВОЙ КОМНАТНОЙ СЛУЖБЕ, ГДЕ ПОДАТЬ ВОВРЕМЯ ЦАРСКИЕ САПОГИ И БЫЛО ВЫСШИМ ОТЛИЧИЕМ ${ }^{149}$. В ЦАРСКОЙ КОМНАТЕ НЕСКОЛЬКО ПОКОЛЕНИЙ СЕМЬИ КНЯЗЯ НИКИТЫ ИВАНОВИЧА ОДОЕВСКОГО СТАРАЛИСЬ ПЕРЕДАВАТЬ СВОЙ СТАТУС БЛИЖНИХ КОМНАТНЫХ ЛЮДЕЙ ПО НАСЛЕДСТВУ. ТЕМ НЕ МЕНЕЕ, ОНИ НЕ СМОГЛИ УДЕРЖАТЬ «ФАМИЛЬНУЮ ЧЕСТЬ» - НЕ ПОТОМУ, ЧТО БЫЛИ ПЛОХИМИ ПРИДВОРНЫМИ И ПЛОХО УГОЖДАЛИ ГОСУДАРЯМ. В ЭТОМ ОНИ КАК РАЗ ПРЕУСПЕЛИ. НЕУДАЧА ТАКОЙ ЛИНИИ ПОВЕДЕНИЯ БЫЛА НЕИЗБЕЖНОЙ ПОТОМУ, ЧТО ПРИДВОРНЫЕ ДОЛЖНОСТИ, В ОТЛИЧИЕ ОТ АРИСТОКРАТИЧЕСКОЙ ФАМИЛЬНОЙ ЧЕСТИ, ПЕРЕДАЮТСЯ НЕ ПО НАСЛЕДСТВУ, А ПО ЦАРСКОЙ МИЛОСТИ.

ПЛОХАЯ СОХРАННОСТЬ ЧАСТНЫХ АРХИВОВ НЕ ПОЗВОЛЯЕТ ПРОСЛЕДИТЬ ПОВСЕДНЕВНУЮ ПРАКТИКУ СПЛАЧИВАНИЯ БОЯРСКОГО СЕМЕЙНОГО КЛАНА ХVII В. ЭТА СТОРОНА ВНУТРЕННЕГО СЕМЕЙНОГО БЫТА ПО БОЛЬШЕЙ ЧАСТИ УСКОЛЬЗАЕТ ОТ ИССЛЕДОВАТЕЛЯ. ТЕМ НЕ МЕНЕЕ, ПО СОХРАНИВШИМСЯ ФРАГМЕНТАМ ЧАСТНОЙ ПЕРЕПИСКИ ХVII - НАЧАЛА XVIII В., А ТАКЖЕ ПО ВОСПОМИНАНИЯМ ЛЮДЕЙ ТОГО ВРЕМЕНИ МОЖНО УСТАНОВИТЬ, ЧТО СЕМЕЙНЫЕ И КЛАНОВЫЕ СВЯЗИ НЕИЗМЕННО ПРЕДПОЛАГАЛИ ДОВЕРИТЕЛЬНУЮ БЕСЕДУ МЕЖДУ РОДСТВЕННИКАМИ И СОЮЗНИКАМИ ПРИ ДВОРЕ. ОБ ЭТОМ СВИДЕТЕЛЬСТВУЮТ ВЫРАЖЕНИЯ, КОТОРЫМИ ЛЮДИ ХVII В. ОБОЗНАЧАЛИ «СВОЕГО» ЧЕЛОВЕКА: У НИХ БЫЛО «ПО СЛОВУ», «НАГОВОРЕНО», ОН ЕМУ «СОВЕТЕН». И, НАОБОРОТ, О ТОМ, КТО ОТКАЗЫВАЛСЯ ПОДДЕРЖАТЬ, ГОВОРИЛИ: «В РАЗГОВОР НЕ ДАЛСЯ», ОН «ЧЕЛОВЕК НЕЗГОВОРНОЙ». СОЕДИНЕНИЕ НЕДРУГОВ МОГЛО БЫТЬ РЕЗУЛЬТАТОМ «НЕПРАВЕДНОГО НАГОВОРА», ОНО СОЗДАВАЛОСЬ «УШНИЧЕСТВОМ И ЛОЖНЫМ НАГОВОРОМ», КОГДА «УШНИЧАЛИ И ОБНОСИЛИ» (Т. Е. КЛЕВЕТАЛИ. - П.С.) ВО ВРЕМЯ ЗАСТОЛИЙ ${ }^{150}$.

ВО ВНУТРИСЕМЕЙНЫХ ОТНОШЕНИЯХ СЛОВО СТАРШИХ БЫЛО ТЕМ БОЛЕЕ ЗНАЧИМЫМ. СЕМЕЙНАЯ СТРАТЕГИЯ НЕМЫСЛИМА БЕЗ ЕЕ ПОСТОЯННОГО ОБСУЖДЕНИЯ В КРУГУ СЕМЬИ. ДЕТИ И ВНУКИ ШЛИ ПРОТОРЕННЫМ ПУТЕМ, ПРЕДНАЧЕРТАННЫМ СТАРШИМИ - ДЕДАМИ И ОТЦАМИ. МЛАДШИЕ НЕ ВЫХОДИЛИ ИЗ ПОВИНОВЕНИЯ СТАРШИХ, ПОВТОРЯЛИ ИХ СЛУЖЕБНУЮ КАРЬЕРУ, ВЕРШИЛИ СВОЮ СУДЬБУ ПО ОБРАЗЦУ СТАРШИХ. КНЯЗЬ НИКИТА ИВАНОВИЧ ОДОЕВСКИЙ ЗАБРАЛ В СВОЙ ДОМ ШЕСТИЛЕТНЕГО ПРАВНУКА, КОТОРОГО «СКОРМИЛ И ВЫУЧИЛ». ЖЕНА КНЯЗЯ АЛЕКСЕЯ НИКИТИЧА ОДОЕВСКОГО КНЯГИНЯ УЛЬЯНА ИВАНОВНА ПОСТУПИЛА ТОЧНО ТАКЖЕ, ВЗЯВ К СЕБЕ НА ВОСПИТАНИЕ СВОЕГО ВНУКА 
КНЯЗЯ Б.И. КУРАКИНА, КОТОРЫЙ ПОТОМ С БЛАГОДАРНОСТЬЮ ВСПОМИНАЛ ЕЕ УМ, НАБОЖНОСТЬ И ВСЕОБЩЕЕ УВАЖЕНИЕ «ОТ ВСЕХ».

В КОНЦЕ XVII И ДАЛЕЕ В XVIII В. ТРАДИЦИОННАЯ СВЯЗЬ ПОКОЛЕНИЙ ПРЕДШЕСТВУЮЩИХ СТОЛЕТИЙ, ОСНОВАННАЯ НА НЕПРЕЛОЖНОМ АВТОРИТЕТЕ СТАРШИХ ЧЛЕНОВ СЕМЬИ, ПОСТЕПЕННО ОСЛАБЕВАЕТ, ОСВОБОЖДАЯ МЕСТО ЛИЧНОСТНОМУ НАЧАЛУ. В 1677 Г. БОЯРИН КНЯЗЬ В.В.ГОЛИЦЫН ПОСМЕЛ ОСЛУШАТЬСЯ СОВЕТА СВОИХ СТАРШИХ РОДСТВЕННИКОВ, О ЧЕМ МАТЬ ПЕНЯЛА ЕМУ В ПИСЬМЕ: «А ДЯДЯ НА ТЕБЯ, СВЕТ МОЙ, СЕРДИТЫ: <..> КАК-ДЕ ОН СЕБЕ ХОЧЕТ, ТАК И ЖИВЕТ» ${ }^{151}$. ВПРОЧЕМ, ОБЫЧАЙ ПОВИНОВАТЬСЯ СТАРШЕЙ РОДНЕ СОХРАНЯЛСЯ ЕЩЕ ДОЛГОЕ ВРЕМЯ. В 1831 Г. А.С. ПУШКИН ПИСАЛ:

Я НЕ ЛЮБЛЮ МОСКОВСКОЙ ЖИЗНИ. ЗДЕСЬ ЖИВИ НЕ КАК ХОЧЕШЬ - КАК ТЕТКИ ХОТЯТ. ТЕЩА МОЯ ТА ЖЕ ТЕТКА. ТО ЛИ ДЕЛО В ПЕТЕРБУРГЕ! ЗАЖИВУ СЕБЕ МЕЩАНИНОМ ПРИПЕВАЮЧИ, НЕЗАВИСИМО И НЕ ДУМАЯ О ТОМ, ЧТО СКАЖЕТ МАРЬЯ АЛЕКСЕЕВНА. ${ }^{152}$

В НОВОЕ ВРЕМЯ ПРЕДСТАВИТЕЛИ ДВОРЯНСКИХ СЕМЕЙ ПОЛУЧИЛИ ВОЗМОЖНОСТЬ ЖИТЬ СВОИМ УМОМ, «СВОЕЮ ДУРОСТИЮ», КАК ЭТО ВОСПРИНИМАЛИ В ДОПЕТРОВСКОЙ РУСИ.

Придворная служба князей Одоевскихв ХVIІв.

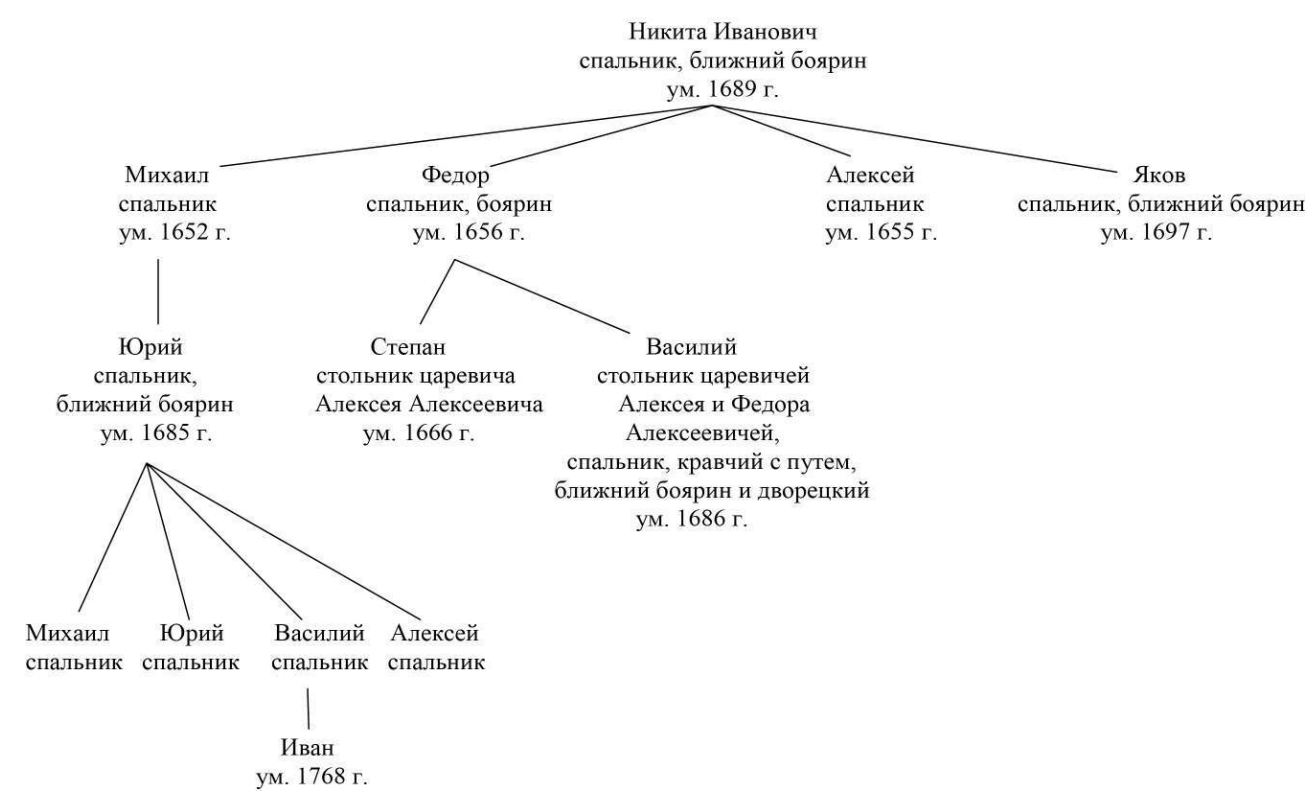

\section{NOTES}

2. Г.А. ВЛАСЬЕВ, ПОТОМСТВО РЮРИКА, Т. І, Ч. 1, СПБ., 1906, С. 68-112; А. БАРСУКОВ, РОД ШЕРЕМЕТЕВЫХ, Т. III-VII, СПБ., 1883-1908; Ю. АРСЕНЬЕВ, БЛИЖНИЙ БОЯРИН КНЯЗЬ НИКИТА ИВАНОВИЧ ОДОЕВСКИЙ И ЕГО ПЕРЕПИСКА С ГАЛИЦКОЙ ВОТЧИНОЙ (1650-1684), М., 1903.

3. КРАТКИЕ БИОГРАФИЧЕСКИЕ ОЧЕРКИ, ПОСВЯЩЕННЫЕ БОЯРИНУ КНЯЗЮ Н.И. ОДОЕВСКОМУ, ЕГО ДЕТЯМ МИХАИЛУ, ФЕДОРУ, АЛЕКСЕЮ И ЯКОВУ, ВНУКАМ ЮРИЮ МИХАЙЛОВИЧУ И ВАСИЛИЮ 
ФЕДОРОВИЧУ СМ.: РУССКИЙ БИОГРАФИЧЕСКИЙ СЛОВАРЬ. ОБЕЗЬЯНИНОВ - ОСКИН, СПБ., 1905, С. $122-124,160-167,169-170$.

4. ВЛАСЬЕВ, ПОТОМСТВО РЮРИКА, Т.І, Ч. 1, С. 77; АРХИМАНДРИТ МАКАРИЙ, АРХЕОЛОГИЧЕСКОЕ ОПИСАНИЕ ЦЕРКОВНЫХ ДРЕВНОСТЕЙ В НОВГОРОДЕ И ЕГО ОКРЕСТНОСТЯХ, М., 1860, Ч. І, С. 467.

5. ДВОРцОВЫЕ РАЗРЯДЫ (ДАЛЕЕ: ДР), Т. І, СПБ., 1855, СТБ. 475, 493, 494, 500, 517, 525, 551, 563, 622, 634, 690; Т. ІІ, СТБ. 209.

6. БАРСУКОВ, РОД ШЕРЕМЕТЕВЫХ, Т. III, С. 1-2.

7. ДР, Т. І, СТБ. 784, 785.

8. ПО БОЛЬШЕЙ ЧАСТИ ЧИН КОМНАТНОГО СТОЛЬНИКА И СПАЛЬНИКА СОВПАДАЛИ, ХОТЯ В ПЕРВОЙ ПОЛОВИНЕ XVII В. ВСТРЕЧАЕТСЯ ЕЩЕ И ЧИН КОМНАТНОГО СТРЯПЧЕГО, ТОЖЕ ИМЕНУЕМОГО СПАЛЬНИКОМ (А.П.ПАВЛОВ, «КОМНАТНЫЕ СТОЛЬНИКИ ЦАРЯ МИХАИЛА РОМАНОВА» ВРЕМЕНА И СУДЬБЫ. СБОРНИК СТАТЕЙ В ЧЕСТЬ 75-ЛЕТИЯ ВИКТОРА МОИСЕЕВИЧА ПАНЕЯХА, СПБ., 2006, С.81, 91). О ЧИНЕ КОМНАТНОГО СТОЛЬНИКА ВТОРОЙ ПОЛОВИНЫ XVII В. СМ.: П.В. СЕДОВ, ЗАКАТ МОСКОВСКОГО ЦАРСТВА. ЦАРСКИЙ ДВОР КОНЦА ХVII В., М., 2006, С. 65-78.

9. А.П. ПАВЛОВ, ГОСУДАРЕВ ДВОР И ПОЛИТИЧЕСКАЯ БОРЬБА ПРИ БОРИСЕ ГОДУНОВЕ, СПБ., 1992, С. 159.

10. РГАДА (РОССИЙСКИЙ ГОСУДАРСТВЕННЫЙ АРХИВ ДРЕВНИХ АКТОВ), Ф. 1209, КН. 150, Л. 317; КН. 588, Л. 180-190; КН. 628, Л. 92-93; ЧТЕНИЯ ОИДР, 1895, КН. І, С. 5. СВЕДЕНИЯ О ЗЕМЛЕВЛАДЕНИИ КНЯЗЯ Н.И. ОДОЕВСКОГО 1620-Х ГОДОВ СООБЩЕНЫ НАМ А.П. ПАВЛОВЫМ.

11. ДР, Т. І, СТБ. 961; Т. ІІ, СТБ. 172, 207, 219.

12. ВЛАСЬЕВ, ПОТОМСТВО РЮРИКА, Т. І, Ч. 1 , С. 76,78 . ОБА ПОХОРОНЕНЫ В ТРОИЦЕ-СЕРГИЕВОМ МОНАСТЫРЕ.

13. ВКЛАДНАЯ КНИГА ТРОИЦЕ-СЕРГИЕВА МОНАСТЫРЯ, М., 1987, С. 109 (ДАЛЕЕ: ТРОИЦКАЯ ВКЛАДНАЯ); Ю.В. ГОТЬЕ, ЗАМОСКОВНЫЙ КРАЙ В XVII В., М., 1937, С. 232.

14. В ПОДМОСКОВНОЙ ВОТЧИНЕ КНЯЗЯ Н.И. ОДОЕВСКОГО НИКОЛЬСКОМ-УРЮПИНЕ БЫЛИ ПРИДЕЛЫ ФОТИЯ И АНИКИТЫ (В ЧЕСТЬ ХОЗЯИНА УСАДЬБЫ), ПРИДЕЛ ПРЕПОДОБНОМУЧЕНИЦЫ ЕВДОКИИ (В ЧЕСТЬ ЕГО ЖЕНЫ) И ПРИДЕЛ МИХАИЛА ЧЕРНИГОВСКОГО И ЕГО БОЯРИНА ФЕДОРА (В ЧЕСТЬ СТАРШИХ СЫНОВЕЙ).

15. Ю.М. ЭСКИН, МЕСТНИЧЕСТВО В РОССИИ ХVI-XVII В. ХРОНОЛОГИЧЕСКИЙ РЕЕСТР, М., 1994, С. 170, № 1320; АРСЕНЬЕВ, БЛИЖНИЙ БОЯРИН КНЯЗЬ НИКИТА ИВАНОВИЧ ОДОЕВСКИЙ, С. 6.

16. МАРШАЛЛ ПО (Marshall Рое), РОССИЙСКАЯ ЭЛИТА В ХVII ВЕКЕ - The Russian Elite in the Seventeeth Century, Т. I, ХЕЛЬСИНКИ, 2004, С. 430; 12 АПРЕЛЯ 1640 Г. ЕМУ БЫЛ УЧИНЕН ОКЛАД В БОЯРАХ 500 РУБЛЕЙ (Н.М. РОГОЖИН, М.П. ЛУКИЧЕВ, БОЯРСКАЯ КНИГА 1639 ГОДА, М., 1999, С. 22, Л. 6).

17. А. БАРСУКОВ, СПИСКИ ГОРОДОВЫХ ВОЕВОД И ДРУГИХ ЛИЦ ВОЕВОДСКОГО УПРАВЛЕНИЯ ХVII В., СПБ., 1902, C. 9.

18. АРХИВ СПБИИ (АРХИВ С.-ПЕТЕРБУРГСКОГО ИНСТИТУТА ИСТОРИИ), Ф. 178, ОП. 1, Д. 1500.

19. АРСЕНЬЕВ, БЛИЖНИЙ БОЯРИН КНЯЗЬ НИКИТА ИВАНОВИЧ ОДОЕВСКИЙ, С. 7.

20. БАРСУКОВ, РОД ШЕРЕМЕТЕВЫХ, Т. ІІІ, С. 292-301, 319-336.

21. ДР, Т. ІІ, СТБ. 750-751; ЭСКИН, МЕСТНИЧЕСТВО В РОССИИ, С. 181, № 1428.

22. ДР, Т. ІІІ, СТБ. 2; В. БЕРХ, ЦАРСТВОВАНИЕ АЛЕКСЕЯ МИХАЙЛОВИЧА, Ч. І, С. 31.

23. ЧТЕНИЯ ОИДР, 1867, Кн. IV, С. 66.

24. ДР, Т. ІІІ, СТБ. 27, 34-35.

25. ТРОИЦКАЯ ВКЛАДНАЯ, Л. 271 ОБ.

26. АКТЫ МОСКОВСКОГО ГОСУДАРСТВА, Т. II, С. 234, 235, 239, 240, 244, 245, 259, 267.

27. О.Е. КОШЕЛЕВА, «КОЛЛЕКТИВНАЯ ЧЕЛОБИТНАЯ ДВОРЯН НА БОЯР (XVII В.)», ВОПРОСЫ ИСТОРИИ, 1982, С. 172-173; О.Е. КОШЕЛЕВА, Б.Н. МОРОЗОВ, «СЛУЖЕБНАЯ ДЕЯТЕЛЬНОСТЬ БОЯР В ХVII ВЕКЕ», Rude and Barbarous Kingdom Revisited. Essays in Russian History and Culture in Honor of Robert 0. Crummey, 2008, P. 13-14. 
28. ЖАЛОБА БЫЛА ПОЛУЧЕНА В МОСКВЕ 12 ЯНВАРЯ 1648 Г. АРХИВ ЮГО-ЗАПАДНОЙ РОССИИ, Т. ІІІ, М., 1861, C. 92.

29. ДР, Т. ІІІ, СТБ. 78-79.

30. ТАМ ЖЕ, СТБ. 95.

31. ТАМ ЖЕ; А.Г. МАНЬКОВ, УЛОЖЕНИЕ 1649 ГОДА КОДЕКС ФЕОДАЛЬНОГО ПРАВА РОССИИ, Л., 1980, С. 45-48; П.Я. ЧЕРНЫХ, ЯЗЫК УЛОЖЕНИЯ 1649 Г., М., 1953, С. 52-79; СЛОВАРЬ КНИЖНИКОВ И КНИЖНОСТИ ДРЕВНЕЙ РУСИ. ВЫП. 3 (ХVII В.), Ч. 2, ПЕТЕРБУРГ, 1993, С. 418-419.

32. «ХАРАКТЕРЫ ВЕЛЬМОЖ И ЗНАТНЫХ ЛЮДЕЙ В ЦАРСТВОВАНИЕ АЛЕКСЕЯ МИХАЙЛОВИЧА», СЕВЕРНЫЙ АРХИВ, 1825, ч. 17, С. 296-297.

33. С.П. ЛУППОВ, А.И. КОПАНЕВ, ЧИТАТЕЛИ ИЗДАНИЙ МОСКОВСКОЙ ТИПОГРАФИИ В СЕРЕДИНЕ ХVII ВЕКА, Л., 1983, С. 115, 126.

34. ДЕЛА ПРИКАЗА ТАЙНЫХ ДЕЛ, КН. 1, ПЕТЕРБУРГ, 1907, СТБ. 1121.

35. С.А. БЕЛОКУРОВ, АРСЕНИЙ СУХАНОВ, М., 1891, Ч. І, С. 243.

36. РУКОПИСНАЯ КНИГА СОБРАНИЯ М.М. ПОГОДИНА. КАТАЛОГ, ВЫП. 2, СПБ., 1992, № 587.

37. М.П. ЛУКИЧЕВ, БОЯРСКИЕ КНИГИ ХVII ВЕКА. ТРУДЫ ПО ИСТОЧНИКОВЕДЕНИЮ, М., 2004, С. 405-406, 408-409, 416.

38. БЛИЗОСТЬ КНЯЗЯ Н.И. ОДОЕВСКОГО К ЭТОМУ КРУЖКУ ЕСТЕСТВЕННО СОПОСТАВИТЬ И С БРАКОМ 1668 Г. ЕГО ВНУКА - КНЯЗЯ ВАСИЛИЯ ФЕДОРОВИЧА С ДОЧЕРЬЮ ИЗВЕСТНОГО ОКОЛЬНИЧЕГО ФЕДОРА МИХАЙЛОВИЧА РТИЩЕВА - АКУЛИНОЙ (Н.Н. КАШКИН, РОДОСЛОВНЫЕ РАЗВЕДКИ, Т. І, СПБ., 1912, С. 17, 169, 446). КАК ИЗВЕСТНО, Ф.М. РТИЩЕВ БЫЛ ДЕЯТЕЛЬНЫМ УЧАСТНИКОМ ЭТОГО КРУЖКА И РАЗДЕЛЯЛ ЕГО ИДЕИ.

39. СЛОВАРЬ КНИЖНИКОВ И КНИЖНОСТИ ДРЕВНЕЙ РУСИ, ВЫП. 3 (XVII В.), Ч. 2, С. 325. ЛЮБОПЫТНО, ЧТО САВВАТИЙ БЫЛ УВОЛЕН С ПЕЧАТНОГО ДВОРА ПАТРИАРХОМ НИКОНОМ И НАШЕЛ ПОКРОВИТЕЛЬСТВО В ДОМЕ КНЯЗЯ Н.И. ОДОЕВСКОГО. ЛИЧНО К НИКОНУ КНЯЗЬ ОДОЕВСКИЙ ОТНОСИЛСЯ НЕТЕРПИМО.

40. ХАРАКТЕРЫ ВЕЛЬМОЖ И ЗНАТНЫХ ЛЮДЕЙ В ЦАРСТВОВАНИЕ АЛЕКСЕЯ МИХАЙЛОВИЧА, С. 299.

41. РУКОПИСНЫЕ КНИГИ СОБРАНИЕ М.П. ПОГОДИНА. КАТАЛОГ, ВЫП. 2, СПБ., 1992, № 399.

42. АРХИВ СПБИИ, Ф. 181, ОП. 1, Д. 2816, Л. 1-2.

43. В.И. МАЛЫШЕВ, «О ВКЛАДНОЙ ЗАПИСИ НА ЛИЦЕВОМ СБОРНИКЕ XVII В. ИЗ КОЛЛЕКЦИИ Ф.А. КАШКИНА» // ТРУДЫ ОТДЕЛА ДРЕВНЕРУССКОЙ ЛИТЕРАТУРЫ (ТОДРЛ) Т. XXVII, Л., 1972, С. 454. В ЭТОТ ЖЕ ХРАМ ОН ПОЖАЛОВАЛ И ТРЕБНИК ПЕТРА МОГИЛЫ (АРСЕНЬЕВ, БЛИЖНИЙ БОЯРИН КНЯЗЬ НИКИТА ИВАНОВИЧ ОДОЕВСКИЙ, С. 9).

44. РГИА (РОССИЙСКИЙ ГОСУДАРСТВЕННЫЙ ИСТОРИЧЕСКИЙ АРХИВ), Ф. 1088, ОП. 3, Д. 22. Л. 6. КНЯЖИЧ ЮРИЙ ЮРЬЕВИЧ ПЕРЕШЕЛ ЖИТЬ НА ДВОР СВОЕГО ПРАДЕДУШКИ В СВЯЗИ С ОТЪЕЗДОМ ОТЦА НА ВОЕВОДСТВО В НОВГОРОД В 1678 Г. КНЯЗЬ Ю.Ю. ОДОЕВСКИЙ РОДИЛСЯ В 1672 Г., И К 1678 Г. ЕМУ КАК РАЗ ИСПОЛНИЛОСЬ ШЕСТЬ ЛЕТ (ВЛАСЬЕВ, ПОТОМСТВО РЮРИКА, Т. І, Ч. 1, С. 88).

45. А.И. РОГОВ, «НОВЫЕ ДАННЫЕ О СОСТАВЕ УЧЕНИКОВ СЛАВЯНО-ГРЕКО-ЛАТИНСКОЙ АКАДЕМИИ», ИСТОРИЯ СССР, 1959, № 3, С. 143.

46. У КАЖДОГО БОЯРСКОГО СЫНА БЫЛ ВОСПИТАТЕЛЬ - ДЯДЬКА, ЗАНИМАВШИЙ ПОЧЕТНОЕ ПОЛОЖЕНИЕ В ДОМЕ. С 1660/1661 Г. ЖИТЕЛЬ МОСКОВСКОЙ МЕЩАНСКОЙ СЛОБОДЫ, «ПРИШОД К МОСКВЕ, ЖИЛ ДОБРОВОЛЬНО КНЯЗЬ ВАСИЛЬЯ ФЕДОРОВИЧА ОДОЕВСКОГО У ДЯДЬКИ ЕВО У ПОЛИКАРПА СЕМЕНОВА ЛЕТ С 8». (Н.А. НАЙДЕНОВ, РЕД., МАТЕРИАЛЫ ДЛЯ ИСТОРИИ МОСКОВСКОГО КУПЕЧЕСТВА, М., 1883, Т. 1, ПРИЛОЖЕНИЕ 2, С. 7).

47. Г. К. КОТОШИХИН, О РОССИИ В ЦАРСТВОВАНИИ АЛЕКСЕЯ МИХАЙЛОВИЧА, М., 2000, С. 30.

48. А. ЗЕРЦАЛОВ, О МЯТЕЖАХ В ГОРОДЕ МОСКВЕ И В СЕЛЕ КОЛОМЕНСКОМ 1648, 1662, 1771 Г, М., 1890, С. 70.

49. УПОМИНАНИЯ 1651 И 1675 ГГ. (РГАДА, Ф. 210, МОСКОВСКИЙ СТ., СТБ. 508, Л. 17; ДР, Т. ІІІ, СТБ. $243,1323,1425,1526,1582,1583,1588,1593,1598,1600$; «СКАЗАНИЕ АДОЛЬФА ЛИЗЕКА О 
ПОСОЛЬСТВЕ ОТ ИМПЕРАТОРА РИМСКОГО ЛЕОПОЛЬДА К ВЕЛИКОМУ ЦАРЮ МОСКОВСКОМУ АЛЕКСЕЮ МИХАЙЛОВИЧУ В 1675 ГОДУ», ЖМНП (ЖУРНАЛ МИНИСТЕРСТВА НАРОДНОГО ПРОСВЕЩЕНИЯ), ч. 16, № 11 (1837), С. 372).

50. «КНИГА ДЯДЬКАМ И МАМАМ И БОЯРЫНЯМ ВЕРХОВЫМ И СТОЛЬНИКАМ ЦАРЕВИЧЕВЫМ» ВРЕМЕННИК ОИДР, КН. ІХ, М., 1850, СМЕСЬ, С. 49.

51. «СОЧИНЕНИЯ ЦАРЯ АЛЕКСЕЯ МИХАЙЛОВИЧА», МОСКОВИЯ И ЕВРОПА, М., 2000, С. 504.

52. ДР, Т. ІІІ, СТБ. 268, 327, 339; БАРСУКОВ, СПИСКИ ГОРОДОВЫХ ВОЕВОД, С. 88.

53. «СОЧИНЕНИЯ ЦАРЯ АЛЕКСЕЯ МИХАЙЛОВИЧА», С. 505-506.

54. ТАМ ЖЕ, С. 507-510.

55. ДР, Т. ІІІ, СТБ. 470, 471.

56. «СОЧИНЕНИЯ ЦАРЯ АЛЕКСЕЯ МИХАЙЛОВИЧА», С. 518.

57. ДОПОЛНЕНИЯ К Т. ІІІ ДВОРЦОВЫХ РАЗРЯДОВ, СПБ., 1884 (ДАЛЕЕ: ДДР), СТБ. 62.

58. ТРОИЦКАЯ ВКЛАДНАЯ, С. 109; ВЛАСЬЕВ, ПОТОМСТВО РЮРИКА, Т. І, Ч. 1, С. 81-83.

59. ДР, Т. ІІІ, 418, 503; ДДР, СТБ. 21, 34, 43, 53, 89, 107, 213, 215, 236, 264, 272, 279, 289.

60. ДДР, СТБ. 392, 394-395.

61. БАРСУКОВ, СПИСКИ ГОРОДОВЫХ ВОЕВОД, С. 11.

62. «ХАРАКТЕРЫ ВЕЛЬМОЖ И ЗНАТНЫХ ЛЮДЕЙ В ЦАРСТВОВАНИЕ АЛЕКСЕЯ МИХАЙЛОВИЧА», C. 299.

63. ДОПОЛНЕНИЯ К АКТАМ ИСТОРИЧЕСКИМ, Т. V, СПБ., 1853, С. 99; С.В. ЛОБАЧЕВ, ПАТРИАРХ НИКОН, СПБ., 2003, С. 108-110, 189, 196-197, 215, 217, 218.

64. ЦИТ. ПО: С.В. ЛОБАЧЕВ, ПАТРИАРХ НИКОН, С. 196.

65. МЕЙЕРБЕРГ АВГУСТИН, «ПУТЕШЕСТВИЕ В МОСКОВИЮ» УТВЕРЖДЕНИЕ ДИНАСТИИ, М., 1997, C. 103.

66. «ХАРАКТЕРЫ ВЕЛЬМОЖ И ЗНАТНЫХ ЛЮДЕЙ В ЦАРСТВОВАНИЕ АЛЕКСЕЯ МИХАЙЛОВИЧА», С. 297. БОЛЕЗНЕННОСТЬ КН. Н.И. ОДОЕВСКОГО УДОСТОВЕРЯЕТ ВЫПИСАННЫЙ ЕМУ 17 ЯНВАРЯ 1668 Г. РЕЦЕПТ. - ОР РНБ (ОТДЕЛ РУКОПИСЕЙ РОССИЙСКОЙ НАЦИОНАЛЬНОЙ БИБЛИОТЕКИ), Ф. 532, ОП. 2, Д. 1652).

67. «ХАРАКТЕРЫ ВЕЛЬМОЖ И ЗНАТНЫХ ЛЮДЕЙ В ЦАРСТВОВАНИЕ АЛЕКСЕЯ МИХАЙЛОВИЧА», C. 296-297.

68. С. РОЖДЕСТВЕНСКИЙ, «РОСПИСЬ ЗЕМЕЛЬНЫХ ВЛАДЕНИЙ МОСКОВСКОГО БОЯРСТВА 1647-1648 ГОДА», ДРЕВНОСТИ. ТРУДЫ АРХЕОЛОГИЧЕСКОЙ КОМИССИИ МОСКОВСКОГО АРХЕОЛОГИЧЕСКОГО ОБЩЕСТВА, Т. 3, М., 1913, С. 205-206.

69. А.А. НОВОСЕЛЬСКИЙ, «РОСПИСЬ КРЕСТЬЯНСКИХ ДВОРОВ 1678 Г.», ИСТОРИЧЕСКИЙ АРХИВ, 1949, Т. IV, С. 122-123; О.А. ШВАТЧЕНКО, СВЕТСКИЕ ФЕОДАЛЬНЫЕ ВОТЧИНЫ В РОССИИ ВО ВТОРОЙ ПОЛОВИНЕ XVII ВЕКА, М., 1996, С. 99-100.

70. РГАДА, Ф. 233, Д. 681, л. 136, 197, 222; Д. 685, л. 22, 106 ОБ.-107, 228.

71. ПАМЯТНИКИ АРХИТЕКТУРЫ МОСКОВСКОЙ ОБЛАСТИ, ВЫП. 3, М., 1999, С. 137-138, 145-146.

72. «КНИГА ДЯДЬКАМ И МАМАМ И БОЯРЫНЯМ ВЕРХОВЫМ И СТОЛЬНИКАМ ЦАРЕВИЧЕВЫМ», С. 49.

73. ТРОИЦКАЯ ВКЛАДНАЯ, С. 110.

74. И. КОЗЛОВСКИЙ, Ф.М. РТИЩЕВ, КИЕВ, 1906, С. 17, 169, 446.

75. «КНИГА ДЯДЬКАМ И МАМАМ И БОЯРЫНЯМ ВЕРХОВЫМ И СТОЛЬНИКАМ ЦАРЕВИЧЕВЫМ», С. 50.

76. СМ.: СЕДОВ, ЗАКАТ МОСКОВСКОГО ЦАРСТВА, С. 114-117.

77. СМ.: ТАМ ЖЕ, С. 155-174.

78. А.Г. МАНЬКОВ, РЕД., ЗАПИСКИ ИНОСТРАНЦЕВ О ВОССТАНИИ СТЕПАНА РАЗИНА, Л., 1968, С. 68-69.

79. ПО ГРАМОТАМ 11 АВГУСТА 1673 Г., 20 ФЕВРАЛЯ И 30 АПРЕЛЯ 1674 Г. КНЯЗЬ Я.Н. ОДОЕВСКИЙ ПОЛУЧИЛ ТРИЖДЫ ПО ТЫСЯЧИ ЧЕТВЕРТЕЙ (РГАДА, Ф. 233, Д. 681, Л. 136, 197, 222).

80. ДР, Т. ІІІ, СТБ. 1635-1640.

81. С.К. БОГОЯВЛЕНСКИЙ, ПРИКАЗНЫЕ СУДЬИ ХVII ВЕКА, М., 1946, С. 16. 
82. ОР РНБ, Ф. 532, ОП. 2, Д. 4619, Л. 1-3; Е. ЗАМЫСЛОВСКИЙ, ЦАРСТВОВАНИЕ ФЕДОРА АЛЕКСЕЕВИЧА, СПБ., 1871, ПРИЛОЖЕНИЕ 1.

83. РГАДА, Ф. 210, МОСКОВСКИЙ СТ., СТБ. 508, л. 126.

84. В.Н. ТАТИЩЕВ, ИСТОРИЯ РОССИЙСКАЯ, Т. VII, М., 1968, С. 172.

85. ПОСОЛЬСТВО КУНРААДА ФАН КЛЕНКА К ЦАРЯМ АЛЕКСЕЮ МИХАЙЛОВИЧУ И ФЕДОРУ АЛЕКСЕЕВИЧУ, СПБ., 1900, С. 484.

86. РГАДА, Ф. 210, БОЯРСКИЕ СПИСКИ, Д. 14, Л. 4; Ф. 233, ОП. 1, Д. 685, Л. 76 ОБ.

87. ТАМ ЖЕ, Ф. 210, БОЯРСКИЕ СПИСКИ, Д. 14, Л. 2 ОБ. В ЭТОТ ЖЕ ДЕНЬ СПАЛЬНИКОМ СТАЛ КНЯЗЬ И.Г. КУРАКИН, ЖЕНАТЫЙ НА ВНУЧКЕ БОЯРИНА КН. Н.И. ОДОЕВСКОГО - ФЕДОСЬЕ АЛЕКСЕЕВНЕ (ТАМ ЖЕ, Л. 14).

88. ПСЗ (ПОЛНОЕ СОБРАНИЕ ЗАКОНОВ РОССИЙСКОЙ ИМПЕРИИ), Т. ІІ, № 648.

89. РГАДА, Ф. 1201, ОП. 1 , Д. 81, Л. 1.

90. ТАМ ЖЕ, Ф. 210, БОЯРСКИЕ СПИСКИ, № 14, л. 4, 6; МОсКОВСКИЙ СТ., СТБ. 501, л. 1536.

91. ТАМ ЖЕ, МОСКОВСКИЙ СТ., СТБ. 484, Л. 119.

92. ТАМ ЖЕ, Ф. 396, ОП. 2, Д. 252, Л. 84-85 ОБ.

93. ТАМ ЖЕ, Ф. 210, МОСКОВСКИЙ СТ., СТБ. 621, Л. 10, 29; Ф. 143, ОП. 2, Д. 1195, Л. 1, 3.

94. СМ.: СЕДОВ, ЗАКАТ МОСКОВСКОГО ЦАРСТВА, С. 260-265.

95. С.И. КОТКОВ, ГРАМОТКИ ХVII - НАЧАЛА ХVIII ВЕКА, М., 1969, С. 131, 141.

96. ОР РНБ, Ф. 532, ОП. 2, Д. 4619, Л. 35-37.

97. РГАДА, Ф. 396, ОП. 2, д. 725, Л. 32, 33, 33 оБ.; Ф. 143, оП. 2, д. 1315, Л. 4-4 оБ.

98. ДР, Т. IV, СПБ., 1855, СТБ. 59-60.

99. ДЕЛА ТАЙНОГО ПРИКАЗА, КН. І, СТБ. 342, 953.

100. Е. ЗАМЫСЛОВСКИЙ, СНОШЕНИЯ РОССИИ СО ШВЕЦИЕЙ И ДАНИЕЙ В ЦАРСТВОВАНИЕ ФЕДОРА АЛЕКСЕЕВИЧА, СПБ., 1889, С. 33, ПРИМЕЧ. 1.

101. ДОНЕСЕНИЕ НИДЕРЛАНСКОГО РЕЗИДЕНТА И. КЕЛЛЕРА ОТ 30 ЯНВАРЯ 1678 Г. (АРХИВ СПБИИ, кол. 40, Д. 56, пИСьмо № 78, л. 83).

102. ОБ ЭТОМ НАЗНАЧЕНИИ СООБЩИЛ И. КЕЛЛЕР В ПИСЬМЕ 1 НОЯБРЯ 1677 Г. БОЯРИН КНЯЗЬ Я.Н. ОДОЕВСКИЙ И ОКОЛЬНИЧИЙ И.И. ЧИРИКОВ ВЫЕХАЛИ ИЗ МОСКВЫ В ДЕКАБРЕ: ПОДОРОЖНЫЕ И.И. ЧИРИКОВУ ДАТИРОВАНЫ 10 И 16 ДЕКАБРЯ (АРХИВ СПБИИ, КОЛ. 40, № 56, ПИСЬМО № 78, л. 83; РГАДА, Ф. 159, ОП. 1 , Д. 885, Л. 150, 152).

103. АРХИВ СПБИИ, Ф. 181, ОП. 1 , Д. 2716, Л. 17. МОНАХИ УСПЕНСКОГО ТИХВИНСКОГО МОНАСТЫРЯ ПОДНЕСЛИ БОЯРИНУ КНЯЗЮ Ю.М. ОДОЕВСКОМУ «ОТ ВЕРЯЖСКОГО ДЕЛА 20 РУБЛЕВ ДА ДЕТЕМ ДВОИМ ПОДНЕСЕНА КРУШКА, ДА ГОЛОВА САХАРУ, ВСЕ ДАНО РУБЛЬ (ТАМ ЖЕ, Ф. 132, ОП. 1, КАРТОН 26, Д. 23, Л. 4). ВИДИМО, ВОЕВОДА ВЗЯЛ С СОБОЙ СТАРШИХ СЫНОВЕЙ КНЯЗЯ МИХАИЛА БОЛЬШОГО И КНЯЗЯ МИХАИЛА МЕНЬШОГО.

104. АРХИВ СПБИИ, Ф. 181, ОП. 1, Д. 2726, Л. 21, 35 ОБ., 37.

105. «В НАЧАЛНИКАХ ПРАВДЫ НЕ СТАЛО, ДЬЯКИ ВСЕ ЗАВЕДАЮТ, А ДО БОЯРИНА ДОЙТИ НЕМОЧНО»; «БОЯРИН В ПРИКАЗ НЕ БЫВАЕТ, А ДЬЯКИ ЧТО ЗАХОТЯТ, ТО И ДЕЛАЮТ» (ТАМ ЖЕ, Д. 2806, Л. 92, 93).

106. ПО ВОЗВРАЩЕНИИ В МОСКВУ КНЯЗЬ Ю.М. ОДОЕВСКИЙ ПРОДОЛЖАЛ ПОЛУЧАТЬ ЛЕКАРСТВА ИЗ ЦАРСКОЙ АПТЕКИ «ДЛЯ ЕВО БОЛЕЗНЕЙ» (РГАДА, Ф. 143, ОП. 2, Д. 1269; Д. 1315, Л. 87, 118).

107. БЕРНГАРД ТАННЕР, ОПИСАНИЕ ПУТЕШЕСТВИЯ ПОЛЬСКОГО ПОСОЛЬСТВА В МОСКВУ В 1678 Г. М., 1891, С. $71,93$.

108. РГАДА, Ф. 210, БЕЛГОРОДСКИЙ СТ., СТБ. 1157, Л. 53-59.

109. ТАМ ЖЕ, Ф. 143, ОП. 2, Д. 1226, Л. 1-4.

110. СМ.: П.В. СЕДОВ, «ЧЕЛОБИТНАЯ КНЯЗЕЙ ОДОЕВСКИХ О СВОИХ РОДОВЫХ ЗЕМЛЯХ НАКАНУНЕ ОТМЕНЫ МЕСТНИЧЕСТВА», В С.В. СТРЕЛЬНИКОВ, СОСТ., ИССЛЕДОВАНИЯ ПО ИСТОРИИ СРЕДНЕВЕКОВОЙ РУСИ: К 80-ЛЕТИЮ ЮРИЯ ГЕОРГИЕВИЧА АЛЕКСЕЕВА, М.; СПБ., 2006, С. 338-344. 
111. РГАДА, Ф. 210, БОЯРСКИЕ СПИСКИ, № 17, Л. 3 ОБ.

112. КНЯЗЬ В.Ф. ОДОЕВСКИЙ ОТНОСИЛ ЛЕКАРСТВА ЦАРЮ ТАКЖЕ 1 И 6 ФЕВРАЛЯ 1680 Г. - ОР РНБ, Ф. 532, оп. 2, д. 4619, л. 72, 75, 77).

113. РГАДА, Ф. 210, МОСКОВСКИЙ СТ., СТБ. 641 , Л. 779; БОЯРСКИЕ СПИСКИ № 19, л. 2 ОБ. (В СПРАВОЧНИКЕ МАРШАЛЛА ПО ДАТА ПОЖАЛОВАНИЯ КНЯЗЯ В.Ф.ОДОЕВСКОГО В ДВОРЕЦКИЕ УКАЗАНА ОШИБОЧНО: 5 МАЯ 1680 Г. - ПО, РОССИЙСКАЯ ЭЛИТА В ХVII ВЕКЕ, Т. І, С. 430). ВИДИМО, У КНЯЗЯ В.Ф. ОДОЕВСКОГО БЫЛИ ДРУЖЕСКИЕ ОТНОШЕНИЯ С Б.М. ХИТРОВО. В 1680 Г. ЧЕЛОБИТЧИКИ ПЫТАЛИСЬ ДОБИТЬСЯ МИЛОСТИ У ЦАРЯ ЧЕРЕЗ ЗАСТУПНИЧЕСТВО У КНЯЗЯ В.Ф.ОДОЕВСКОГО, КОТОРОГО ПРОСИЛИ ДОЛОЖИТЬ ГОСУДАРЯ «ПРИ БОГДАНЕ МАТВЕЕВИЧЕ» (Н.А.БАКЛАНОВА, ТОРГОВО-ПРОМЫШЛЕННАЯ ДЕЯТЕЛЬНОСТЬ КАЛМЫКОВЫХ ВО ВТОРОЙ ПОЛОВИНЕ ХVII В., М., 1959, С. 24).

114. ОТДЕЛ ПИСЬМЕННЫХ ИСТОЧНИКОВ ГОСУДАРСТВЕННОГО ИСТОРИЧЕСКОГО МУЗЕЯ, Ф. 440, оп. 1 , д. 366, л. 56,82 оь.

115. С.М. СОЛОВЬЕВ, ИСТОРИЯ РОССИИ С ДРЕВНЕЙШИХ ВРЕМЕН, КН. VII, М., 1991, С. 304.

116. РГАДА, Ф. 396, ОП. 1 , Д. 19089.

117. КНЯЗЬ Ю.М. ОДОЕВСКИЙ БЫЛ НАЗНАЧЕН В РАСПРАВНУЮ ПАЛАТУ 21 ДЕКАБРЯ 1680 Г., НО УЖЕ 8 АВГУСТА 1681 Г. ВЫВЕДЕН ИЗ ЕЕ СОСТАВА «ДЛЯ БОЛЕЗНИ» (ДР, Т. ІV, СТБ. 187; РГАДА, Ф. 210, МОСКОВСКИЙ СТ., СТБ. 597, л. 222, 287; СТБ. 641, л. 503).

118. СМ.: СЕДОВ, ЗАКАТ МОСКОВСКОГО ЦАРСТВА, С. 410-421.

119. В.И. ДАЛЬ, ТОЛКОВЫЙ СЛОВАРЬ ЖИВОГО ВЕЛИКОРУССКОГО ЯЗЫКА, М., 2000, Т. 1, С. 121.

120. СМ.: П.В.СЕДОВ, «О БОЯРСКОЙ ПОПЫТКЕ УЧРЕЖДЕНИЯ НАМЕСТНИЧЕСТВ В РОССИИ В 1681-1682 гГ.», ВЕСТнИК ЛГУ, 1985, № 9, ВЫП. 2, С. 25-29.

121. К.А. КОЧЕГАРОВ, РЕЧЬ ПОСПОЛИТАЯ И РОССИЯ В 1680-1686 ГОДАХ. ЗАКЛЮЧЕНИЕ ДОГОВОРА О ВЕЧНОМ МИРЕ, М., 2008, С. 87.

122. РГАДА, Ф. 210, БОЯРСКИЕ СПИСКИ, № 21, Л. 15 ОБ.; СОЛОВЬЕВ, ИСТОРИЯ РОССИИ С ДРЕВНЕЙШИХ ВРЕМЕН, КН. VII, С. 315.

123. А.П. БОГДАНОВ, В.Е. ВОЗГРИН, «МОСКОВСКОЕ ВОССТАНИЕ 1682 Г. ГЛАЗАМИ ДАТСКОГО ПОСЛА», ВОПРОСЫ ИСТОРИИ, 1986, № 3, С. 86. В ДАННОЙ ПУБЛИКАЦИИ ВКРАЛАСЬ НЕТОЧНОСТЬ В ПЕРЕДАЧИ ЧИНА «СТАРИКА ОДОЕВСКОГО», РАЗЪЯСНЕННАЯ А.С. ЛАВРОВЫМ, ПРАВИЛЬНО СЛЕДУЕТ: «ГОСУДАРСТВЕННЫЙ ГОФМЕЙСТЕР». НА ЭТОМ ОСНОВАНИИ А.С. ЛАВРОВ ПОЛАГАЕТ, ЧТО РЕЧЬ ИДЕТ О ДВОРЕЦКОМ КНЯЗЕ В.Ф. ОДОЕВСКОМ (А.С. ЛАВРОВ, «ПОЛИТИЧЕСКАЯ БОРЬБА В РОССИИ 1680-Х ГОДОВ В ДОНЕСЕНИЯХ ХИЛЬДЕБРАНТА ФОН ГОРНА», ВЕСТНИК СПБГУ, СЕРИЯ 2, 1999, ВЫП. 3 (16), С. 17). СОМНИТЕЛЬНО, ЧТОБЫ КНЯЗЬ ВАСИЛИЙ ФЕДОРОВИЧ, КОТОРОМУ В 1682 Г. БЫЛО ОКОЛО СОРОКА ЛЕТ, МОГ СЧИТАТЬСЯ «СТАРИКОМ». ТАКОВЫМ ЕСТЕСТВЕННО БЫЛО НАЗВАТЬ ЕГО ДЕДА ВОСЬМИДЕСЯТИЛЕТНЕГО КНЯЗЯ НИКИТУ ИВАНОВИЧА. ТАКИМ ОБРАЗОМ, ДАТСКИЙ ДИПЛОМАТ ПУТАЕТ ЛИБО ВОЗРАСТ, ЛИБО ЧИН УПОМИНАЕМОГО ОДОЕВСКОГО.

124. М.П. ПОГОДИН, «ПОВЕСТВОВАНИЕ О МОСКОВСКИХ ПРОИСШЕСТВИЯХ», ЖМНП, 1835, Ч. 5, № 1 , ОТд. ІІ, С. 79.

125. АРХИВ СпьИИ, Ф. 181, оП. 1 , Д. 3109, л. 11.

126. РГАДА, Ф. 396, ОП. 2, Д. 730, Л. 114 ОБ., 115, 116 ОБ, 117 ОБ., 118 ОБ., 119, 120-121 оБ., 146-147 ОБ., 122, 123-123 оБ., 148-149 ОБ.

127. ДЯДЬКЕ ЦАРЕВИЧА ИВАНА - БОЯРИНУ КНЯЗЮ П.И. ПРОЗОРОВСКОМУ, БОЯРИНУ И.М. МИЛОСЛАВСКОМУ, ОКОЛЬНИЧЕМУ Б.Г. ЮШКОВУ, СОСТОЯВШЕМУ ПРИ КОМНАТАХ СТАРШИХ ЦАРЕВЕН, ОКОЛЬНИЧЕМУ М.Б. МИЛОСЛАВСКОМУ, ДУМНОМУ ДВОРЯНИНУ В.С. НАРБЕКОВУ, ОПРЕДЕЛЕННОМУ ПРИ КОМНАТАХ МЛАДШИХ ЦАРЕВЕН, В ТОМ ЧИСЛЕ И СОФЬИ, СПАЛЬНИКАМ ЦАРЯ ИВАНА - КНЯЗЮ И.И. ХОВАНСКОМУ, А.И., А.М., Л.С., С.И. МИЛОСЛАВСКИМ (РГАДА, Ф. 396, оП. 2 , Д. 730 , Л. 175 ОБ.-176 ОБ.).

128. А.А. МАТВЕЕВ, «ЗАПИСКИ», РОЖДЕНИЕ ИМПЕРИИ, М., 1997, С. 384.

129. АРХИВ КН. Ф.А. КУРАКИНА, ИЗДАННЫЙ ПОД РЕДАКЦИЕЙ М.И. СЕМЕВСКОГО, СПБ., 1890, С. 44-45, 246. 
130. КОЧЕГАРОВ, РЕЧЬ ПОСПОЛИТАЯ И РОССИЯ В 1680-1686 ГОДАХ, С. 256.

131. З.И. СЕРГИЙ (СПАССКИЙ), АРХИМАНДРИТ, ИСТОРИЧЕСКОЕ ОПИСАНИЕ МОСКОВСКОГО ЗНАМЕНСКОГО МОНАСТЫРЯ, ЧТО НА СТАРОМ ГОСУДАРЕВОМ ДВОРЕ, М., 1866, С. 58.

132. КОЧЕГАРОВ, РЕЧЬ ПОСПОЛИТАЯ И РОССИЯ В 1680-1686 ГОДАХ, С. 283.

133. БОГОЯВЛЕНСКИЙ, ПРИКАЗНЫЕ СУДЬИ, С. 16, 22, 180.

134. Paul Bushkovitch, Peter The Great: The struggle for Power, 1671-1725, Cambridge, 2001, c. 139.

135. В СЕНТЯБРЕ 1683 Г. КНЯЗЬ Я.Н. ОДОЕВСКИЙ ПИСАЛ ДУМНОМУ ДЬЯКУ В.Г. СЕМЕНОВУ: «ПО УКАЗУ ВЕЛИКИХ ГОСУДАРЕЙ СКАЗАЛ МНЕ ИХ ГОСУДАРСКИЙ УКАЗ РОЗРЯДНОЙ ДЬЯК ПЕРФИЛЕЙ ОЛОВЯННИКОВ, ЧТО ВЕЛЕНО ПРИСЛАТЬ КАЗАНСКОГО ПРИКАЗУ ДЬЯКА, А С НИМ ПОДЛИННОЕ ДЕЛО И ПЕРЕЧНЕВУЮ ВЫПИСКУ И ЧОРНУЮ ЗАПИСКУ КНЯЗЬ СЕМЕНА АГАНИНА С КНЯЗЬ ФЕДОРОМ МУСТОФИНЫМ. И ПО УКАЗУ ВЕЛИКИХ ГОСУДАРЕЙ ТОЕ ПОДЛИННОЕ ДЕЛО И ЧОРНУЮ ЗАПИСКУ ПОСЛАЛ Я $З$ ДЬЯКОМ С ЫВАНОМ КУЧЕЦКИМ, А ПЕРЕЧНЕВУЮ ВЫПИСКУ ПОДНЕС Я НА МОСКВЕ ВЕЛИКОЙ ГОСУДАРЫНЕ БЛАГОРОДНОЙ ЦАРЕВНЕ И ВЕЛИКОЙ КНЯЖНЕ СОФИИ АЛЕКСЕЕВНЕ В КОМНОТЕ» (РГАДА, Ф. 210, МОСКОВСКИЙ СТ., СТОЛПИК 4, СТБ. 647, Л. 49).

136. А.С. ЛАВРОВ, РЕГЕНТСТВО ЦАРЕВНЫ СОФЬИ АЛЕКСЕЕВНЫ, М., 1999, С. 87, 104, 110-111.

137. ТРОИЦКАЯ ВКЛАДНАЯ, С. 280.

138. АРХИВ СТОЛЬНИКА АНДРЕЯ ИЛЬИЧА БЕЗОБРАЗОВА, Ч. І, М., 2012, С. 321, 323, 328.

139. АРХИВ СПБИИ, Ф. 181, ОП. 1 , Д. 3105 , Л. 2-3.

140. АРХИВ СТОЛЬНИКА АНДРЕЯ ИЛЬИЧА БЕЗОБРАЗОВА, Ч. І, С. 388.

141. ПО, РОССИЙСКАЯ ЭЛИТА В ХVII В., Т. 1, С. 430; ВЛАСЬЕВ, ПОТОМСТВО РЮРИКА, Т. І, Ч. 1, С. 79, 85.

142. РГИА, Ф. 1088, ОП. 3, Д. 22, Л. 9.

143. НА ЗАВИСИМОСТЬ ОСОБЕННОСТЕЙ ДУХОВНЫХ БОЯР ХVII В. ОТ ИНДИВИДУАЛЬНЫХ ЧЕРТ ИХ АВТОРОВ ОБРАТИЛА ВНИМАНИЕ О.Е. КОШЕЛЕВА (О.Е. КОШЕЛЕВА, «“ОТХОДЯ ОТ СВЕТА СЕГО...” ЧАСТНАЯ ЖИЗНЬ МОСКОВСКОЙ ЭЛИТЫ ХVII ВЕКА ЧЕРЕЗ ПРИЗМУ ЗАВЕЩАНИЙ», ЧЕЛОВЕК В МИРЕ ЧУВСТВ: ОЧЕРКИ ПО ИСТОРИИ ЧАСТНОЙ ЖИЗНИ В ЕВРОПЕ И НЕКОТОРЫХ СТРАНАХ АЗИИ ДО НАЧАЛА НОВОГО ВРЕМЕНИ, М., 2000).

144. ЯВЛЕНИЕ «ДОМОВОГО ПОДДАНСТВА» КАК ХАРАКТЕРНАЯ ЧЕРТА ТРАДИЦИОННОГО СЕМЕЙНОГО БЫТА РУССКОЙ ЗНАТИ ХVIII В. ПРОСЛЕЖЕНО А.В. БЕКАСОВОЙ НА ПРИМЕРЕ СЕМЬИ РУМЯНЦЕВЫХ: А.В. БЕКАСОВА, СЕМЬЯ, РОДСТВО И ПОКРОВИТЕЛЬСТВО В РОССИИ ХVIII ВЕКА: ЩДОМОВОЕ ПОДДАНСТВО» ГРАФА П.А. РУМЯНЦЕВА, АВТОРЕФ. КАНД. ДИС., СПБ., 2006.

145. ЛАВРОВ, РЕГЕНТСТВО ЦАРЕВНЫ СОФЬИ АЛЕКСЕЕВНЫ, С. 113.

146. РГИА, Ф. 1088, ОП. 3, Д. 23, Л. 6-7.

147. ЗАПИСКИ КНЯЗЯ ПЕТРА ДОЛГОРУКОВА, СПЬ., 2007, С. 130-133.

148. А.С. ПУШКИН, ПОЛНОЕ СОБРАНИЕ СОЧИНЕНИЙ В 16 Т., М. - Л., 1937-1959, т. 3, С. 262.

149. О РОЛИ КОМНАТНОЙ ПРИДВОРНОЙ СЛУЖБЫ В СУДЬБЕ ДРУГОГО БОЯРСКОГО РОДА ХVII В. СМ.: П.В. СЕДОВ, «ВОДИЛИСЬ ПУШКИНЫ С ЦАРЯМИ»: РОД ПУШКИНЫХ И ПРИДВОРНОЕ ОБЩЕСТВО ВТОРОЙ ПОЛОВИНЫ XVII ВЕКА», ПУШКИН И ПРИДВОРНАЯ СРЕДА ЕГО ВРЕМЕНИ. БЕЛЯЕВСКИЕ ЧТЕНИЯ: СБОРНИК НАУЧНЫХ СТАТЕЙ, ВЫП. V, СПБ., 2015, С. 11-30.

150. СМ.: СЕДОВ, ЗАКАТ МОСКОВСКОГО ЦАРСТВА, С. 93, 125, 130, 241-242, 377, 419.

151. С.И. КОТКОВ, А.С. ОРЕШНИКОВ, И.С. ФИЛИППОВА, РЕД., МОСКОВСКАЯ ДЕЛОВАЯ И БЫТОВАЯ ПИСЬМЕННОСТЬ ХVII ВЕКА, М., 1968, С. 19.

152. ПУШКИН, ПОЛНОЕ СОБРАНИЕ СОЧИНЕНИЙ В 16 т., Т. 14, с. 143. 


\section{RÉSUMÉS}

$\mathrm{Au} \mathrm{XVII}{ }^{\mathrm{e}}$ siècle, les princes Odoevskij appartenaient à la crème de l'élite moscovite. Tirant parti de documents inédits, l'auteur reconstruit l'histoire de quatre générations de cette famille, à commencer par le prince Nikita Ivanovič Odoevskij, l'un des plus célèbres bojare de l'époque d'avant Pierre le Grand. L'auteur montre comment chacune des générations successives s'efforçait de maintenir la tradition familiale, reproduisant autant que possible la carrière de ses pères. C'est ainsi que les princes Odoevskij s'affirmèrent durablement dans les premiers rangs de la Duma et dans le cercle intime du tsar. En ce sens, le règne de Pierre le Grand marque une rupture: le modèle comportemental dans lequel l'autorité des aïeux dictait les objectifs des descendants n'y a pas survécu. Durant la première moitié du XVIII ${ }^{\mathrm{e}}$ siècle, les princes Odoevskij édifièrent leurs carrières en suivant leurs goûts et préférences personnels pour finalement ne laisser d'eux que l'image de gens « médiocres », « serviles » et « tricheurs aux cartes ».

In the seventeenth century, the Odoevskii princes belonged to the upper crust of the Muscovite elite. On the basis of unpublished documents, the article reconstructs the history of four generations of the family starting with Nikita Ivanovich Odoevskii, one of the most notorious boyars of the pre-Petrine era. The author shows how each generation strove to maintain family traditions by reproducing, as much as possible, their father's and grand-father's careers. They thus secured their position in the top Duma ranks and the tsar's close circle. In that respect, Peter's reign marked a breaking point in a behavioral pattern in which younger generations were inspired by their forebears. During the first half of the eighteenth century, the Odoevskii princes built their careers following their personal tastes and preferences and were remembered as "mediocre" people, notorious for "fawning" and "cheating at cards."

\section{AUTEUR}

\section{PAVEL SEDOV}

САНКТ-ПЕТЕРБУРГСКИЙ ИНСТИТУТ ИСТОРИИ РАН, sedovpv@rambler.ru 